\title{
AN ASSESSMENT OF INDOOR INFILTRATION PARAMETERS FOR BLACK CARBON FROM RESIDENTIAL WOOD COMBUSTION AND THE SPECTRAL DEPENDENCE OF LIGHT ABSORPTION FOR ORGANIC CARBON
}

\author{
A Thesis \\ presented to \\ the Faculty of California Polytechnic State University, \\ San Luis Obispo \\ In Partial Fulfillment \\ of the Requirements for the Degree \\ Master of Science in Civil and Environmental Engineering
}

By

Christopher John Malejan

June 2009 
(C) 2009

Christopher John Malejan

ALL RIGHTS RESERVED 


\title{
COMMITTEE MEMBERSHIP
}

TITLE:

\begin{abstract}
AN ASSESSMENT OF INDOOR INFILTRATION PARAMETERS FOR BLACK CARBON FROM RESIDENTIAL WOOD COMBUSTION AND THE SPECTRAL DEPENDENCE OF LIGHT ABSORPTION FOR ORGANIC CARBON
\end{abstract}

AUTHOR: $\quad$ Christopher John Malejan

DATE SUBMITTED: $\quad$ December 2009

COMMITTEE CHAIR: $\quad$ Tracy Thatcher, Ph.D.

COMMITTEE MEMBER: Harold Cota, Ph.D.

COMMITTEE MEMBER: Heather Smith, M.S. 


\begin{abstract}
AN ASSESSMENT OF INDOOR INFILTRATION PARAMETERS FOR BLACK CARBON FROM RESIDENTIAL WOOD COMBUSTION AND THE SPECTRAL DEPENDENCE OF LIGHT ABSORPTION FOR ORGANIC CARBON
\end{abstract}

\title{
Christopher John Malejan
}

Black carbon, a proxy for woodsmoke was measured indoors and outdoors for an occupied residence in Cambria, CA during the winter months of 2009. The purpose was to investigate the infiltration parameters: air exchange rate, deposition rate, and penetration factor. The second part of this study investigated the light absorption properties of organic carbon from residential wood combustion, the dominant fraction of woodsmoke.

To assess woodsmoke variation, a study conducted parallel to the one presented in this thesis (Ward, 2009), a grid array of personal emission monitors (PEMS) and aethalometers were placed in a small area, approximately one square kilometer, within a community in Cambria, California between the months of November 2008 and March 2009. In this study, PEMS were used to collect particles on filters, which were analyzed for tracers for woodsmoke, including levoglucosan, elemental carbon, and organic carbon. Aethalometers measured black carbon, an indicator of carbon combustion. Additional PEMS and aethalometers were placed inside one residential home to better understand infiltration of woodsmoke.

To model the infiltration of woodsmoke, the Lawrence Berkeley National Laboratory Air Infiltration Model was used. The home of interest was chosen such that indoor sources of particulate matter (PM) were minimal. This ensures that all PM 
measured indoors was from outdoor sources, namely household chimneys. While indoor sources such as indoor fires and resuspension of particles were of concern, homes were chosen to minimize these sources.

To investigate the infiltration parameters, four different solution techniques were used. Two of the solution techniques used SOLVER, a Microsoft Excel program, to minimize the sum of squared differences between calculated indoor concentrations and measured indoor concentrations, with all three parameters (air exchange rate, penetration, and deposition) as independent variables. The other two solution techniques used the Air Exchange Rate (AER) model from Lawrence Berkeley National Laboratory (LBNL) (Sherman \& Grimsrud, 1980) and then used SOLVER to calculate deposition rate and penetration factor.

Solution techniques 1 and 3, which used SOLVER to find all three parameters, had average penetration factors of 0.94 and 0.97 respectively, while solution techniques 2 and 4, which used the LBNL AER model had average penetration factors of 0.85 and 0.78 respectively. The deposition rates for solution techniques $1,2,3$, and 4 were 0.10 , $0.07,0.08$, and $0.04 \mathrm{hr}^{-1}$ respectively. The air exchange rates varied throughout the study and ranged from 0.1 to $0.7 \mathrm{hr}^{-1}$. The average indoor/outdoor ratio was also found to be 0.75 .

The aerosols derived from the study samples were found to have light absorption properties that were heavily spectrally dependent, which is consistent with expectations for wood combustion aerosols. Conversely, traffic derived aerosols are not found to be heavily spectrally dependent and follow the power law relationship of $\lambda^{-1}$ whereas our samples followed $\lambda^{-1.7}$ across all wavelengths and $\lambda^{-2.25}$ for wavelengths less than $600 \mathrm{~nm}$. 
The reason for the difference in spectral dependence is the presence of light absorbing organic carbon in wood smoke that is not found in diesel aerosols. The optical absorbances were also calculated for our samples and average values were found to be 3 and $1 \mathrm{~m}^{2} / \mathrm{g}$ for 370 and $450 \mathrm{~nm}$ wavelengths respectively. 


\section{ACKNOWLEDGEMENTS}

I would like to thank Dr. Tracy Thatcher, a wonderful and supportive advisor for her patience and willingness to help problem solve at any time. Her encouragement when doubt was the prevailing thought often brought confidence and a smile. Finally, her eagerness to allow us to work independently paved the way for an incredible learning opportunity.

I also want to thank my research partner, Courtney Ward for keeping those spirits high, even when it was Saturday, at 9pm, in Cambria. I appreciate her ability to remain calm after I've asked her for the $100^{\text {th }}$ time to back up in the car just a tad to get a better picture of the chimney.

Of course I need to mention everyone (figuratively) in the Grad lab who kept me sane and listened to my complaints when it seemed nothing was going well. Matt, Mike, Jeff, Ruth thanks for making this year worth it.

I want to thank everyone at the San Luis Obispo Air Pollution Control District who helped in the development. Finally, I want to thank all the residents of Cambria, including Eugene, Margarita, Gary, Jackie, Jack, Jim, Joni and Mary. I will never forget their kindness. 


\section{TABLE OF CONTENTS}

\section{Table of Contents}

LIST OF TABLES.......................................................................................................

LIST OF FIGURES.................................................................................................

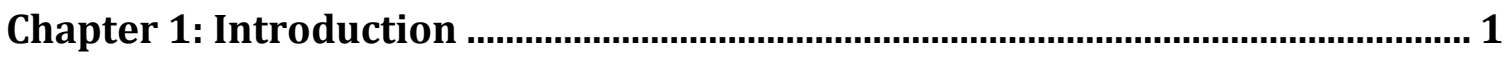

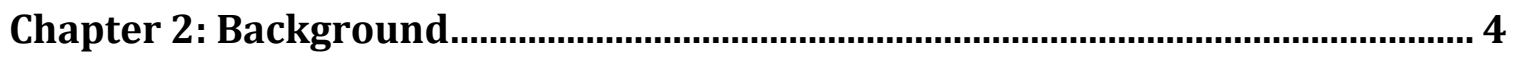

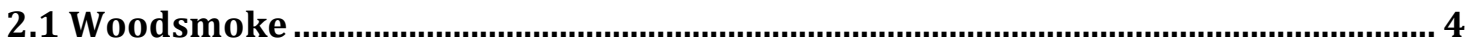

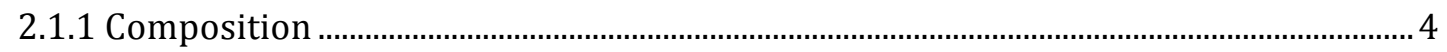

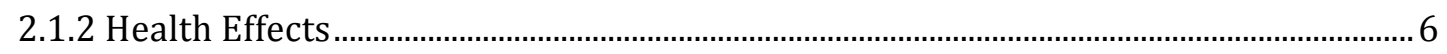

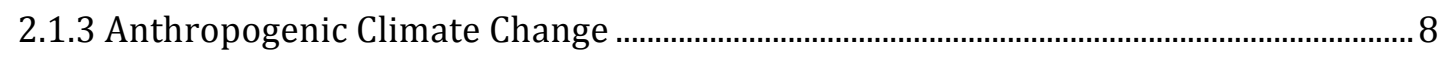

2.3 Relationship between Indoor and Outdoor Concentrations ................................... 9

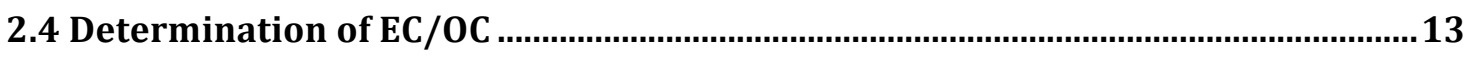

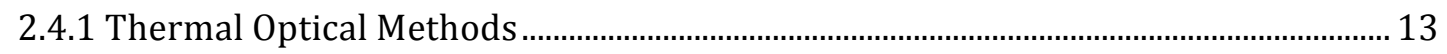

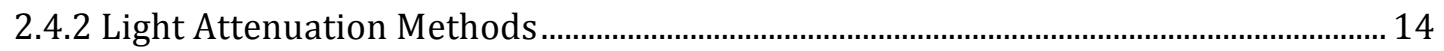

Chapter 3: Methods and Study Design..................................................................17

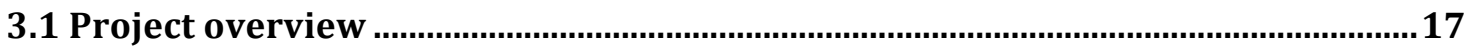

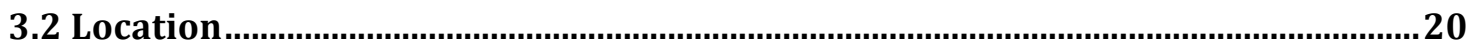

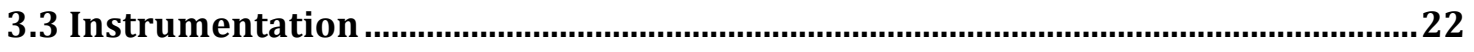

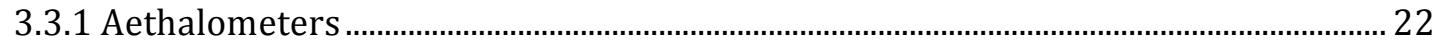

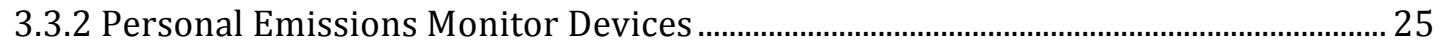

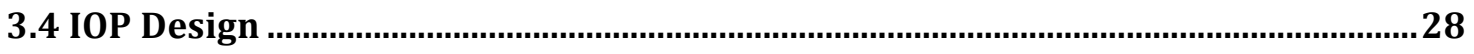

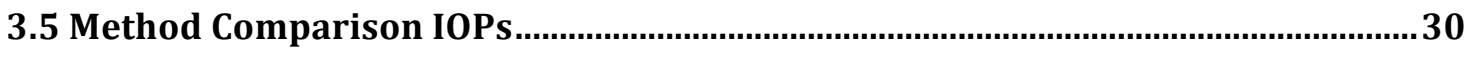


Chapter 4: Results and Discussion .......................................................................33

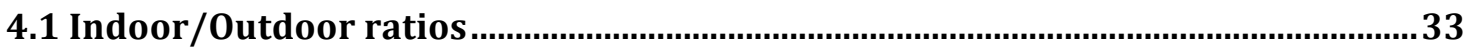

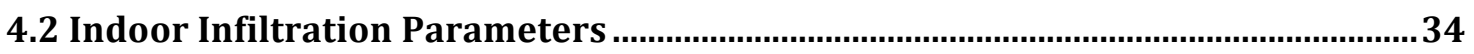

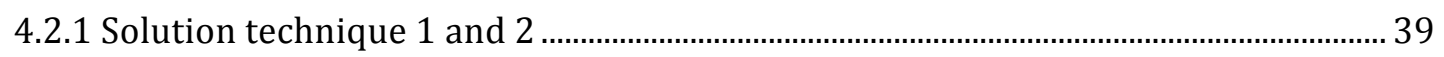

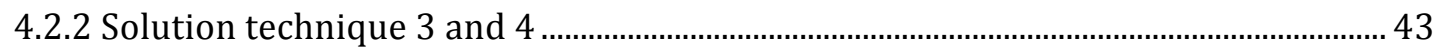

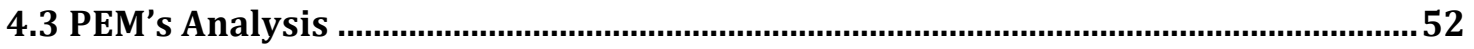

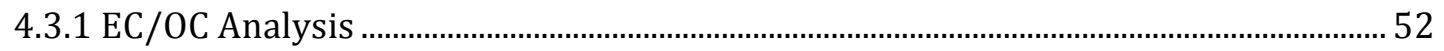

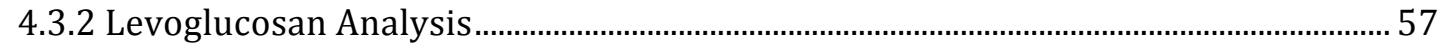

4.3.3 Spectral dependence on light absorption..................................................................... 59

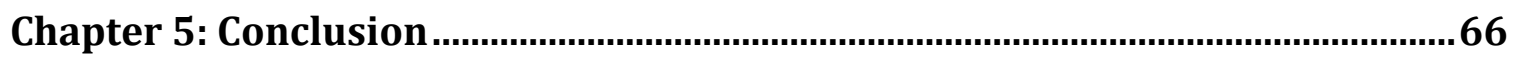

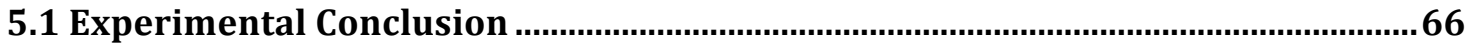

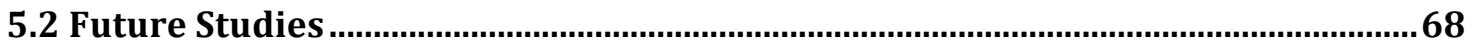

References

Appendix A: GLM Models for Aethalometer Comparison Before and After Specific

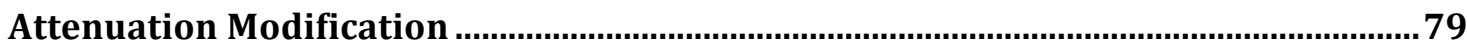

Appendix B: Regression Analysis for Levoglucosan including High Leverage

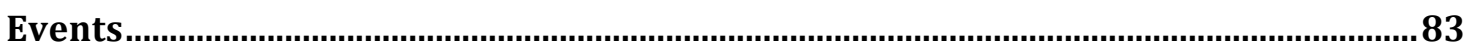

Appendix C: Penetration Factors, Deposition Rates and Air Exchange Rates ............84

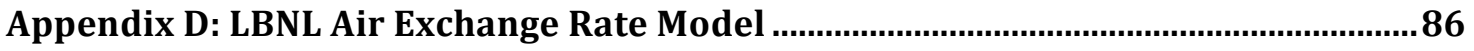

Appendix E: Detailed Burning Events and Regional Data used in LBNL AER

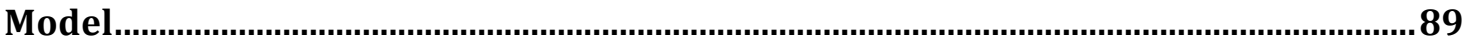




\section{LIST OF TABLES}

Table 1: Summary table of the approach to determine each infiltration parameter for

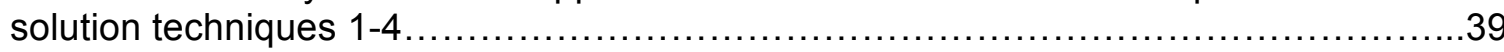

Table 2: Deposition rates and penetration factors for solution techniques 1 and $2 \ldots \ldots . .39$

Table 3: Deposition rates and penetration factors for solution techniques 3 and $4 \ldots \ldots . .44$

Table 4: Summary of penetration factors and deposition rates for solution techniques

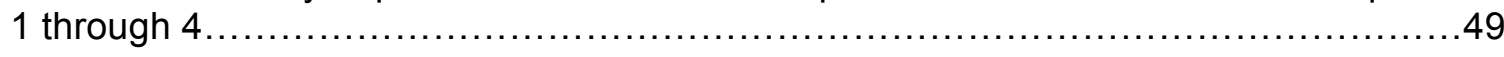

Table 5: Ångström coefficients for each sample determined from a best-fit power law

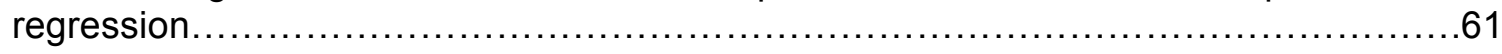

Table 6: Specific Attenuation Coefficients for comparison samples at $370 \mathrm{~nm}$ and 450

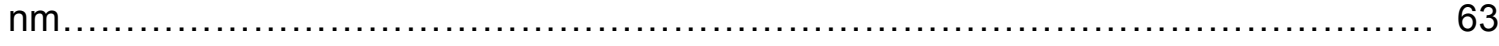




\section{LIST OF FIGURES}

Figure 1: Simple sketch of a home showing how each parameter affects the infiltration of particles. The penetration factor, $P$, is the fraction of particles that penetrates the shell of the building. The deposition rate, $\mathrm{k}_{\text {dep }}$, is the rate that particles deposit onto surfaces inside the home, and the air exchange rate, $\lambda_{v}$, which is defined as the flow divided by the inside volume.

Figure 2: Map of roadway system of Cambria, California ..................................... 21

Figure 3: An Aethalometer used during research in Cambria, CA at a local resident's home.

Figure 4: PEMs are various stages of set-up (1) disassembled PEM showing impactor ring, (2) quartz filter between aluminum-ringed masks, (3) impactor ring placed on top of mask and filter and (4) completed PEM assembly.

Figure 5: PEM and pump housing configuration

Figure 6: Thermal image of a chimney stack with a high temperature of $182.9^{\circ} \mathrm{F}$, indicative of wood burning

Figure 7: Method comparison IOP showing four PEMs, two aethalometers and a minivol co-located in a resident's backyard.

Figure 8: Outdoor Concentration of Black Carbon in one location in Cambria, CA

Figure 9: Modeled Indoor concentrations for Solution technique 1 during the burning event of March $16-17^{\text {th }}$ in Cambria, CA.

Figure 10: Modeled Indoor concentrations for Solution technique 2 during the burning event of March $16-17^{\text {th }}$ in Cambria, CA.....

Figure 11: Coefficient of determinations of solution technique 1 (top) and solution technique 2 (bottom) for the burning event on March 16-1 $7^{\text {th }}$.....

Figure 12: Coefficient of determinations of solution technique 3 (top) and solution technique 4 (bottom) for the burning event on March $16-17^{\text {th }}$.

Figure 13: Modeled Indoor concentrations for Solution technique 3 during the burning event of March $16-17^{\text {th }}$ in Cambria, CA.

Figure 14: Modeled indoor concentrations for Solution technique 4 during the burning event of March $16-17^{\text {th }}$ in Cambria, CA. 
Figure 15: Coefficients of determination for each solution technique starting at 1 (top) down to 4 (bottom) in order solution technique. The black line represents a perfect correlation between actual $\mathrm{I} / \mathrm{O}$ ratios and calculated $\mathrm{I} / \mathrm{O}$ ratios

Figure 16: Performance analysis of solution technique 1 for the average penetration factor and depositon rate.

Figure 17: Actual I/O ratios compared with predicted I/O ratios from Eq. 9 with the air exchange rate as the independent variable solution technique

Figure 18: Total Carbon determined from NIOSH 5040 and LBNL TOA method 54

Figure 19: NIOSH 5040 (Elemental Carbon) and LBNL TOA (Black Carbon) comparison

Figure 20: Black carbon comparison with LBNL TOA, the aethalometer and LBNL ATN methods

Figure 21: The relationship between levoglucosan and the organic carbon fraction .....57

Figure 22: The fraction of total carbon represented by Levoglucosan.....

Figure 23: The light attenuation of sample 3 taken in Cambria, CA (blue line) and the attenuation of purely black carbon (black line) extrapolated from the attenuation in the sample at $880 \mathrm{~nm}$. The grey line is the best fit power law regression for sample $3 \ldots \ldots .60$

Figure 24: Light attenuation of a sample taken in Cambria, CA (blue line) showing the amount of attenuation due to black carbon in the sample.

Figure 25: Optical Absorbance of Organic and Black Carbon for samples 3 through 8. Samples 1 and 2 were excluded because of the uncertainty previously discussed. 65 


\section{Chapter 1: Introduction}

Residential wood smoke accounts for a significant portion of particulate matter in many communities during the winter months. This is especially true in communities where a primary residential heat source is wood-burning stoves and fireplaces.

Additionally, wood fires for recreation and comfort can be very prevalent. This all tends to lead to higher concentrations of wintertime $\mathrm{PM}_{2.5}$. Woodsmoke has been associated with adverse health effects in sensitive populations (Browning et al., 1990; Honicky et al., 1985), for example, the young. Additionally, increased exposure to fine particulate matter, the dominate fraction of woodsmoke particle sizes (Kleeman et al., 1999; Rau, 1989), in young children can lead to respiratory and cardiovascular problems later in life (Schroeder et al., 2003).

The effect of an increase in wintertime $\mathrm{PM}_{2.5}$ can be readily seen in locations such as Fresno, California, where particulate concentrations regularly exceed the federal 24-h NAAQS limit of $35 \mu \mathrm{g} / \mathrm{m}^{3}$. These locations are known as nonattainment zones and are defined as areas that persistently exceed national ambient air quality standards. Other nonattainment areas for $\mathrm{PM}_{2.5}$ in California include Los Angeles County and Riverside County (US EPA). To combat the high particulate concentrations, Fresno and other cities like it have implemented no burn policies, where residents are instructed not to have household fires until atmospheric levels are safe.

In this study, two issues regarding woodsmoke were considered. The first section examines the infiltration of woodsmoke from outdoor sources (i.e. other resident's chimneys). In addition, the ratios of indoor to outdoor woodsmoke were also 
investigated. The second section examines the properties of woodsmoke's two main fractions: elemental carbon and organic carbon. These fractions have different properties that allow them to be quantified, however current measurement techniques are inherently problematic because these properties can overlap. Oxidation temperature is one property that is used to distinguish elemental and organic carbon, which can overlap in the presence of potassium and phosphorus, both which are present in woodsmoke (Novakov \& Corrigan, 1995).

Two different stationary monitoring devises were used in this study: Personal Emissions Monitors (PEMS) and Aethalometers. Both instruments are filter based, however each differs in the measurement taken from the filter and time resolution. The PEMS were operated to collect a single integrated 12-hour sample, which was analyzed by spectral analysis for organic carbon and elemental carbon, both fractions of wood smoke. The aethalometers measured black carbon, which has properties similar to elemental carbon and for most purposes is the same fraction, and were sensitive enough to determine concentrations with minute resolution. However, during periods of extremely low concentrations, there was significant noise in the instrument. Using the raw data, the concentrations were re-integrated over a longer period of time when noise was a problem.

The study was conducted in Cambria, CA, a location generally known for excellent air quality. However, during the winter months, increased wood burning activity has led to resident complaints about woodsmoke. Cambria is an interesting choice from a scientific perspective because wintertime particulate matter is believed to originate almost exclusively from wood combustion. The following four chapters include 
a background section on woodsmoke composition and measurement techniques, a

methods and study design section which includes how the study was conducted, a results and discussion section which details the findings and their significance, and a conclusions section which summarizes the findings and details future research needs. 


\section{Chapter 2: Background}

This chapter begins with an examination of the properties of woodsmoke and why it is a concern to public health and the environment. Then it discusses the infiltration of particles of outdoor origin, such as woodsmoke, into residences where important exposure can occur. Finally, it explains the different techniques currently available to determine woodsmoke concentrations in ambient air.

\subsection{Woodsmoke}

\subsubsection{Composition}

Particulate matter from wood smoke primarily consists of sub micron particles and is split into two major fractions, elemental carbon (EC) and organic carbon (OC). Remaining smaller fractions include ions, metals and unknown constituents (Fine et al., 2002; Fine et al., 2004a). Elemental carbon has been defined as near elemental-soot carbon that is oxidized in an oxygen environment, above a certain temperature threshold (Andreae \& Gelencser, 2006). Organic carbon is defined as compounds that oxidize below the EC temperature threshold, usually in an oxygen-deprived environment. To separate EC and OC fractions, thermal optical measurement methods have been developed (Birch \& Cary, 1996; Cadle et al., 1983; Ellis \& Novakov, 1982; Huntzicker et al, 1982).

Black carbon (BC) is another classification sometimes used to describe the carbon content of ambient particle matter. It is thought to be composed mostly of elemental carbon and therefore overlaps the EC fraction significantly, but not entirely. $\mathrm{BC}$ is quantified only by optical methods (Gundel et al., 1984; Rosen et al., 1978). These 
optical methods to distinguish fractions were developed to characterize combustion emissions quickly and cost effectively. Further discussion on this topic is provided in section 2.3.

Wood type and burning conditions can have a significant impact on woodsmoke composition. In the study area, a common tree is Pinus radiate or Monterey Pine, which is a native California tree that inhabits much of Cambria and other central coast locations such as Santa Cruz and Monterey. Because of the availability of the wood to the citizens of Cambria, it can be assumed that the wood burned in fireplaces would mostly consist of Monterey Pine. Fine et al., 2004b) showed that particles resulting from the combustion of Ponderosa Pine, a relative of the Monterey Pine, had a high organic carbon content, $90.1 \%$ by mass, and a low elemental carbon content, $7.3 \%$ by mass. Slash Pine, another pine tree found in California, also has a considerable organic fraction compared to elemental carbon (Fine et al., 2002). In contrast, motor vehicle exhaust, which presumably would be the only other source of aerosols, has lower organic carbon content and higher elemental content, $56.19 \% \pm 53.63$ and $41.07 \% \pm 20.64$ respectively (Watson et al., 2001). found that highway vehicles on average emit a greater percentage of elemental carbon to total carbon than do residential fireplaces.

The relative composition of carbon concentrations is also influenced by combustion temperature. Wood combusted at higher burning temperatures emits more elemental carbon than wood combusted at lower temperatures (Rau, 1989). In the study, they found that the EC/TC ratio ranged between $52 \%$ and $73 \%$ for higher combustion temperatures and between 5\% and 13\% for lower combustion temperatures. Kocbach et al. (2005) found that high burn temperatures, which do not allow for the devolatilization 
of wood compounds, are more associated with lower OC/TC ratios, 42.7\%, and therefore higher EC/TC ratios. This is an indication that carbon composition is highly dependent on combustion temperature.

Of the organic species emitted from the combustion of woodsmoke, levoglucosan is significantly more abundant than others. More importantly, levoglucosan is stable in the atmosphere and is specific to only cellulose pyrolysis (Fraser \& Lakshmanan, 2000; Locker, 1988). Levoglucosan has been found in large quantities in combustion emissions from all wood types studied (Simoneit et al., 1999). In Fresno CA, where PM concentrations regularly exceed California standards during the winter months, levoglucosan concentrations have been as high as $4.05 \mu \mathrm{g} / \mathrm{m}^{3}$ (Simoneit et al., 1999). In another study, an aged prescribed fire dramatically increased the 24-h average levoglucosan level on the event day from $114 \mathrm{ng} \cdot \mathrm{m}^{-3}$ to $1210 \mathrm{ng} \cdot \mathrm{m}^{-3}$ and contributed overall to $7 \%$ of total organic carbon (Yan et al., 2007). However, levoglucosan is not a quantitative tracer for woodsmoke since it is not universally emitted at the same rate from all wood types. Additionally, burning temperatures can affect the emission concentration of levoglucosan. However, despite theses variabilities and the significant analytical costs associated with determining the levoglucosan concentration, it is currently the best chemical marker for biomass combustion.

\subsubsection{Health Effects}

The combustion of wood in residential household fires releases significant amounts of fine particulate matter $(\mathrm{d}<2.5 \mu \mathrm{m})$. While the upper respiratory tract does well in removing coarse particulate matter $(\mathrm{d}>2.5 \mu \mathrm{m})$, it fails to remove fine particulate matter, allowing for small particles to penetrate deep into the lung tissue (Yan et al., 
2007). The use of wood-burning stoves for indoor heating has been associated with increased symptoms of respiratory illness, such as frequent coughs (Honicky et al., 1985). Honicky found that $84 \%$ of young children, age 1 to 7 , whose household's primary heating source was wood-burning exhibited at least one of the following severe respiratory illness symptom (1) Usually coughs at night, (2) Coughs more than 4 days a week or (3) Occasionally wheezes other than when sick. This is opposed to only $3.2 \%$ of children whose household's primary heating was not wood, normally fuel oil or a gas furnaces, exhibiting at least one of those symptoms. Browning et al. (1990) also found increased occurrences of respiratory symptoms in young children ages 1 to 5 whose household's primary heating source was wood combustion.

In another study (Koenig et al., 1993), increased ambient fine particulate matter during the winter season was associated with decreased pulmonary function in asthmatic children, measured by forced expiratory volume in 1 second $\left(\mathrm{FEV}_{1}\right)$. $\mathrm{FEV}_{1}$ is a measure of restricted airflow caused by obstructed airways. Gauderman et al., (2004) also found decreased $\mathrm{FEV}_{1}$ with elevated ambient $\mathrm{PM}_{2.5}$ and $\mathrm{BC}$ concentrations. Decreased $\mathrm{FEV}_{1}$ has been linked to coronary heart disease, lung cancer, and stroke (Schroeder et al., 2003) (Hole et al., 1996).

The highly complex mixture of woodsmoke is composed of hundreds of different compounds including alkanes, alkenes, alkanoic acids, benzenes, phenols, polycyclic aromatic hydrocarbons (PAHs) and others (Fine et al., 2004a). This diverse chemical makeup has been shown to be mutagenic with $\mathrm{NO}_{\mathrm{x}}$ photooxidation in Salmonella typhimurium, especially gas phase products (Kleindienst et al., 1986). Polycyclic organic matter, a general term which includes but is not limited to PAHs, substituted aromatic 
hydrocarbons, and heterocyclic aromatic hydrocarbons, has also been associated with increased cancer risk (Lewtas, 1993). All of these findings suggest that inhalation of woodsmoke can negatively impact human health both acutely in sensitive individuals, such as young children, asthmatics or the elderly, or with long term exposure in the general population.

\subsubsection{Anthropogenic Climate Change}

Black carbon is a dominant contributor of anthropogenic climate change in two ways; (i) by absorbing solar radiation in the atmosphere, $\mathrm{BC}$ absorbs light energy and converts it to heat, warming the surrounding air and (ii) by decreasing the surface albedo of snow and ice. Decreasing surface albedo increases the absorption of solar radiation by the snow, exacerbating snowmelt rate. Furthermore, black carbon increases the length of the season that snow and ice melt. It has been suggested that the effect of black carbon on snow and ice albedo alone has contributed to one quarter of observed global warming, or $0.17^{\circ} \mathrm{C}$ (Hansen \& Nazarenko, 2004). A 10 -year global average increase in temperature due to all fossil fuel and biomass burning $\mathrm{BC}$ was estimated at $0.27^{\circ} \mathrm{C}$ (Jacobson, 2004). Because $\mathrm{BC}$ has a relatively short retention time in the atmosphere, due to rain and dry deposition (Jacobson, 2004), reducing emissions reduces global warming rates without a significant lag period. Jacobson (2002) predicts that eliminating all fossil fuel black carbon and organic carbon would slow net global warming by $20-45 \%$ in $3-5$ years.

However, there is some contention about whether black carbon and other aerosols that accompany combustion contribute to anthropogenic global warming. Sulfates, found both in fossil fuel emissions and biomass burning emissions, increase atmospheric albedo, causing a net cooling effect (Charlson et al., 1992). Jones et al., (2005) suggests 
that the net effect of atmospheric black carbon and sulfates from fossil fuel burning is zero. Another study came to the conclusion that while aerosols from fossil fuel and biomass burning do indeed impart a positive global warming impact, it is too costly to try to reduce emissions and that most anthropogenic aerosols come from developing countries where emission sources are often seen as a necessity (Bond \& Sun, 2005).

Finally, a study by Hansen et al., (2005) concluded that the impact on anthropogenic climate change is difficult to ascertain because four different factors come into play and all pose problems for determining a definitive magnitude. In the end, the net effective climate forcing from fossil fuel emissions and biomass burning soot was estimated to be $+0.25 \pm 0.2$ and $-0.23 \pm 0.17 \mathrm{~W} / \mathrm{m}^{2}$ respectively from $1750-2000$. As a comparison, the same study found $\mathrm{CO}_{2}$ to have a climate forcing of $1.5 \mathrm{~W} / \mathrm{m}^{2}$ during the same time period. Unlike fossil fuel combustion, the impact of biomass burning may not warrant the introduction of source controls for climate reasons alone.

\subsection{Relationship between Indoor and Outdoor Concentrations}

Assessing exposure to harmful ambient air pollution has been the concern of Americans since 1967 with the adoption of the Clean Air Act. The primarily focus of the program was on source emissions control and ambient monitoring, however studies have shown that Californians spend eighty-seven percent of their time indoors (Jenkins et al., 1992). So while ambient monitoring is vital, to understand exposure levels fully, we have to understand the relationship between ambient and indoor concentrations.

The process of determining the concentration of indoor particles based on outdoor concentrations begins with a simple mass balance equation as shown below in equation 1 . 


$$
\frac{\partial C}{\partial t} V=\left(C_{o u t}-C_{\text {in }}\right) Q
$$

$$
\begin{array}{ll}
\text { where } C_{\text {out }}(\mathrm{mg} / \mathrm{L}) & =\text { concentration outside boundary, } \\
C_{\text {in }}(\mathrm{mg} / \mathrm{L}) & =\text { concentration inside boundary }, \\
Q(\mathrm{~L} / \mathrm{s}) & =\text { volumetric flow through boundary, } \\
V(\mathrm{~L}) & =\text { volume inside the boundary, } \\
\partial C / \partial t(\mathrm{mg} / \mathrm{L} \cdot \mathrm{s}) & =\text { change in concentration over time, } t,
\end{array}
$$

Equation 1 above however is a gross simplification of the process of infiltration. Lawrence Berkley National Laboratory (LBNL) has developed an extensive model shown below in equation 2 (Thatcher et al., 2001).

$$
\begin{array}{cl}
\frac{\partial C_{t}}{\partial t}=\left(C_{O} P-C_{I}\right) \lambda_{V}-C_{I} k_{d e p}+G+S+F+K+H+R \\
\text { where } C_{I}\left(\mu \mathrm{g} / \mathrm{m}^{3}\right) & =\text { indoor particle concentration at time } t, \\
C_{O}\left(\mu \mathrm{g} / \mathrm{m}^{3}\right) & =\text { outdoor particle concentration at time } t, \\
P(\text { dimensionless }) & =\text { penetration factor, } \\
\lambda_{V}\left(\mathrm{~h}^{-1}\right) & =\text { air exchange rate due to infiltration, } \\
k_{d e p}\left(\mathrm{~h}^{-1}\right) & =\text { deposition loss rate, } \\
G\left(\mu \mathrm{g} / \mathrm{m}^{3} \bullet \mathrm{h}\right) & =\text { generation of particles from indoor sources, } \\
S\left(\mu \mathrm{g} / \mathrm{m}^{3} \bullet \mathrm{h}\right) & =\text { particle formation through gas/particle exchange, } \\
F\left(\mu \mathrm{g} / \mathrm{m}^{3} \bullet \mathrm{h}\right) & =\text { particle formation due to reaction } \\
K\left(\mu \mathrm{g} / \mathrm{m}^{3} \bullet \mathrm{h}\right) & =\text { particle size change through coagulation } \\
H\left(\mu \mathrm{g} / \mathrm{m}^{3} \bullet \mathrm{h}\right) & =\text { particle size change through hygroscopic growth }
\end{array}
$$




$$
R\left(\mu \mathrm{g} / \mathrm{m}^{3} \bullet \mathrm{h}\right) \quad=\text { generation of indoor particles from resuspension }
$$

Most of the terms above are assumed to be negligible but are shown to exemplify the complexity of the relationship between indoor and outdoor concentrations. To model concentrations inside a building with an inert pollutant, we can simplify equation 2 to equation 3 below (Hering et al., 2007). Equation 3 also requires that generation and resuspension of particles indoors are negligible.

$$
\frac{\partial C_{I}}{\partial t}=C_{O} P \lambda_{V}-C_{I}\left(\lambda_{V}+k_{d e p}\right)
$$

In equation $3, P$ (dimensionless) represents the penetration factor, $k_{d e p}\left(h r^{-1}\right)$ is the deposition rate coefficient and $\lambda\left(h r^{-1}\right)$ is the air exchange rate. The penetration factor refers to the fraction of particles that pass through the shell of the building. The deposition rate defines the rate that particles are lost due to deposition on surfaces throughout the home: carpets, furniture, etc. The final model parameter is the air exchange rate, which is defined as the airflow through the building divided by the building volume. It describes the inverse of the residence time of the air inside the home. A simple sketch of a home showing how each term affects the indoor concentration can be seen in figure 1 on the next page.

Because mechanical or natural ventilation was not included in the scope of this research, which would equilibrate concentrations more readily, the only path for air flow is between the cracks of homes, electrical wall sockets, etc. (Thatcher et al., 2001). This airflow is known as infiltration, where the primary driving force is an indoor/outdoor pressure difference. This can arise from wind impacting on a wall face imparting 
pressure differences or an indoor/outdoor temperature difference.

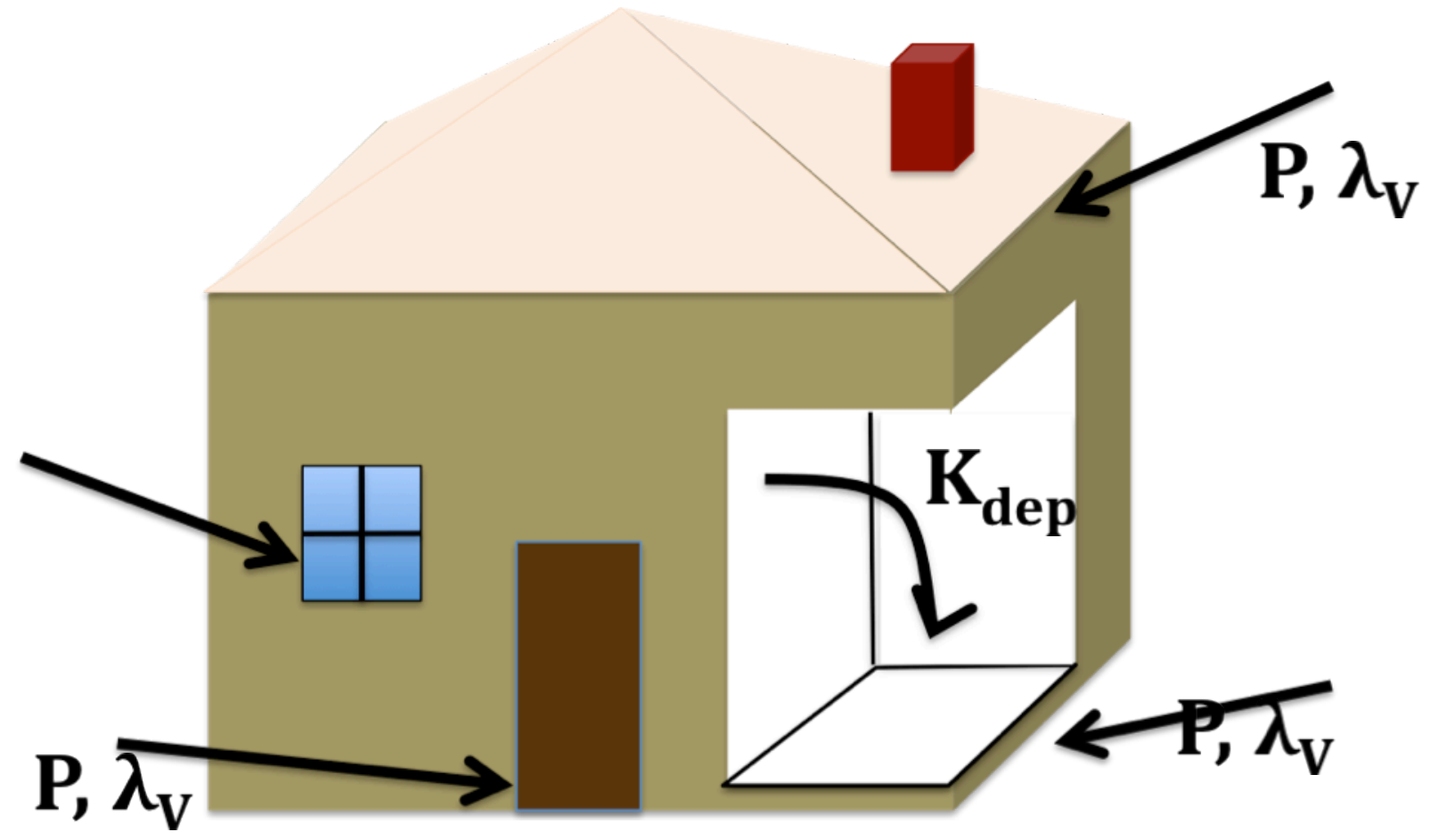

Figure 1: Simple sketch of a home showing how each parameter affects the infiltration of particles. The penetration factor, $P$, is the fraction of particles that penetrates the shell of the building. The deposition rate, $\mathbf{k}_{\text {dep }}$, is the rate that particles deposit onto surfaces inside the home, and the air exchange rate, $\lambda_{v}$, which is defined as the flow divided by the inside volume.

Lawrence Berkeley National Laboratory developed a model to estimate

infiltration rates based upon the temperature difference, wind speed, and building and environmental factors (Sherman \& Grimsrud, 1980). The model shown below in equation 4 describes infiltration rate $\left(\mathrm{hr}^{-1}\right)$. The model only applies to infiltration and not to mechanical or natural ventilation. A detailed description of the model can be found in Appendix D.

$$
\lambda=3600 \frac{A_{L E A K}}{A_{F L O O R} H} \sqrt{f_{S}^{2} \Delta T+f_{W}^{2} W^{2}}
$$

where $A_{\text {leak }}\left(\mathrm{m}^{2}\right)$ $=$ the total leakage area of the building,

$$
A_{\text {floor }}\left(\mathrm{m}^{2}\right) \quad=\text { floor area of the building, }
$$




$$
\begin{array}{ll}
H(\mathrm{~m}) & =\text { building height, } \\
f_{s}\left(\mathrm{~ms}^{-1} \mathrm{~K}^{1 / 2}\right) & =\text { the stack parameter determined by the geometry of the } \\
& \text { building, } \\
& =\text { absolute temperature difference, } \\
\Delta T(\mathrm{~K}) & =\text { the wind factor determined environmental shielding, and } \\
f_{w}(\text { unitless }) & =\text { the wind speed. }
\end{array}
$$

This model will be used later in one section of the analysis to determine the other two infiltration parameters, $P$ and $k_{d e p}$.

\subsection{Determination of EC/OC}

The elemental and organic fractions of aerosols are commonly determined using two distinct methods: thermal-optical and light attenuation. These methods typical yield slightly different results, since they measure different aerosol properties. However, neither method can be considered better than the other for all situations. The method chosen for an individual study is generally based on the specific goals of that study.

\subsubsection{Thermal Optical Methods}

To determine EC and OC from combustion sources, samples are collected on quartz fiber filters and heated at a prescribed temperature rate in a specific environment. There are several methods to determine EC/OC and each has its own operational definition of EC/OC. The Interagency Monitoring of Protected Visual Environments (IMPROVE) method (Chow et al., 1993) has been in use since 1987 to provide a record of background carbon concentrations in the U.S. The National Institute of Occupational Safety and Health (NIOSH) developed a competing method, which uses different temperature and optical protocols (NIOSH, 2003). Both methods ramp up the 
temperature in discrete ranges, with each range evolving more carbon compounds and providing a visual peak to be integrated for total carbon content. They differ by the temperature held at each stage. IMPROVE measures organic carbon in a 100\% helium environment by integrating $\mathrm{OC} 1\left(120^{\circ} \mathrm{C}\right), \mathrm{OC} 2\left(250^{\circ} \mathrm{C}\right), \mathrm{OC} 3\left(450^{\circ} \mathrm{C}\right)$, and $\mathrm{OC} 4\left(550^{\circ} \mathrm{C}\right)$ and further measures elemental carbon in a $2 \%$ oxygen $98 \%$ helium environment by integrating $\mathrm{EC} 1\left(550^{\circ} \mathrm{C}\right), \mathrm{EC} 2\left(700^{\circ} \mathrm{C}\right)$ and $\mathrm{EC} 3\left(850^{\circ} \mathrm{C}\right)$. NIOSH measures organic carbon in a $100 \%$ helium environment by integrating $\mathrm{OC} 1\left(250^{\circ} \mathrm{C}\right), \mathrm{OC} 2\left(500^{\circ} \mathrm{C}\right), \mathrm{OC} 3$ $\left(650^{\circ} \mathrm{C}\right)$, and $\mathrm{OC} 4\left(850^{\circ} \mathrm{C}\right)$ and further measures elemental carbon in a $2 \%$ oxygen $98 \%$ helium environment by integrating $\mathrm{EC} 1\left(650^{\circ} \mathrm{C}\right), \mathrm{EC} 2\left(750^{\circ} \mathrm{C}\right)$ and $\mathrm{EC} 3\left(850^{\circ} \mathrm{C}\right)$. Both methods therefore provide different operational definitions for EC and OC.

A third method (LBNL EGA) was developed by Ellis and Novakov (1982) and is fundamentally different from IMPROVE and NIOSH. Their method heats the sample at a constant temperature rate of $20^{\circ} \mathrm{C} / \mathrm{min}$ from 50 to $600^{\circ} \mathrm{C}$ in an oxygen atmosphere. The carbonaceous gasses that evolve from the heating are catalyzed to carbon dioxide over a magnesium dioxide probe. The carbon dioxide is measured with FID and the result is a thermogram, which is integrated to determine total organics. Some interpretation is required to separate EC and OC. In this study, NIOSH 5040 was used to determine EC/OC and LBNL EGA was used to determine BC and total carbon.

\subsubsection{Light Attenuation Methods}

$\mathrm{BC}$ is considered to absorb light better than any other aerosol species (Kirchstetter et al., 2004). The shorter the wavelength is, however, the greater the absorption capacity of BC. For example, the light absorption at $440 \mathrm{~nm}$ should be twice that of $880 \mathrm{~nm}$ because absorption is inversely proportional to wavelength (Hansen, 2005); but as the 
wavelength decreases, other aerosol constituents, namely organics, can contribute to absorption of light, specifically at wavelengths lower than 600nm (Kirchstetter et al., 2004). Because woodsmoke is mostly composed of organic carbon gravimetrically, it therefore may be an underestimated contributor to aerosol light absorption.

Light absorption by particles follows the empirical relationship known as Beer's law or the power law relationship: $\sigma=\mathrm{K} \cdot \lambda^{-\alpha}$, where $\sigma$ is the spectrally dependent mass adsorption efficiency, which is directly proportional to attenuation, $\mathrm{K}$ is a constant, $\lambda$ is the wavelength of light transmitted, and $\alpha$ is the adsorption Ångström exponent (Kirchstetter et al., 2004). In the above equation, what is most important in characterizing adsorption is the Ångström exponent. Kirchstetter and Novakov found samples more associated with motor vehicle exhaust had an adsorption exponent of 1 , or that adsorption was inversely proportional to wavelength. They also found that samples more associated with biomass burning exhibited an adsorption exponent of around 2 . Another study saw similar adsorption exponents for biomass burning and traffic aerosols (Sandradewi et al., 2008)

The difference in the adsorption exponent is directly related to the presence of organic carbon in the sample. By immersing samples in acetone, all organic carbon present is dissolved and removed from the filter. A comparison can be made between biomass samples and motor vehicle samples before and after acetone treatment. It would follow that if the biomass sample had light absorbing organic carbon present, after the acetone treatment, the adsorption exponent should decrease. For the motor vehicle sample, the adsorption exponent should stay relatively the same after the acetone treatment if little to no light absorbing organic carbon was present. This is exactly what 
Kirchstetter and Novakov found. In one example biomass sample, the adsorption exponent decreased from 2.2 to 1.3 after the acetone treatment. In an example traffic aerosol sample, the adsorption exponent decreased from 1.2 to 1.1 after the treatment, indicating comparatively little light absorbing $\mathrm{OC}$ in the traffic sample.

One method posed by (Sandradewi et al., 2008), aimed to separate woodsmoke and diesel $\mathrm{PM}_{2.5}$ along with their specific organic carbon fractions from total particle mass by using light absorption and radiocarbon identification. Using light attenuation to find organic carbon fractions would be faster and cheaper than traditional thermal methods. However some chemical species, including PAH's, can absorb light orders of magnitude more efficiently than others (Hansen, 2005). So unless relative organic composition was known, it would be impossible to tell how much light absorbing organic carbon was present.

In the present study, the absorption properties of organic carbon derived from wood combustion was examined using light attenuation from quartz fiber filters. This was achieved by comparing samples run in the same location and under the same conditions with traditional thermal optical methods and light attenuation methods. Detailed in the next chapters are the methods, analysis, and discussion on how this was achieved. 


\section{Chapter 3: Methods and Study Design}

\subsection{Project overview}

Most air quality studies have focused on outdoor air as a means of characterizing exposure levels, however a majority of people's time is spent indoors (Jenkins et al., 1992). Therefore, there is a disconnect between actual exposure levels of pollutants and those found in the studies that base their results on outdoor air. To combat this discrepancy, many researchers have investigated how aerosols enter buildings (Freijer \& Bloemen, 2000; Geller et al., 2002; Hering et al., 2007; LaRosa, Buckley, \& Wallace, 2002; Lunden, et al., 2008; Nazaroff \& Cass, 1986). The first goal of this project was to further this understanding for the specific case of wood smoke generated by sources near the homes of interest by taking an existing reputable model and applying it to an environment where woodsmoke is the dominant wintertime pollutant. This includes determining the parameters of the indoor infiltration model detailed in section 2.2 and 12hour time integrated exposure levels of individuals indoors.

A second goal of this project was to investigate light absorption of organic carbon from woodsmoke. Thermal methods, as described in section 2.4.2 quantify organic and elemental carbon, however the methods provide no discernable information to the source of the carbon fractions. Under thermal methods, organic carbon derived from diesel emissions cannot be distinguished from organic carbon derived from woodsmoke. Optical analysis however can be used to provide evidence for woodsmoke presence when observing light attenuation in the UV range. Unlike vehicle emissions, woodsmoke 
derived organic carbon greatly increases light absorbance in the UV range (Kirchstetter et al., 2004). This property specific to woodsmoke is the second focus of this paper.

To achieve the study goals, location, sampling plan, equipment, methods of measurement, and weather all had to be considered. As a basic requirement, the location had to have sufficient ambient particle matter so that it was above the detection limit of the instruments. Local weather patterns had to accommodate outdoor instruments. A location with frequent rain during the winter months, where the probability of rain on more than one sequential day is high, would not be a good place to study. Rain scavenges aerosols, potentially leading to woodsmoke concentrations below detection limits and reducing the number of potential sampling days. The study area needed an active population of individuals who regularly burn wood, whether for nighttime heating or recreation. Finally, the selected neighborhood needed to be representative of an average American neighborhood with respect to home age, home density, and property size.

To assess the relationship between indoor and outdoor concentrations, instruments needed to be placed both inside and outside a home. This required access to a home within the study location. Before the study began, an individual within the study area was contacted and approval gained for access into the home. It has been well documented that particle matter in cities generally carries a diurnal cycle with elevated concentrations in the morning and night: the former from automobile traffic and the later from residential woodsmoke (Chow et al, 2006; LaRosa et al., 2002). It is therefore reasonable to measure at night for woodsmoke. The instruments would need to begin sampling before individuals begin woodstove or fireplace ignition and continue 
throughout the night until concentrations return to levels observed before wood burning events.

Many methods and instruments are used to characterize aerosols, all with their strengths and weaknesses. The time resolution for these instruments fall into two categories (1) time-integrated and (2) semi-instantaneous. Time-integrated samplers collect total mass of a pollutant of interest on a filter integrated over the total length of time the sample was run, usually 12 to 24 hours. For example, EC/OC can be analyzed in a time-integrated approach as outlined in section 2.4.1. This gives an average concentration over the course of the sampling period. The analysis is usually performed in a laboratory, away from where the sampling took place. For woodsmoke, many timeintegrated samplers have been used including FRMs (the federal reference method for determination of 24-hr PM2.5 or PM10 concentrations), mini-vols and hi-vols (a smaller version of an FRM but are not federally recognized), and Personal Environmental Monitors (PEMs, small devises that measure various pollutants depending on the filter analysis). In this study, PEMs were used to determine EC/OC using the NIOSH 5040 method. The PEMs were also used to determine BC and total carbon with LBNL EGA method and analyzed for light absorption under an array of wavelengths.

In contrast, semi-instantaneous sampling works on the same principal, but the averaged sampling period is much less. In the case of the Aethalometer, that time period can be as low as 1 minute. The same instrument that takes the sample usually performs the analysis. For semi-continuous monitoring, the list of instruments used is rather extensive and includes the Tapered Element Oscillating Micobalance (TEOM), Particle Soot Absorption Photometer (PSAP), Aethalometer, Nephelometer, and R\&P 5400. This 
is just a small list of instruments have that been developed to characterize ambient particle matter. In this study, the Aethalometers were used to determine indoor/outdoor $\mathrm{BC}$ concentration to characterize the infiltration parameters,

\subsection{Location}

Cambria California, located in San Luis Obispo County, is known to have some of the best air quality in the state (State of the Air: 2007). However, during the winter months, Cambria is subject to heavy residential wood burning, evident by the large volume of complaint calls to San Luis Obispo County Air Pollution Control District in the winter months of 2008. Cambria, known as Pines by the Sea, has a total population of 6,232 as of 2007 (US Census Bureau, 2007), with a median age of 50.9 years. The nickname derives from the abundance of pine trees, mostly Monterey Pine located throughout the town. These tall trees can shield homes from wind, affecting the infiltration of particles. The homes in Cambria are mostly newer with more than half built after 1980 and greater than $75 \%$ after 1970 (US Census Bureau, 2007). The town is located on the ocean and has one 2-lane highway, Highway 1, which runs through the center of the town. Figure 2 on the next page shows Cambria's roadway system, with a red box around the approximate study area.

Cambria is unique among most towns in that there is very little commercial diesel traffic that operates nearby and it has no industrial pollution sources. Additionally, because the predominate wind direction is from the ocean into the town and there are no immediately neighboring towns, there should be minimal PM entering Cambria from outside sources. In the absence of traffic and industrial sources, the major source of winter-time PM and subsequent carbonaceous burning tracers can be assumed to derive 
primarily from residential wood smoke. The region is also relatively dry with rain fall during the proposed study period, December to March, averaging 10.9 inches, well below the national average for precipitation (Cambria Weather, 2008).

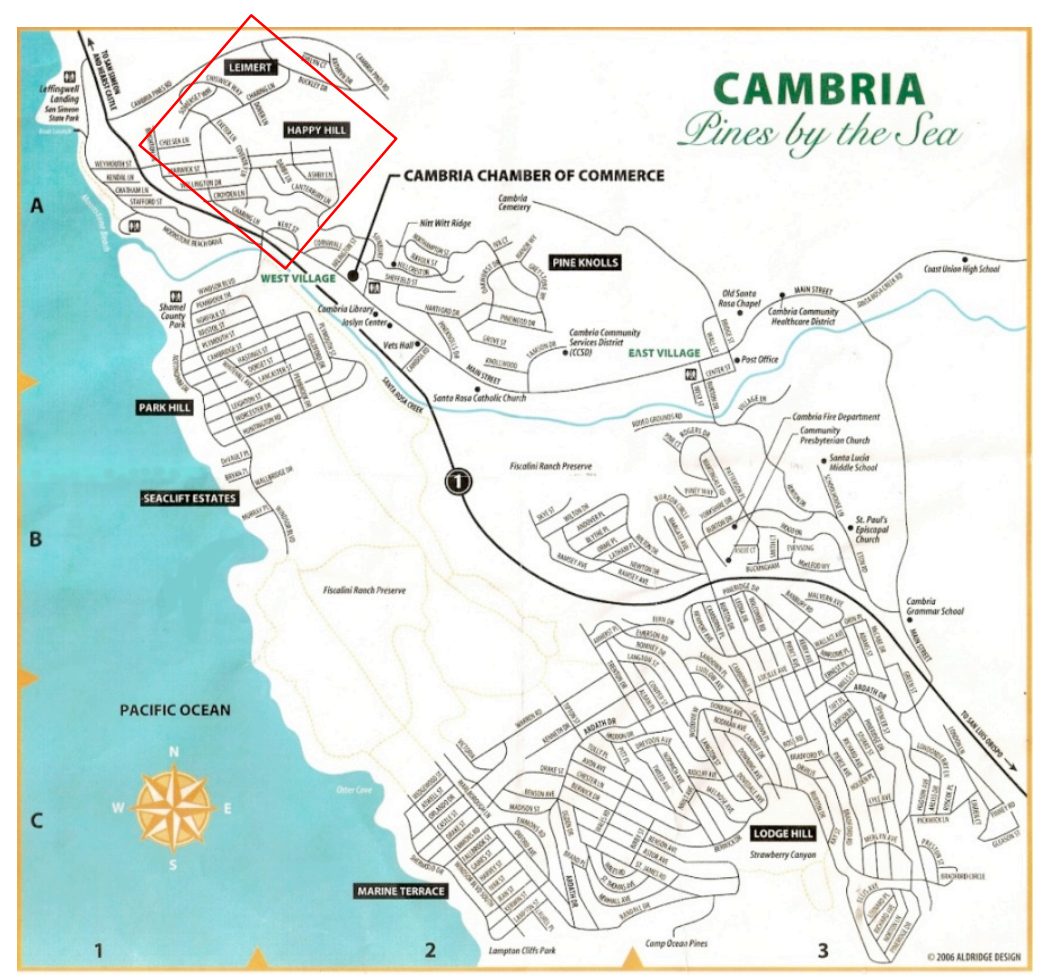

Figure 2: Map of roadway system of Cambria, California

The neighborhoods selected for the project are known as Happy Hill and Leimert, located in the northern part of Cambria shown in Figure 2 in red. The study area is approximately $1 \mathrm{~km}^{2}$ with about 400 homes. The neighborhood is mostly flat, although some small hills are present. Because of the large volume of complaint calls received in winter 2008, many of the residents were eager to have monitoring instruments placed in or around their home, despite the inconvenience.

The home that was used in the study was a single story home built in the 1970's with a basement. During the course of the study, all of the windows inside the home 
remained closed and the fireplace was never used. With the home having only 2 adult occupants, heavy foot traffic was avoided. There was no stand-alone air filter unit present in the household.

\subsection{Instrumentation}

\subsubsection{Aethalometers}

Black Carbon (BC) is released during the combustion of any carbon source. The rate that $\mathrm{BC}$ is emitted can vary widely depending on the source of carbon and combustion conditions. Even with knowledge of the source and the amount of fuel consumed during the process, emissions rates can still vary tremendously. Because $\mathrm{BC}$ concentrations cannot be readily determined from knowledge of the source, or from data about the combustion process, it is necessary to directly measure actual concentrations using an instrument known as an Aethalometer (Fig. 3). This is true for other combustion emission rates, including organic carbon.

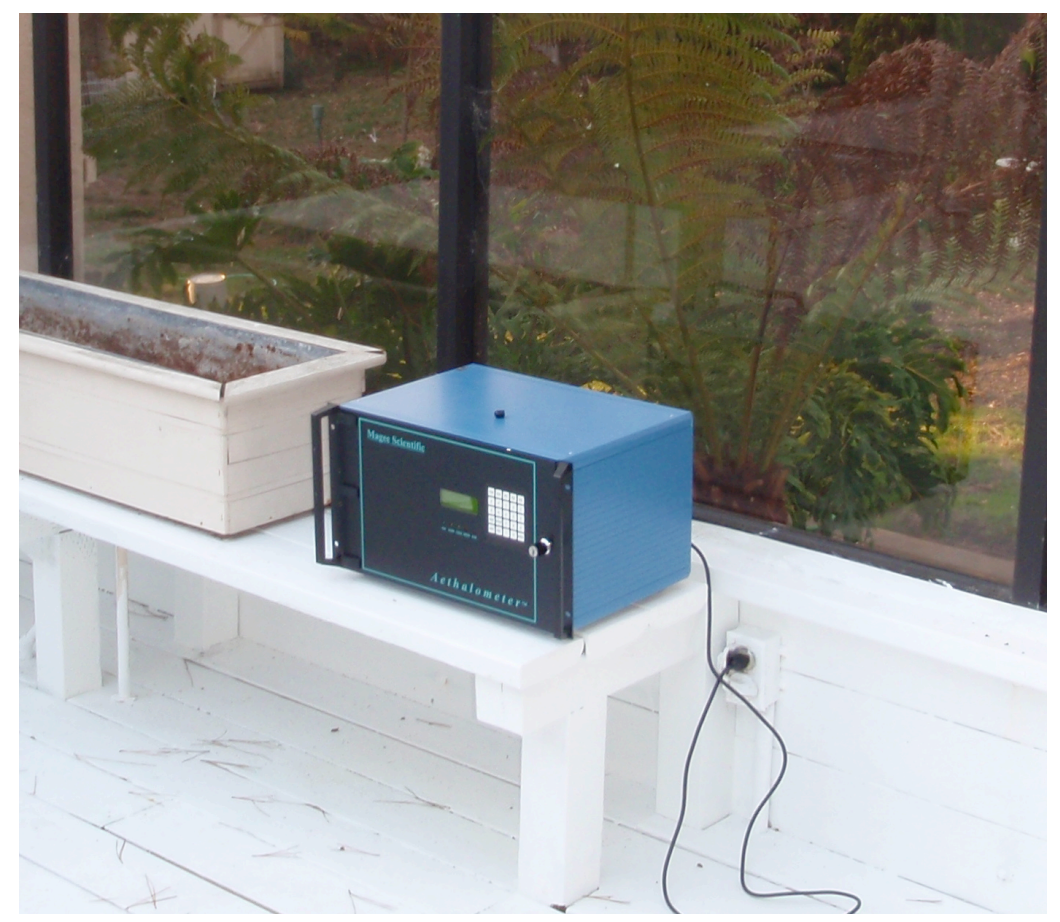

Figure 3: An Aethalometer used during research in Cambria, CA at a local resident's home 
Black Carbon originates only from the combustion of a carbon source and is not known to come from biological, geological, or meteorological sources including volcanic eruptions, which are generally composed of mineral dust (Hansen, 2005). The four main sources of $\mathrm{BC}$ are fuel combustion, biomass burning for agricultural reasons, naturally occurring forest fires, and residential household fires.

The Aethalometer takes advantage of the optical absorbing properties of black carbon, which were first proposed by (Rosen \& Novakov, 1977). This optical method measures attenuation of light transmitted through a quartz fiber filter using Eq. 5 below. Gundel et al., (1984) showed that BC absorbs light linearly proportional to the mass on the filter, therefore a constant can be applied to find mass based on attenuation.

$$
A T N=100 * \ln \left(I_{O} / I\right)
$$

In the equation above, $I_{\mathrm{o}}$ is the intensity of light transmitted with no filter deposit and $I$ is the intensity of light transmitted through the filter with aerosol deposit. Black carbon is calculated by the difference in attenuation from time 0 to time 1 , denoted d(ATN) divided by a constant, known as the specific attenuation cross-section. The result of that calculation gives the weight (in grams) of black carbon per $\mathrm{cm}^{2}$. To find black carbon concentration, the result from the equation above is multiplied by the area of the filter and divided by the total volume of air sampled from time 0 to time 1 . This is summed up as:

$$
B C=\frac{d(A T N) * A}{V^{*} S G}
$$

where $\mathrm{A}\left(\mathrm{cm}^{2}\right)$ is the area of the filter where deposits are present, $\mathrm{V}\left(\mathrm{m}^{3}\right)$ is the total volume passed through the filter from time 0 to time 1 , and $\mathrm{SG}\left(\mathrm{m}^{2} / \mathrm{g}\right)$ is the specific attenuation cross-section. Eq. 6 is dependent on two assumptions, the attenuation cross 
section is constant for all aerosol compositions and light attenuation is linearly proportional to mass. Both are unfortunately found to be untrue. Petzold et al., (1997) found that the absorbance cross-section varied with particle size and composition. They found cross sections ranging from $8 \mathrm{~m}^{2} / \mathrm{g}$ for rural areas to $19 \mathrm{~m}^{2} / \mathrm{g}$ for a street crossing. Liousseet al., (1993) also found cross sections ranging from $14 \mathrm{~m}^{2} / \mathrm{g}$ to $20 \mathrm{~m}^{2} / \mathrm{g}$. More unfortunately still, the attenuation of black carbon has been observed to be dependent on filter loading (Weingartner et al., 2003). The Aethalometers continually load a small area of the filter until a predetermined optical attenuation set point. Once the filter passes the set point, the filter tape advances and the Aethalometer begins loading a new area. It has been observed that as filter loading increases the optical path in the filter decreases contributing to lower reported concentrations. As a result, empirical equations have been developed to correct for this effect (Virkkula et al., 2007). However, in our study, we observed no decrease in concentration as the filter became more loaded. This was determined by running Aethelometers side by side and comparing the concentrations with a different amount of filter loading. If one Aethalometer is closer to the attenuation set point and reports a lower concentration than an adjacent Aethalometer just after the filter tape had advanced, then we would need to correct for the problem using the equation provided by Virkkula et al., 2007, however we did not observe this effect.

Five Aethalometers were used during the course of this research, four were dualwavelength, measuring at $370 \mathrm{~nm}$ and $880 \mathrm{~nm}$ and one was a multi-wavelength Aethalometer, measuring at $370,470,520,590,660,880$ and $950 \mathrm{~nm}$. Of the four dualwavelength Aethalometers, one was portable and the multi-wavelength Aethalometer was 
also portable. Black carbon was measured at $880 \mathrm{~nm}$ every minute with the Aethalometer handbook recommending $16.6 \mathrm{~m}^{2} / \mathrm{g}$ as the specific attenuation cross section.

Intermittently during the study, the Aethalometers were placed side by side for comparison. It is more important for this research that the Aethalometers be precise than accurate. Therefore, the Aethalometers were adjusted to match each other as precisely as possible. To adjust the Aethalometer, the specific attenuation value was increased or decreased corresponding to whether it reported on average higher or lower concentrations. A total of 191 half hour concentrations were compared using Minitab. Before the adjustment the F statistic was 63.84 corresponding to a P-value of 0 . After the adjustment, the F statistic was 1.78 with a corresponding P-value of 0.131 . Since the Pvalue is above 0.05 , we can say the Aethalometers do not report statistically different concentrations. A comprehensive statistical summary of this adjustment is given in Appendix A. The Aethalometers need to record precise concentrations to make comparisons for indoor/outdoor modeling. Because there is no known way to accurately calibrate Aethalometers, adjusting the specific attenuation values is the most accepted method.

\subsubsection{Personal Emissions Monitor Devices}

In conjunction with Aethalometers, small quartz fiber filters were also used to collect aerosols. PM2.5 was the size range selected for using Model 200 Personal Environmental Monitors (PEMs). The PEMs were designed for a flow of $10 \mathrm{~L} / \mathrm{min}$, which was accommodated by flow-controlled pumps (Leland Legacy, SKC Inc.). Each pump was calibrated using a single Bios DryCal DC-2 calibrator (Model DC-HC-1).

Unlike the Aethalometers, which recorded concentrations with minute resolution, the 
PEMs ran continuously for an integrated 12-hour sampling period. A picture of our PEM set-up is located below in figure 4 .

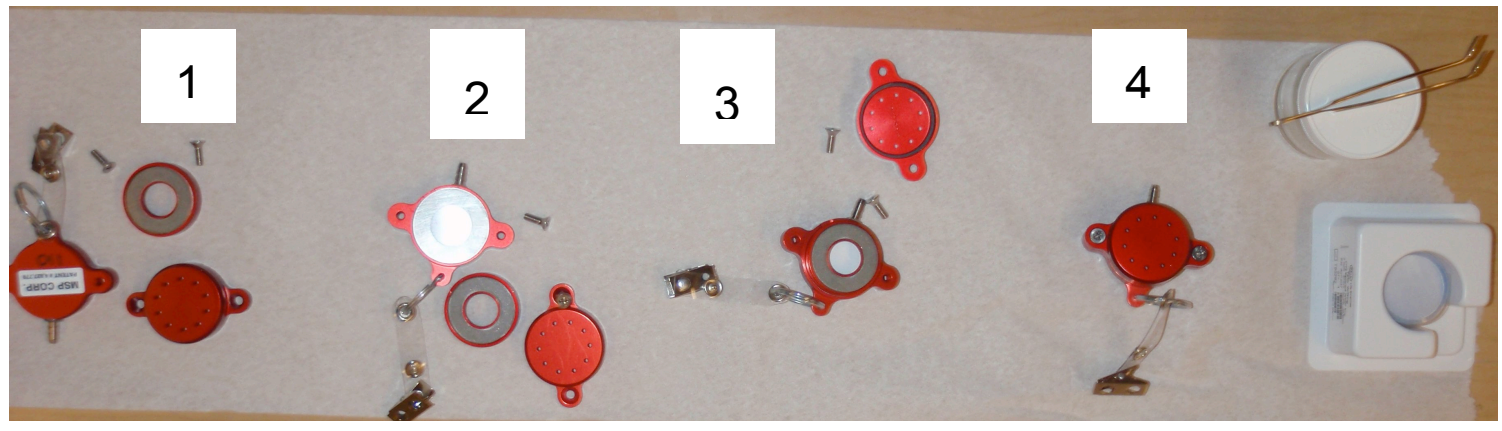

Figure 4: PEMs are various stages of set-up (1) disassembled PEM showing impactor ring, (2) quartz filter between aluminum-ringed masks, (3) impactor ring placed on top of mask and filter and (4) completed PEM assembly.

Stage 1 shows the completely disassembled PEM top, bottom and impactor ring. The holes on the top are where air is drawn through the PEM. The air then makes a tight turn around the impactor ring, where particles larger than 2.5 microns in diameter deposit. Stage two shows the quartz fiber filter sandwiched between two aluminumringed masks. This decreases the area that particles deposit onto the filter and provides greater sensitivity. The opening on the mask measured $2 \mathrm{~cm}$ in diameter giving a deposit area of $3.14 \mathrm{~cm}^{2}$. Stage three shows the impactor located on top of the filter and stage four shows the completed assembly of a PEM.

Before every sampling period, the PEMs were thoroughly cleaned with methanol and allowed to dry completely. This insured any leftover carbon remnants from the last sampling period were removed. The impactor was subsequently cleaned and greased with mineral oil, providing a "sticky" surface for particles to deposit. The filters were meticulously placed in the PEM with special tweezers, minimizing the risk of contamination. After securing the top, each PEM was placed in a zip lock bag to transport to Cambria. 
Method and field blanks were also collected during each sampling period. After PEM assembly, the sample randomly designated the method blank would not be removed from the plastic bag, but instead be left unexposed. Its purpose was to determine if contamination occurred during assembly. Field banks were exposed to the same conditions as other samples, often lying adjacent to an active sampler, and were collected the next day as if they were samples. However field blanks, were not connected to a pump and therefore no flow was recorded. This gave us information about whether the samples were being contaminated during PEM deployment. Both field blanks and method blanks were analyzed using the same method as our samples.

For each IOP, the PEMs ran from 6 p.m. to 6 a.m., providing a 12-hour integrated sampling period. The pumps were housed in a plastic housing filled with ripped pieces of low-density upholstery foam shown below in figure 5 .

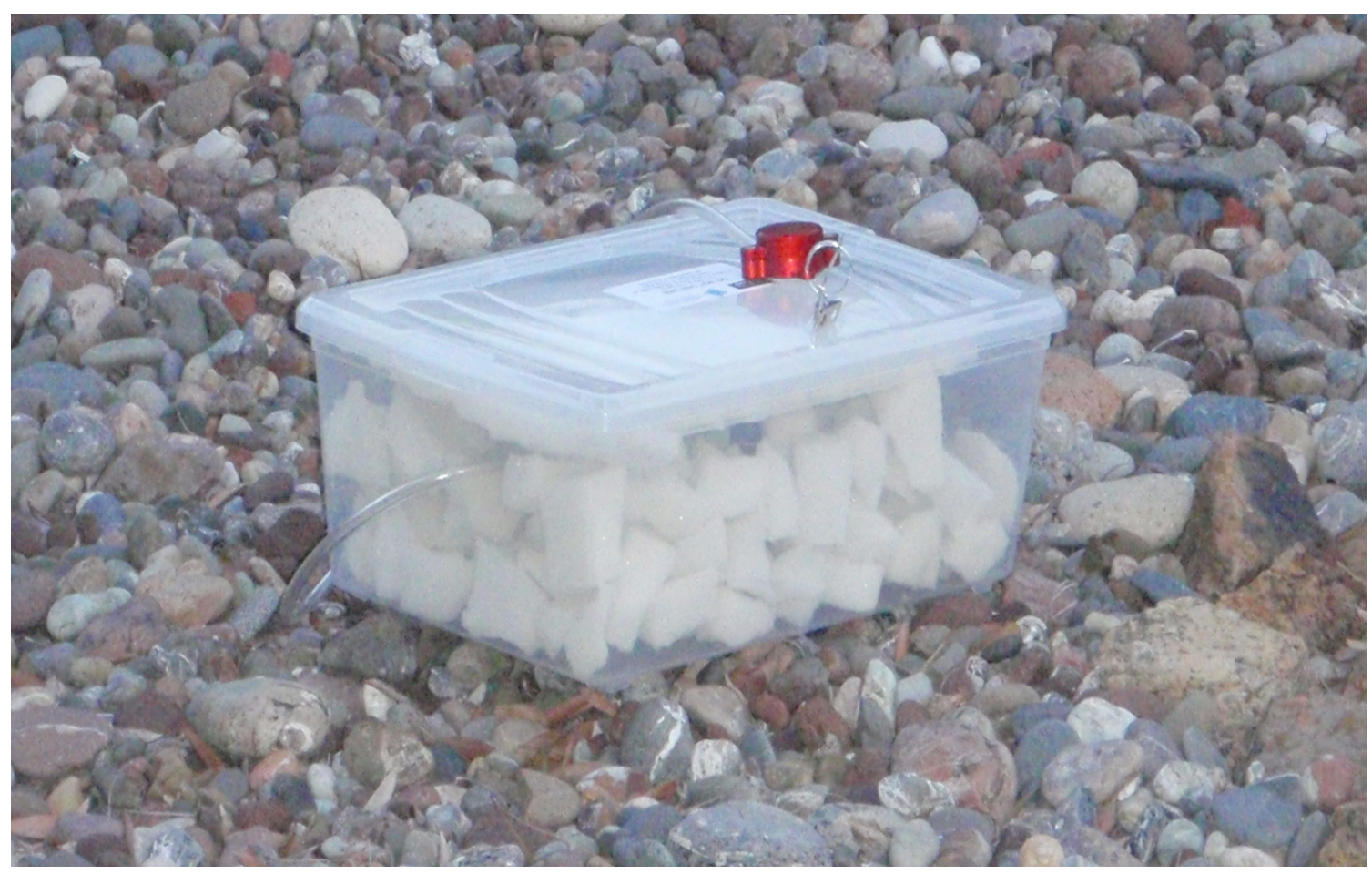

Figure 5: PEM and pump housing configuration 
The filters from the PEMs were analyzed with a custom built multiple wavelength light transmission instrument from Lawrence Berkeley National Laboratory that measures light attenuation ranging from $350 \mathrm{~nm}$ to $1000 \mathrm{~nm}$ taking readings every 0.3 nm. It accomplishes this sensitivity with an array of light emitting diodes. As noted in section 2.3.2, a plot of attenuation vs. wavelength can be created from the instrument for particulate analysis.

\subsection{IOP Design}

From late November 2008 to early January 2009, Aethalometers were placed inside and outside one resident's home to assess average woodsmoke levels for the area. For the winter season, on selected days beginning January 2009 and ending March 2009, Aethalometers and PEMs were placed indoors and outdoors of the same home within Cambria. Information about the home was gathered, including whether the resident ever burns wood inside, age of home, and how often windows are left open during the night. Starting January $31^{\text {st }}, 2009$, Intensive Operating Procedures (IOPs) began. A total of 8 IOPs were conducted through the 2009 winter season: January $31^{\text {st }}$, February 18th, February $26^{\text {th }}$, February $27^{\text {th }}$, March $5^{\text {th }}$, March $13^{\text {th }}$, March $15^{\text {th }}$, and March $20^{\text {th }}$.

Before every IOP, the PEMs were cleaned thoroughly and loaded with baked, precut quartz fiber filters. For baking, the filters were placed in an oven at $800^{\circ} \mathrm{C}$ for 2 hours. Pumps were programmed to operate between 6 p.m. and 6 a.m. for a total of 12 hours at $10 \mathrm{~L} / \mathrm{min}$, giving a total volume of 7,200 liters of air. This time period was chosen to encompass the entire burning period, as observed using aethalometer data. Upon arrival to Cambria, PEMs and Aethalometers were placed inside and outside of one home. Another study took place simultaneously, which assessed near field outdoor 
woodsmoke variability. For this study, PEMs were placed throughout the study area. The locations of the outdoor study PEMs were not restricted to homes and were often placed on public property near light posts and electrical poles.

After the PEMs were placed, researchers awaited nightfall to begin woodsmoke emission source location identification. A Fluke TI25 infrared camera was used to spot homes with elevated chimney temperatures from woodsmoke combustion. Below in Figure 6 is one example of a home identified as burning wood on March $15^{\text {th }}$.

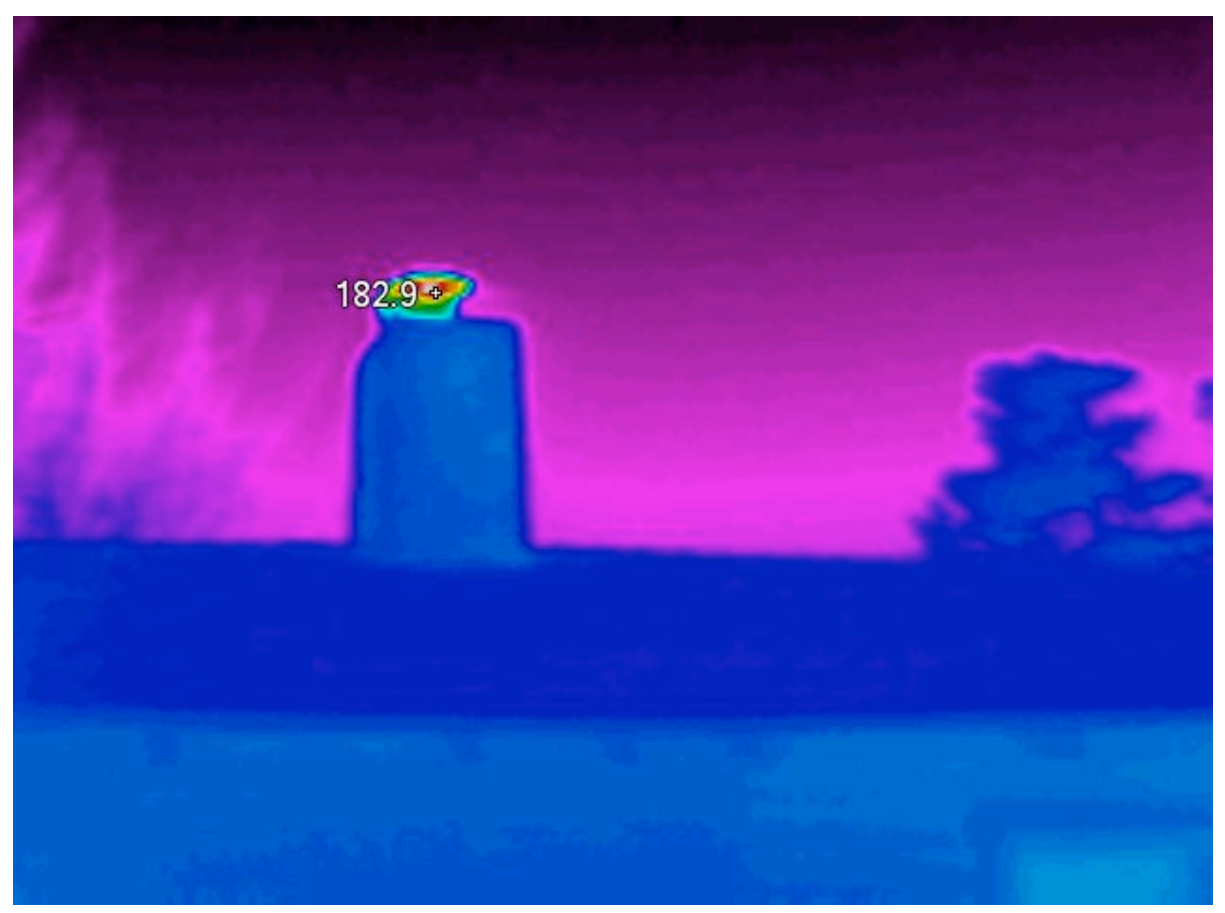

Figure 6: Thermal image of a chimney stack with a high temperature of $182.9^{\circ} \mathrm{F}$, indicative of wood burning

While recording the homes that burned was not important to the indoor portion of the project, it was a vital facet to the woodsmoke variability assessment study. A single circuit of the homes in the area was made each night to detect wood smoke sources. The following day, all PEMs and pumps were picked up, although sometimes aethalometers were left running until the following weekend, if the weather permitted (no rain 
forecasted) and the homeowner consented. The filters were carefully removed from the PEMs, stored in individual Petri dishes, which were sealed with Teflon tape and then wrapped together (one per IOP) in aluminum foil, and shipped to the appropriate labs for analysis.

\subsection{Method Comparison IOPs}

On March $7^{\text {th }}$ and March $15^{\text {th }}$, methods comparisons IOPs were executed instead of the normal IOPs described in Section 3.4. The goal was to compare established methods for determining woodsmoke EC/OC with the light attenuation method used in this study. To compare different methods, four PEMs were co-located at four different sites, for a total of 16 PEMs deployed. An aethalometer and a mini-vol were also placed at each site.

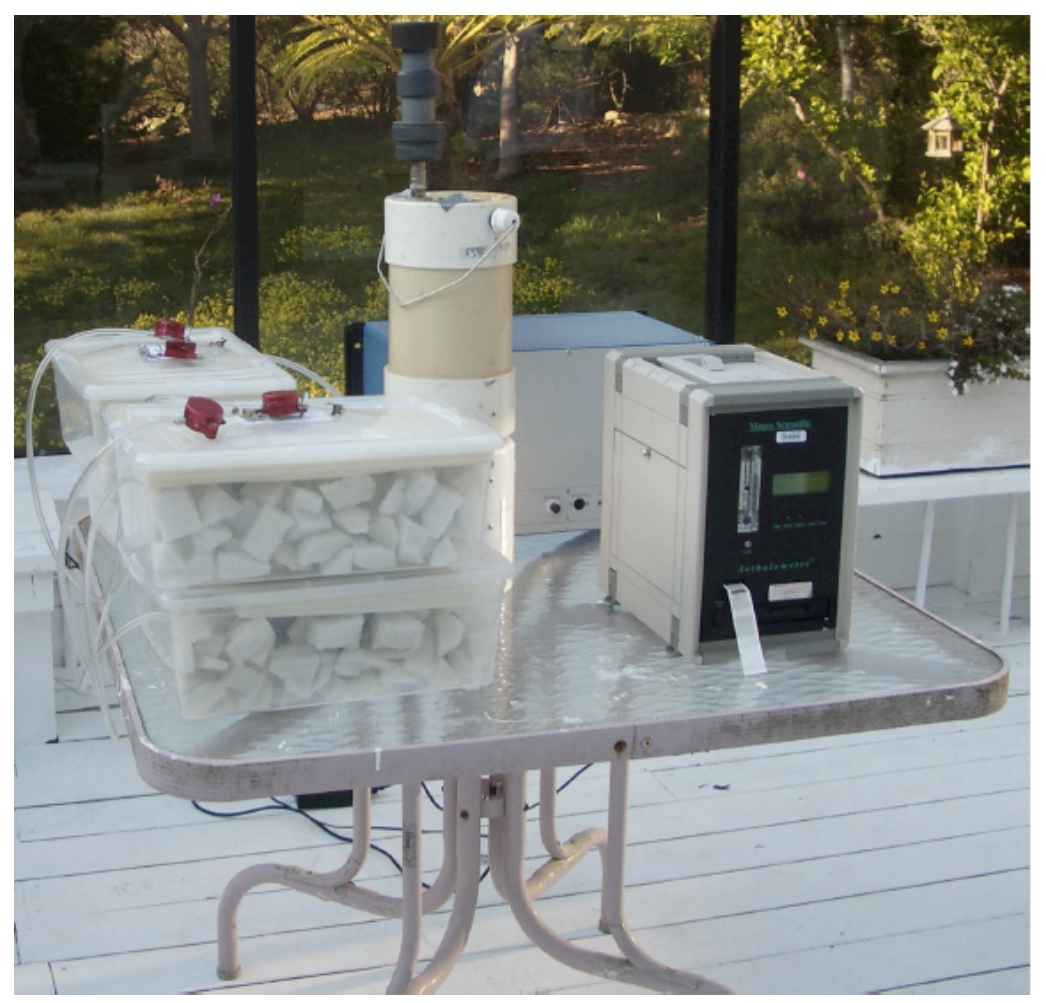

Figure 7: Method comparison IOP showing four PEMs, two aethalometers and a mini-vol co-located in a resident's backyard. 
Mini-vols are compact, battery operated gravimetric $\mathrm{PM}_{2.5}$ or $\mathrm{PM}_{10}$ measurement instruments. They differentiate $\mathrm{PM}_{2.5}$ or $\mathrm{PM}_{10}$ mass fractions by the aerodynamic properties of the particles using a special inlet. Because our PEMs collected only the $\mathrm{PM}_{2.5}$ fraction, a PM 2.5 selection inlet was used in the mini-vol system for this study. Figure 7 on the previous page shows a method comparison IOP set-up at one site.

For each co-location site, two of the PEM filters were sent to Sunset Laboratories in Tigard OR, for EC/OC analysis by the NIOSH 5040 method. Of the two filters sent to Sunset Labs, one was loaded identically to the filters sent for light attenuation, with only a quartz filter, and the second PEM was loaded similarly, except with a Pall Fiberfilm (Teflon-coated glass fiber) filter placed on top of the quartz filter sent for analysis. Quartz fiber filters adsorb gaseous organic compounds that lead to positive artifacts, or an overestimation of the particulate mass of organic carbon (Kirchstetter et al., 2001). Since the Teflon filter does not absorb organic gases but does remove particles, the quartz filter behind the Teflon will only absorb organic gases. The PEM with only the quartz filter will have gases plus PM and the quartz with the Teflon in front will only have gases, therefore the gases can be subtracted from the quartz filter, leaving only the mass of particle bound organic carbon. The third filter PEM from each site was analyzed at Lawrence Berkeley National Laboratory using the same optical method described in Section 3.3.2. Wisconsin State Laboratory of Hygiene analyzed the fourth PEM filter for levoglucosan. Levoglucosan is the best-known tracer for wood combustion and can provide additional information about the levels of woodsmoke.

Finally, the mini-vol filter was analyzed for total gravimetric particulate matter with aerodynamic diameter less than $2.5 \mu \mathrm{m}$. The mini-vols ran at $6 \mathrm{~L} / \mathrm{min}$ from 6 p.m. to 
6 a.m. for providing a 4,320 L sampling volume. The PM was collected on a $47 \mathrm{~mm}$ Teflon filter and was analyzed by Ventura County Air Pollution Control District. Problems arose when using the mini-vols; therefore the data was discarded. The PM mass data is not necessary to achieve the goals of this study and would only have provided reference concentrations to compare to other city's historical PM data. 


\section{Chapter 4: Results and Discussion}

\subsection{Indoor/Outdoor ratios}

The subject of indoor/outdoor pollutant ratios has been a topic of investigation since the late 70's. When discussing exposure levels for individuals indoors, an average indoor/outdoor ratio for a particular pollutant is a quick and easy assessment tool. Knowing an average outdoor concentration for a pollutant and an average indoor/outdoor ratio, one can easily assess an average indoor concentration. However, there are some inherent uncertainties with this procedure. For example, the indoor/outdoor ratio is heavily dependent on atmospheric conditions and home parameters. This means that not only can two homes in the same region have different indoor/outdoor ratios, but also that the same home may have different ratios on different nights. Additionally, as demonstrated in the study performed along side this one; there can be a huge variation in outdoor concentrations over a relatively small area. Nevertheless, indoor/outdoor ratios provide the most basic level for understanding indoor contaminant levels.

For this study, black carbon was the only pollutant examined. The Aethalometer raw data was reintegrated over the course of the entire burning period to obtain an average indoor and an average outdoor concentration. For black carbon the average indoor/outdoor ratio was $0.74 \pm 0.05$ for all burning events using a $95 \%$ confidence interval. A total of 16 burning events were recorded, defined as a substantial increasing in outdoor black carbon concentration followed by a return to concentrations pre-event. This means that over the course of the burning period, an individual indoors will be exposed to approximately three quarters of the exposure a person standing just outside 
the house would receive. This compares with previous studies for indoor/outdoor ratios, where Geller et al., (2002) reported 0.85, Lunden et al., (2008) reported 0.6, and Polidori et al., (2006) reported 1.0 for either black carbon or elemental carbon.

\subsection{Indoor Infiltration Parameters}

Knowledge of infiltration parameters is vitally important to assessing exposure levels of pollutants indoors from an outdoor origin. To calculate deposition rate, penetration factor, and air exchange rate, actual indoor concentrations were compared with indoor concentrations calculated using the indoor infiltration model using a minimization of the sum of squared differences between the modeled and measured concentrations. Repeated below in Eq. 7 is the indoor infiltration model that was used for this study. This simplified form of Eq. 2 in Section 2.3 assumes re-suspension, chemical reactions, and source generation inside the home are negligible. Minimal foot traffic during the night hours allows the dismissal of re-suspension. Because black carbon is a conservative aerosol, chemical reactions are assumed to be insignificant. Finally, the home was chosen such that the residents did not burn firewood, so source generation could be removed from the equation. A cooking stove is a possible generation source of black carbon, however no anomalous increases in black carbon concentrations were observed indoors.

$$
\frac{\partial C_{I}}{\partial t}=C_{O} P \lambda_{V}-C_{I}\left(\lambda_{V}+k_{d e p}\right)
$$

For minimization, the Solver program for Microsoft Excel, developed by

Frontline Systems was used. This program calculates optimal solutions to models within Excel, when the objective is to find maximum or minimum values based upon inputs and 
constraints, if needed. For the infiltration model, two minimization techniques were used simultaneously to calculate the optimal values for air exchange rates, penetration factors, and deposition rates. The first was to use the minimization of the sum of squared differences between the actual indoor concentration determined from the aethalometer and the calculated indoor concentration determined from the actual outdoor concentration and the infiltration model. The sum of squared difference term was normalized by dividing the difference term by the actual concentration (Eq. 8). The purpose for dividing by the actual concentration is to deemphasize large concentration increases, which may shift the infiltration parameters to minimize small regions of highly fluctuating concentrations.

$$
S S D=\sum\left(\frac{C_{A c t}-C_{M o d}}{C_{A c t}}\right)^{2}
$$

where $C_{A c t}\left(\mu \mathrm{g} / \mathrm{m}^{3}\right)$

$$
C_{M o d}\left(\mu \mathrm{g} / \mathrm{m}^{3}\right)
$$

$$
\begin{aligned}
= & \text { actual indoor concentration of black carbon } \\
& \text { determined by the aethalometer }, \\
= & \text { concentration of black carbon determined from } \\
& \text { indoor infiltration model }
\end{aligned}
$$

For the second minimization term, we first have to examine the equation used to model indoor concentrations (Eq. 7), which can be integrated over time, $t_{s}$ to calculate indoor/outdoor ratios.

$$
\frac{\overline{C_{i}}}{\overline{C_{O}}}=\frac{\hat{P} \lambda}{\lambda+\hat{k}_{\text {dep }}}-\frac{\Delta C_{i}}{\overline{C_{O}}\left(\lambda+\hat{k}_{\text {dep }}\right) t_{s}}
$$

In Eq. 9 above, the first term represents the average behavior while the second term represents the dynamic behavior when responding to increases or decreases in concentration over time $t_{s}$. When the averaged time $>3-6 \mathrm{~h}$, the second term can be 
dropped resulting in a constant indoor/outdoor ratio (Lunden et al., 2003). The resulting equation after the simplification is shown below in Eq. 10.

$$
\left(\frac{\overline{C_{i}}}{\overline{C_{O}}}\right)_{M o d}=\frac{\hat{P} \lambda_{v}}{\lambda_{v}+\hat{k}_{d e p}}
$$

Eq. 10 expresses the indoor/outdoor ratio based on the averaged penetration factor, deposition rate, and air exchange rate. Using Eq. 10 and the actual indoor/outdoor ratio, another minimization term can be created shown below in Equation 11. This minimization term looks at the performance of the model over the whole burning event while the first minimization term focuses on semi-instantaneous changes. A method using Solver to minimize the sum of the two minimization terms was used determine the infiltration parameters.

$$
S D=\left[\left(\frac{C_{i}}{C_{O}}\right)_{A c t}-\left(\frac{\overline{C_{i}}}{\overline{C_{O}}}\right)_{M o d}\right]^{2}
$$

One problem that arises from this method is that the equation is over parameterized, that is, there can be more than one value for each parameter that minimizes the sum of squared differences. Depending on the starting values for each parameter, Solver may find different solutions for minimization. This problem can be solved by simultaneously measuring one of the parameters, usually the infiltration rate, $\lambda$, either with a tracer gas study or calculating it using a blower door method. In this study, however, only the actual indoor and outdoor concentrations were measured, so finding optimal values for the parameters proved more difficult. Because of the uncertainty, four 
different solution techniques were investigated to determine which, if any, provided the most likely values for the three parameters.

The first solution technique assumed that the deposition rate and the penetration factor were constant throughout the burning event. This assumption has been made in a previous indoor study (Hering et al., 2007). The infiltration rate, however, is unlikely to remain constant throughout the burning event, since it is dependent on meteorological conditions and indoor/outdoor temperature difference. Consequently, the value for infiltration rate could be adjusted every 2 hours. Burning events were characterized by sharp increases in outdoor BC concentration followed by a return to original levels. In contrast, indoor concentrations experienced steadier increases and long decays, which lagged behind outdoor concentrations.

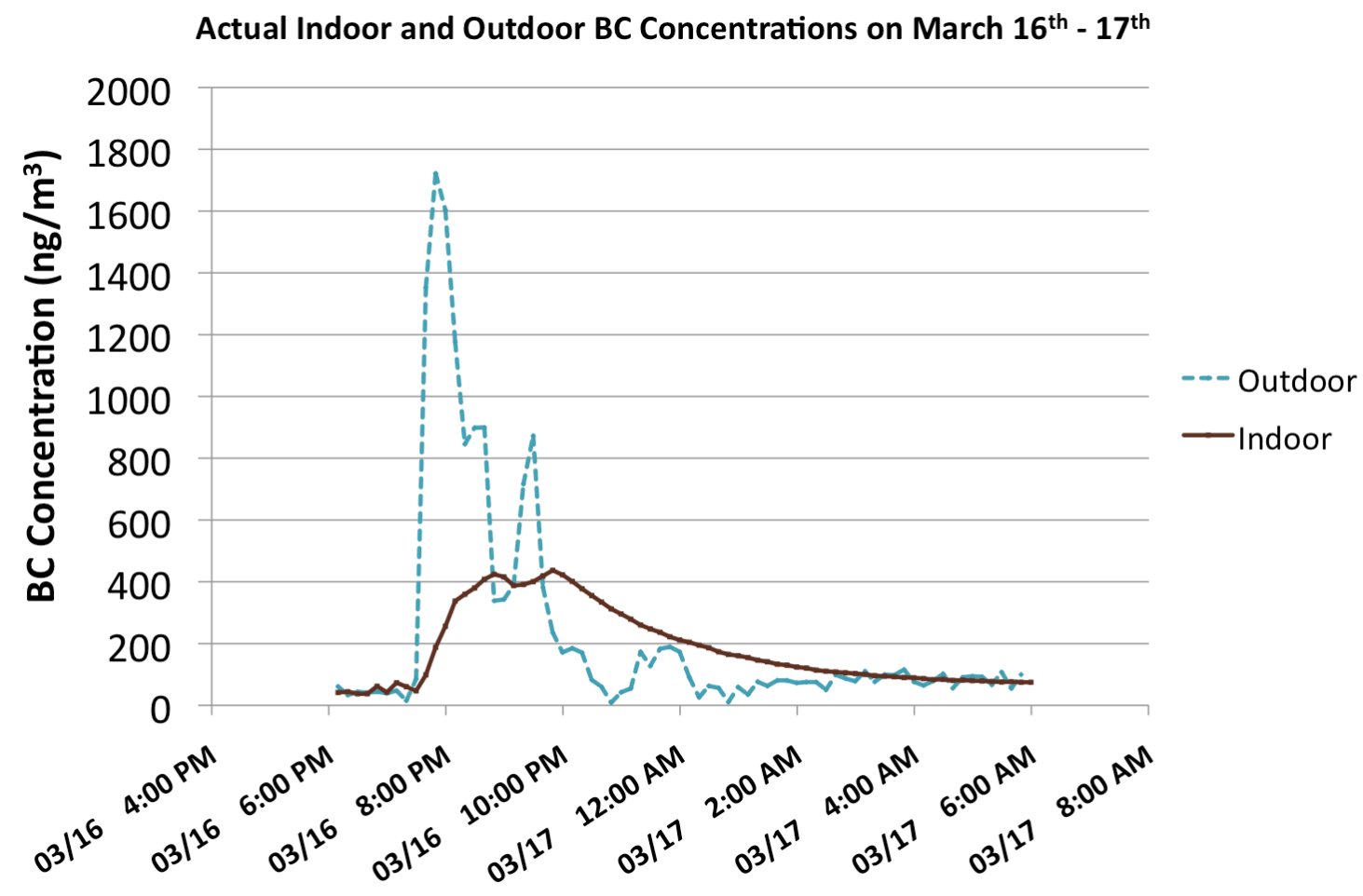

Figure 8: Outdoor Concentration of Black Carbon in one location in Cambria, CA 
A total of 16 burning events occurred during the course of the indoor study.

Figure 8 shows one such event. These events usually began around 7 to $8 \mathrm{PM}$ and ranged from a few hours to less than an hour. Detailed graphs of wind speed, temperature, and air exchange rate of each burning event can be found in Appendix E. The second solution technique assumed a constant deposition rate and penetration factor throughout the burning event, but used the LBNL air exchange rate model shown in Eq. 4 of Section 2.2 to determine the most appropriate infiltration rate. In this solution technique, the infiltration rate varied over time with the changes in temperature and wind speed.

The third and fourth solution techniques differed from the first and second by calculating deposition rates and penetration factors based on the relative dominance of each term for the indoor concentration. The deposition rate has a greater influence on the concentration of indoor $\mathrm{BC}$ when concentrations are decreasing while the penetration factor influences increasing indoor concentrations more heavily. In the third and fourth methods, the penetration factor was calculated only when indoor concentrations were increasing and the deposition rate was calculated only when indoor concentrations were decreasing. This analytical method was developed by Thatcher et al., (2003). The air exchange rate calculations mimicked the first and second solution technique, respectively. The following four sections outline the results from the different solution techniques. Table 1 on the next page is a summary of how each parameter was determined for the different solution techniques. 
Table 2: Summary table of the approach to determine each infiltration parameter for solution techniques 1-4.

\begin{tabular}{|c|c|c|c|}
\hline & $\begin{array}{c}\text { Deposition Rate, } \\
\mathrm{k}_{\mathrm{dep}}\left(\mathrm{hr}^{-1}\right)\end{array}$ & $\begin{array}{c}\text { Penetration Factor, } \\
\text { P }\end{array}$ & $\begin{array}{c}\text { Air exchange rate, } \lambda_{\mathrm{v}} \\
\left(\mathrm{hr}^{-1}\right)\end{array}$ \\
\hline ST1 & Constant & Constant & Varied \\
\hline ST2 & Constant & Constant & LBNL AER \\
\hline ST3 & $\begin{array}{c}\text { Increasing } \\
\text { Concentration }\end{array}$ & $\begin{array}{c}\text { Decreasing } \\
\text { Concentration }\end{array}$ & Varied \\
\hline ST4 & $\begin{array}{c}\text { Increasing } \\
\text { Concentration } \\
\end{array}$ & $\begin{array}{c}\text { Decreasing } \\
\text { Concentration }\end{array}$ & LBNL AER \\
\hline
\end{tabular}

\subsubsection{Solution technique 1 and 2}

For the first solution technique, the average deposition rate and penetration factor were calculated to be $0.10 \pm 0.02 \mathrm{hr}^{-1}$ and $0.94 \pm 0.03$ respectively. The average deposition rate and penetration factor for the second solution technique was measured at $0.07 \pm 0.05 \mathrm{hr}^{-1}$ and $0.85 \pm .09$ respectively. All margins of error were constructed using a $95 \%$ confidence interval. A table of deposition rates and penetration factors for techniques 1 and 2 can be seen in Table 2. The lower deposition rates and penetration factors are directly related to the higher air exchange rates calculated in solution technique 2. A detailed table of all deposition rates, penetration factors and air exchange rates for each solution technique can be found in Appendix C.

Table 2: Deposition rates and penetration factors for solution techniques 1 and 2

\begin{tabular}{|c|c|c|c|}
\hline & $\begin{array}{c}\text { Deposition } \\
\text { Rate }\left(\mathrm{hr}^{-1}\right)\end{array}$ & $\begin{array}{c}\text { Penetration } \\
\text { Factor }\end{array}$ & $\begin{array}{c}\text { Air Exchange } \\
\text { Rate }\left(\mathrm{hr}^{-1}\right)\end{array}$ \\
\hline 1 & $0.10 \pm 0.02$ & $0.94 \pm 0.03$ & $0.35 \pm 0.07$ \\
\hline 2 & $0.07 \pm 0.05$ & $0.85 \pm 0.09$ & $0.43 \pm 0.02$ \\
\hline
\end{tabular}


On average, the air exchange rate for solution technique 1 was $0.35 \pm 0.07 \mathrm{hr}^{-1}$, whereas the average air exchange rate for solution technique 2 was $0.43 \pm 0.02$. In solution technique 1, the air exchange rate was calculated from the minimization of the sum of differences, whereas in solution technique 2, the air exchange rate was calculated from the AER model, detailed in Appendix D. Regional temperature and wind speed was gathered at a weather station located 1.7 miles southwest from our site using wunderground.com. Indoor temperature was recorded using a $\mathrm{HOBO}$ environmental data logger. The house was assumed to have equal distribution of air infiltration giving a value of $\mathrm{X}=0$ and $\mathrm{R}=0.67$. Because the home was one story, the height was assumed to be $2.5 \mathrm{~m}$ giving a value of $f_{s}=0.13 \mathrm{~m} \cdot \mathrm{s}^{-1} \cdot \mathrm{K}^{-1 / 2}$. Cambria is located in a heavily forested area and thus was classified as terrain class 4 . The shielding factor was classified as a class 4 because of the heavy shielding provided by the trees. The resultant wind factor, $f_{w}$, was calculated at 0.062 . The leakage area was calculated using an average normalized leakage area for California determined by Sherman \& Dickerhoff, (1998). Using a building height of $2.5 \mathrm{~m}, A_{\text {Leak }} / A_{\text {Floor }}=0.00073$. Figs. 9 and 10 are graphs of the modeled concentrations for solution techniques one and two for the burning event shown in Figure 8. 
Solution Technique 1 for Modeled Indoor BC Concentration on

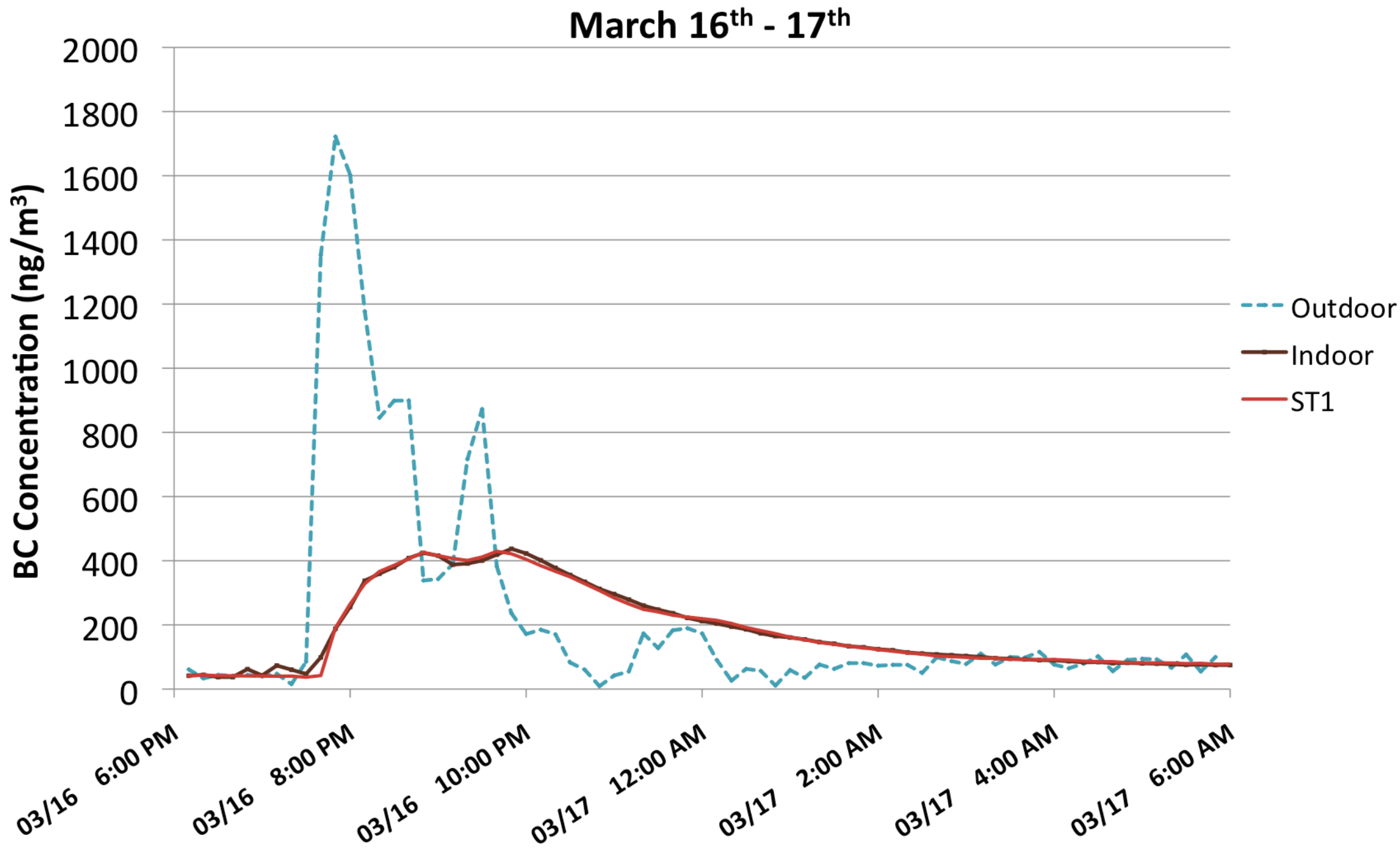

Figure 9: Modeled Indoor concentrations for Solution technique 1 during the burning event of March $16-17^{\text {th }}$ in Cambria, CA 
Solution Technique 2 for Modeled Indoor BC Concentration on

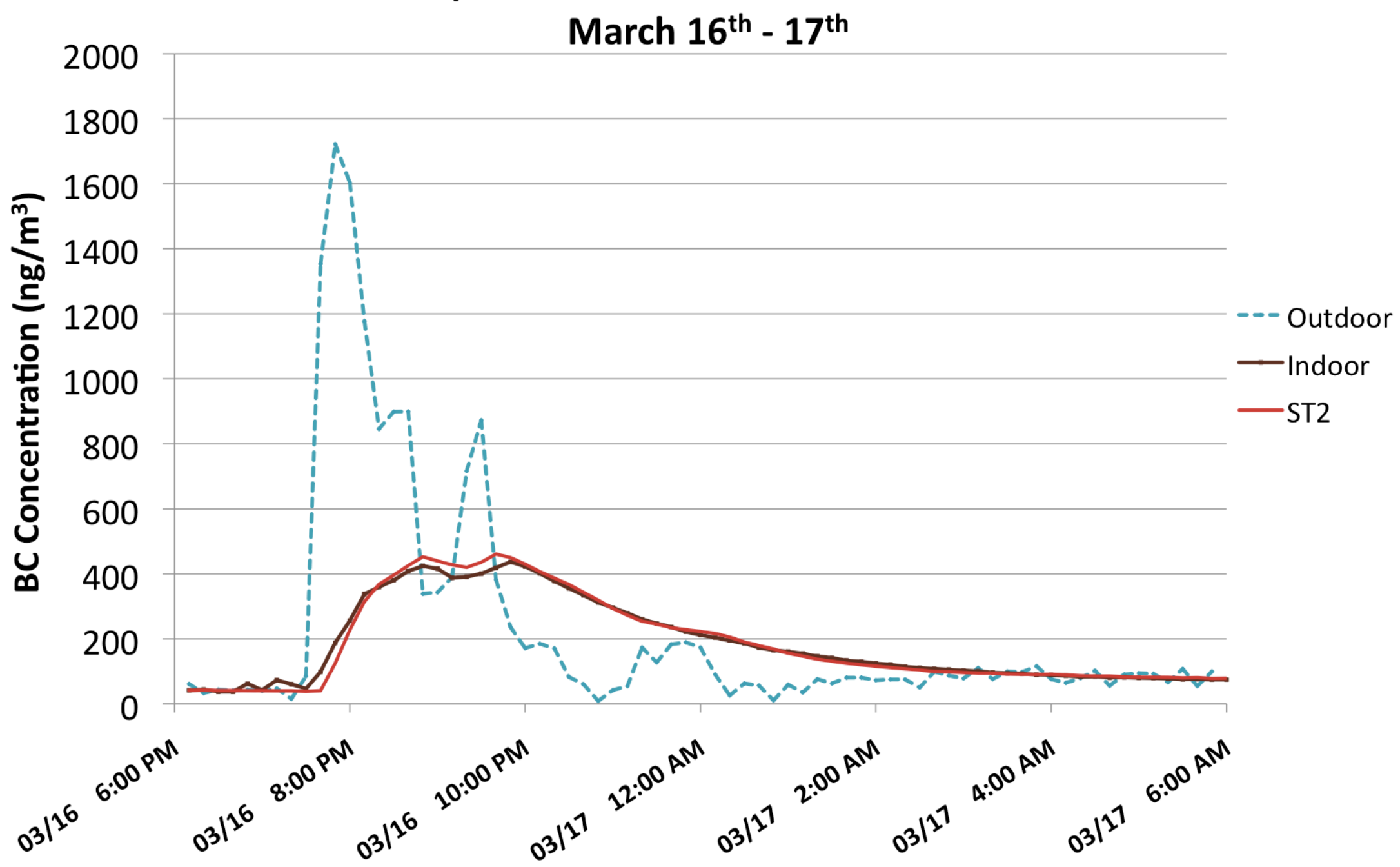

Figure 10: Modeled Indoor concentrations for Solution technique 2 during the burning event of March $16-17^{\text {th }}$ in Cambria, CA 
One method to assess the accuracy of the model is to look at the coefficient of determination. For the parameters above, only those burning periods that produced a coefficient of determination above 0.95 were included. The most common reason for exclusion was detection limit problems in the Aethalometers causing highly variable fluctuations in concentrations. Figure 11 shows the relationship between actual and calculated indoor concentrations for solution techniques 1 and 2 and the corresponding coefficients of determinations, 0.993 and 0.984 respectively.

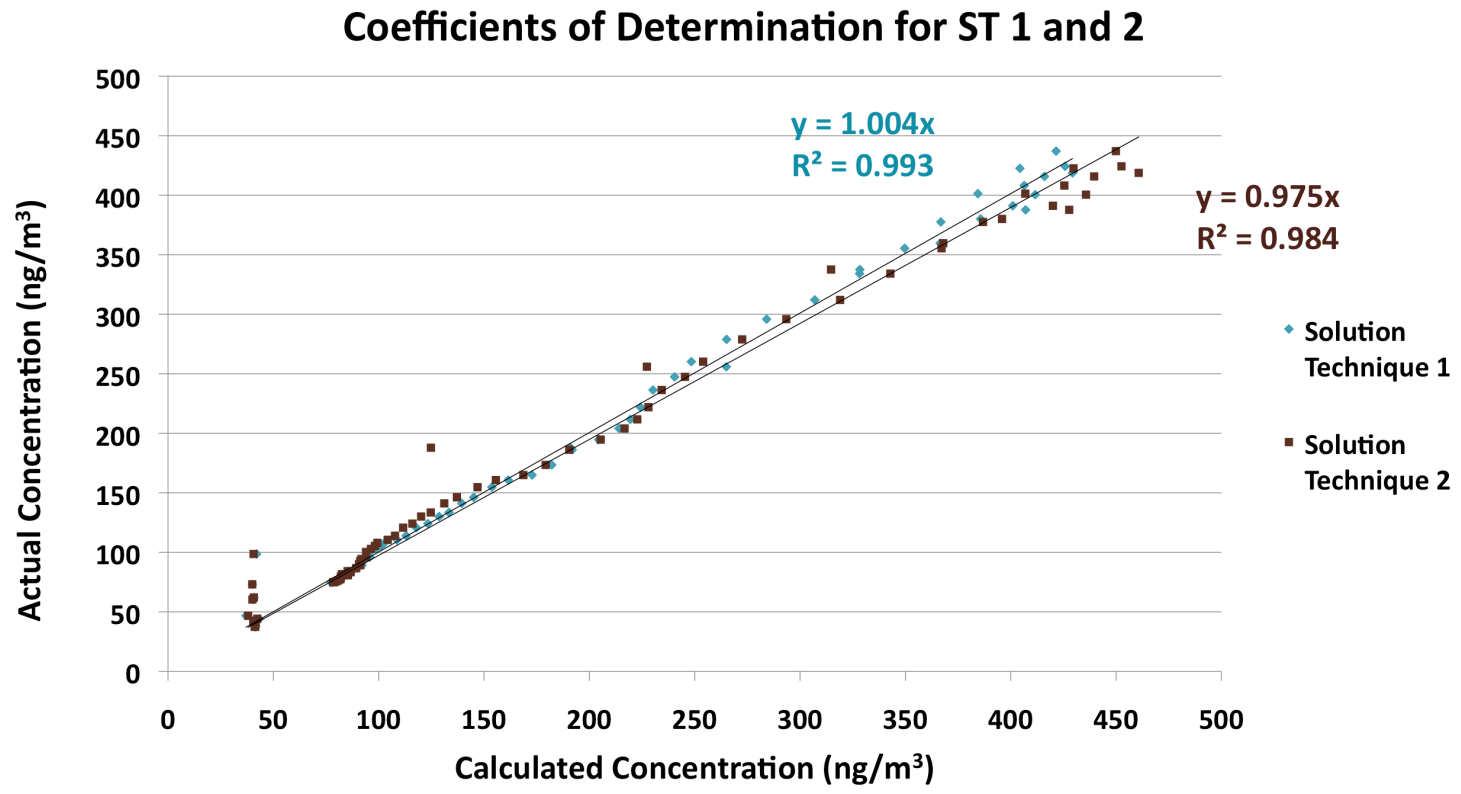

Figure 11: Coefficient of determinations of solution technique 1 (top) and solution technique 2 (bottom) for the burning event on March 16-17 .

\subsubsection{Solution technique 3 and 4}

The third and fourth solution technique differed from the first two by calculating deposition rate and penetration factor by their relative dominance in determining indoor concentrations. While concentrations indoors are increasing, penetration factor influences the indoor concentration more heavily than deposition rate. Conversely, during times of decreasing concentration, deposition rate is the dominant term. As a result, the determination of the two terms occurred during their relative dominance over 
the indoor concentration. As with solution techniques 1 and 2, the third solution technique's air exchange rate was allowed to vary over the burning event while the fourth solution technique used LBNL AER model to calculate the air exchange rate. For the third solution technique, the average deposition rate and penetration factor were $0.08 \pm$ $0.03 \mathrm{hr}^{-1}$ and $0.97 \pm 0.02$ respectively. For the fourth solution technique, the average deposition rate and penetration factor were $0.04 \pm 0.03 \mathrm{hr}^{-1}$ and $0.78 \pm 0.08$ respectively. A table of the infiltration parameters can be seen in Table 3 below.

Table 3: Deposition rates and penetration factors for solution techniques 3 and 4

\begin{tabular}{|c|c|c|c|}
\hline & $\begin{array}{c}\text { Deposition Rate } \\
\left(\mathrm{hr}^{-1}\right)\end{array}$ & $\begin{array}{c}\text { Penetration } \\
\text { Factor }\end{array}$ & $\begin{array}{c}\text { Air Exchange } \\
\text { Rate }\left(\mathrm{hr}^{-1}\right)\end{array}$ \\
\hline 3 & $0.08 \pm 0.03$ & $0.97 \pm 0.02$ & $0.26 \pm 0.08$ \\
\hline 4 & $0.04 \pm 0.03$ & $0.78 \pm 0.08$ & $0.44 \pm 0.02$ \\
\hline
\end{tabular}

The lower deposition rate and penetration factor for solution technique 4 over 3 follows the same logic as before in solution techniques 1 and 2 . The average air exchange rate for solution technique 3 was $0.26 \pm 0.08 \mathrm{hr}^{-1}$ while the average air exchange rate for solution technique 4 was $0.44 \pm 0.02 \mathrm{hr}^{-1}$, thus lowering the deposition rate and penetration factor. The higher air exchange rate in solution techniques 2 and 4 also often resulted in having to constrain the deposition rate by zero; otherwise SOLVER could not find optimal solutions and adjusted values, sometimes with deposition rates highly negative, until the number of iterations reached the programmed limit.

The variability in the each solution technique appears high, especially for the deposition rates. It is difficult to say if this is true variability inherent to the parameters or if this is variability in the solution technique used because there is no direct 
comparison. However, because the equation used is over parameterized and the solution technique uses a simple minimization, the high variability is probably not real and part of the solution technique. The graphs for solution techniques 3 and 4 can be seen in Figures 13 and 14 . Similarly to solution techniques 1 and 2 , the coefficients of determination for solution techniques 3 and 4 were very high at 0.992 and 0.989 respectively (Figure 12). This high level of correlation between calculated concentrations and actual concentrations could be seen in all burning events for every solution technique.

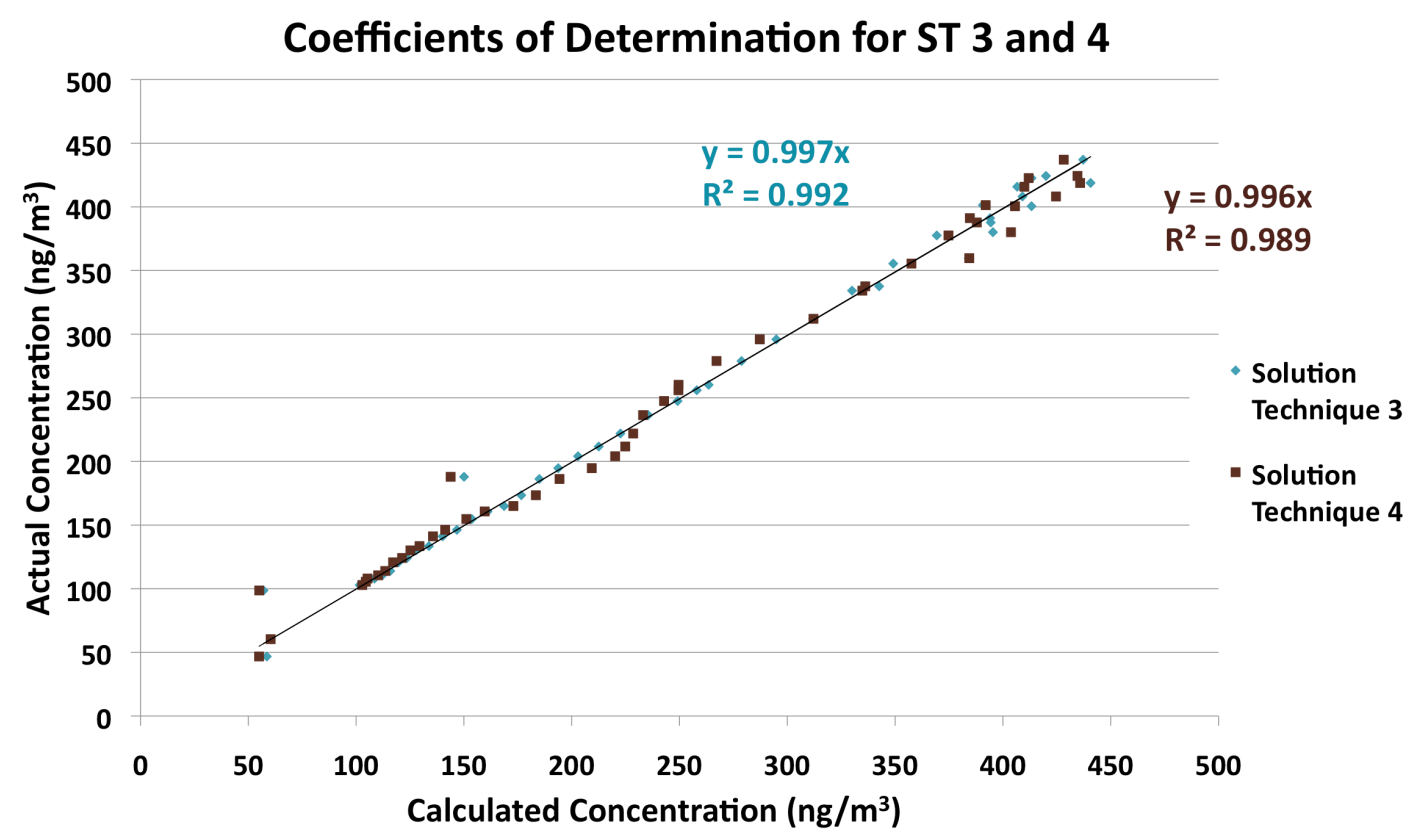

Figure 12: Coefficient of determinations of solution technique 3 (top) and solution technique 4 (bottom) for the burning event on March 16-17 .

It is difficult then to assess which method provides results more closely matching the actual values. No one solution technique imparted better "accuracy" than the others, however, higher fixed air exchange rates exhibited between solution techniques 2 and 4 often resulted in deposition rates and penetration factors lower than solution techniques 1 and 3 . 
Solution Technique 3 for Modeled Indoor BC Concentration on

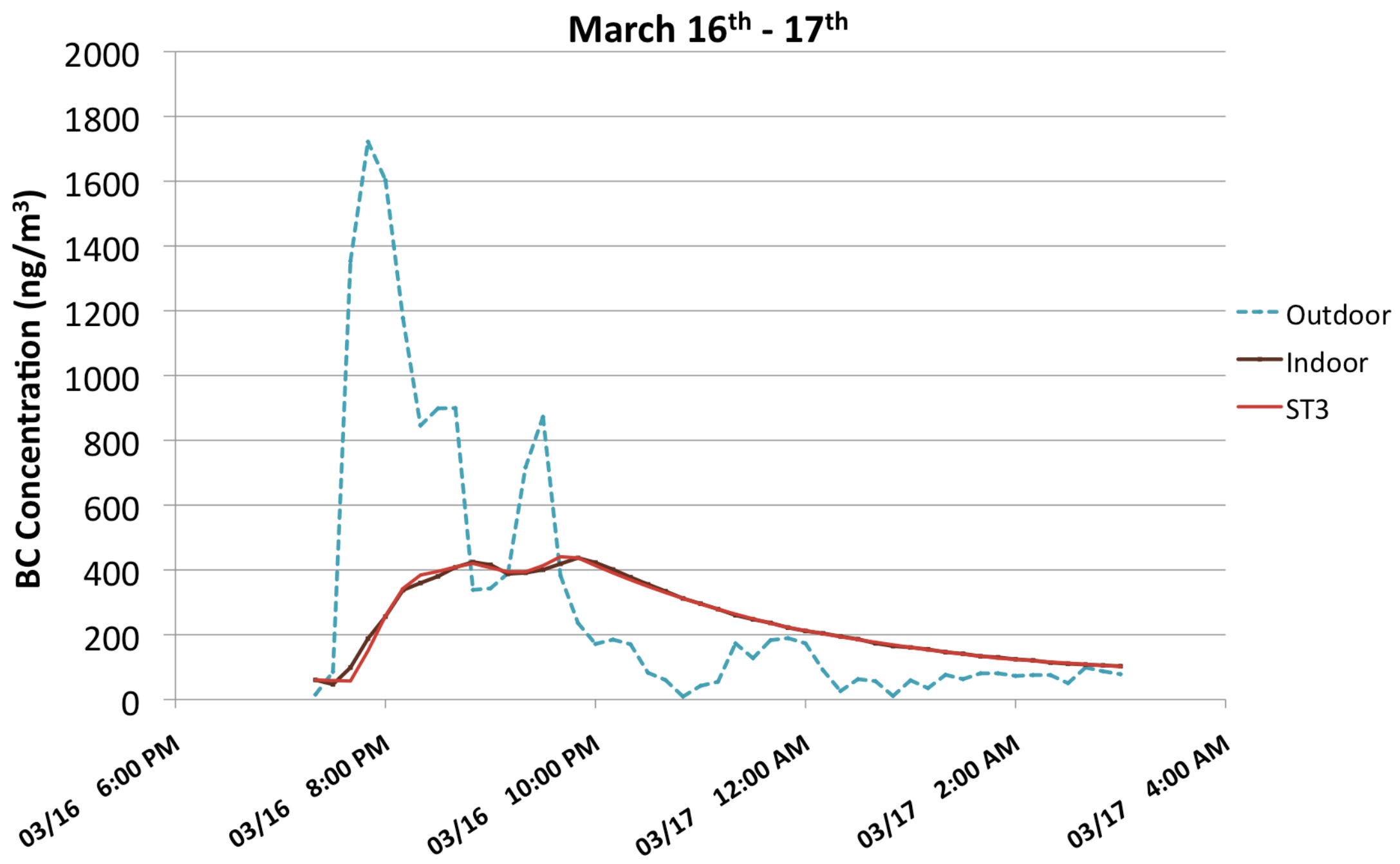

Figure 13: Modeled Indoor concentrations for Solution technique 3 during the burning event of March 16-17 ${ }^{\text {th }}$ in Cambria, CA 
Solution Technique 4 for Modeled Indoor BC Concentration on

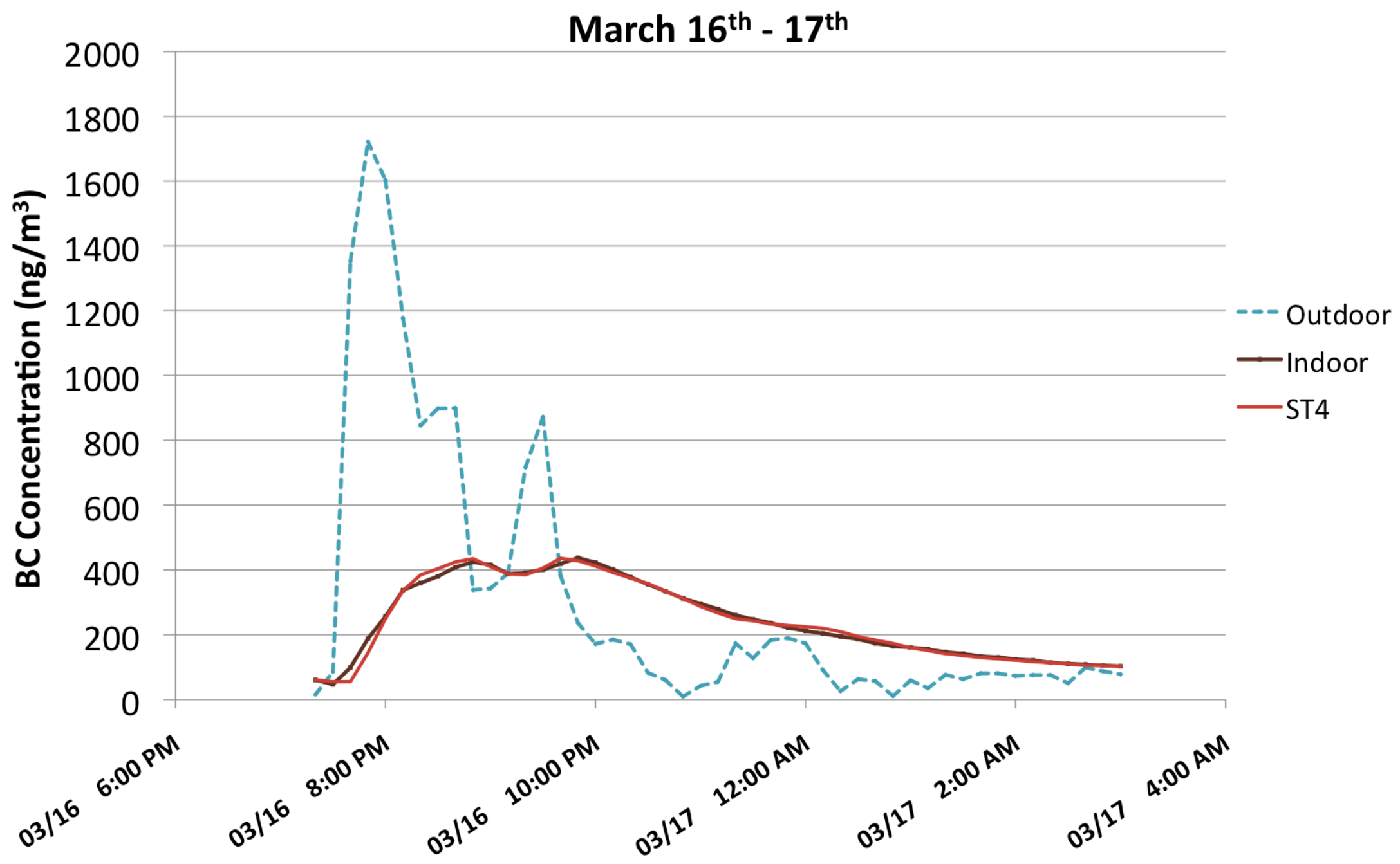

Figure 14: Modeled indoor concentrations for Solution technique 4 during the burning event of March 16-17 ${ }^{\text {th }}$ in Cambria, CA 
The data from the four solution techniques suggest that black carbon from recently combusted woodsmoke exhibits low deposition rates and high penetration factors. Similar findings have been suggested by various authors, however most studies investigate penetration factors and deposition rates based on particle size and not aerosol source. For woodsmoke, particle size distributions have been reported between 30-100 $\mathrm{nm}$ in diameter (Davy et al., 2007), $38 \pm 11 \mathrm{~nm}$ in diameter (Kocbach et al., 2005) and 100-200 $\mathrm{nm}$ in diameter (Kleeman et al., 1999). Some coagulation could be expected as these studies examined particles from freshly burned sources. Differences in burning conditions, type of wood, and time since combustion have the most predominate effects on the size distribution, however, an average particle size range $<200 \mathrm{~nm}$ should be a reasonable assumption when comparing penetration factors and deposition rates.

In the concentration rebound method described earlier by Thatcher et al., (2003) for median optical diameter particles less $0.225 \mu \mathrm{m}$, average deposition rates ranged from $0.12-0.3 \mathrm{hr}^{-1}$, while penetration factors ranged from $0.8-1$. In another study to determine the effects of room furnishings on deposition rates, values between 0.1 to 0.23 $\mathrm{hr}^{-1}$ were found for particle sizes less than $0.55 \mu \mathrm{m}$ (Thatcher et al., 2002). Finally, Thatcher \& Layton, (1995) found deposition rates for particle sizes between 1.0-2.0 $\mu \mathrm{m}$ to be around $0.25 \mathrm{hr}^{-1}$, while penetration factors neared unity. Table 4 is a summary of the findings from the four solution techniques. Based on the deposition rates and penetration factors determined from this study, for recently combusted woodsmoke, deposition rates approach zero while penetration factors approach unity. 
Table 4: Summary of penetration factors and deposition rates for solution techniques 1 through 4

\begin{tabular}{|l|c|c|c|}
\hline & $\begin{array}{c}\text { Deposition } \\
\text { Rate }\left(\mathrm{hr}^{-1}\right)\end{array}$ & $\begin{array}{c}\text { Penetration } \\
\text { Factor }\end{array}$ & $\begin{array}{c}\text { Air Exchange } \\
\text { Rate }\left(\mathrm{hr}^{-1}\right)\end{array}$ \\
\hline \hline & $0.10 \pm 0.02$ & $0.94 \pm 0.03$ & $0.35 \pm 0.07$ \\
2 & $0.07 \pm 0.05$ & $0.85 \pm 0.09$ & $0.43 \pm 0.02$ \\
3 & $0.08 \pm 0.03$ & $0.97 \pm 0.02$ & $0.26 \pm 0.08$ \\
4 & $0.04 \pm 0.03$ & $0.78 \pm 0.08$ & $0.44 \pm 0.02$ \\
\hline
\end{tabular}

This is important because these parameters greatly affect indoor exposures. The lower the deposition rate and the higher the penetration factor, the closer the indoor exposures approach outdoor exposures.

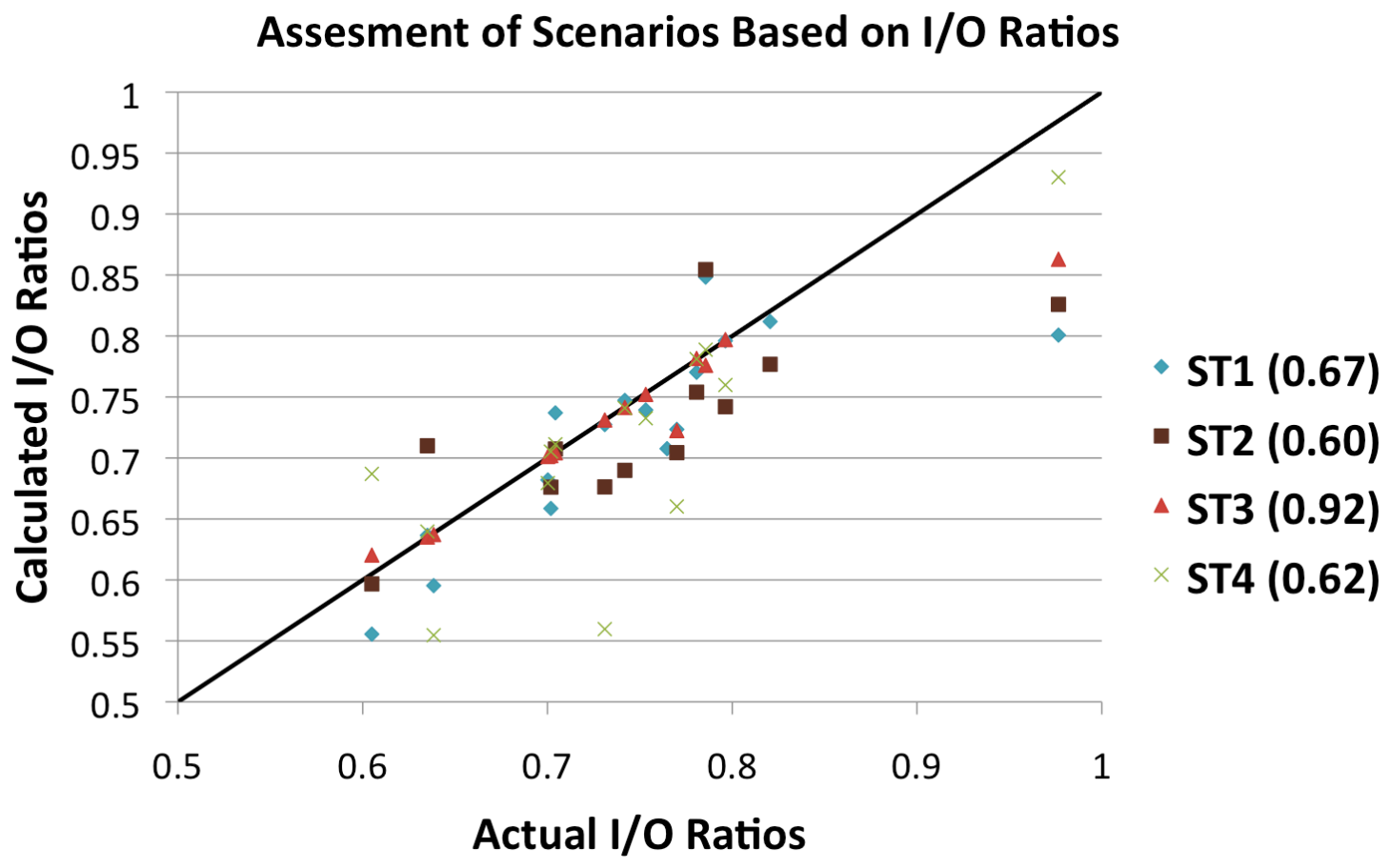

Figure 15: Coefficients of determination for each solution technique starting at 1 (top) down to 4 (bottom) in order solution technique. The black line represents a perfect correlation between actual $\mathrm{I} / \mathrm{O}$ ratios and calculated $\mathrm{I} / \mathrm{O}$ ratios

Figure 15 graphs the I/O ratio determined from Eq. 10 and the actual I/O ratio. Part of the minimization scheme is directed to the equalization of the predicted I/O ratio 
to the actual I/O ratio. The graph shows a visual representation of the performance of each solution technique. The coefficients of determination for each solution technique (ST) are in the parentheses next to each number in the legend. Figure 15 shows that solution technique 3 provides the best fit for modeled indoor concentrations with solution technique 1, 4, and 2 following in order. Looking at how each solution technique would behave under different air exchange rates is another method to test their validity, assuming that the deposition rate and penetration factor are constants and a property of woodsmoke. The solid line in Figure 16 represents the indoor/outdoor ratio under different air exchange rates for solution technique 1 .

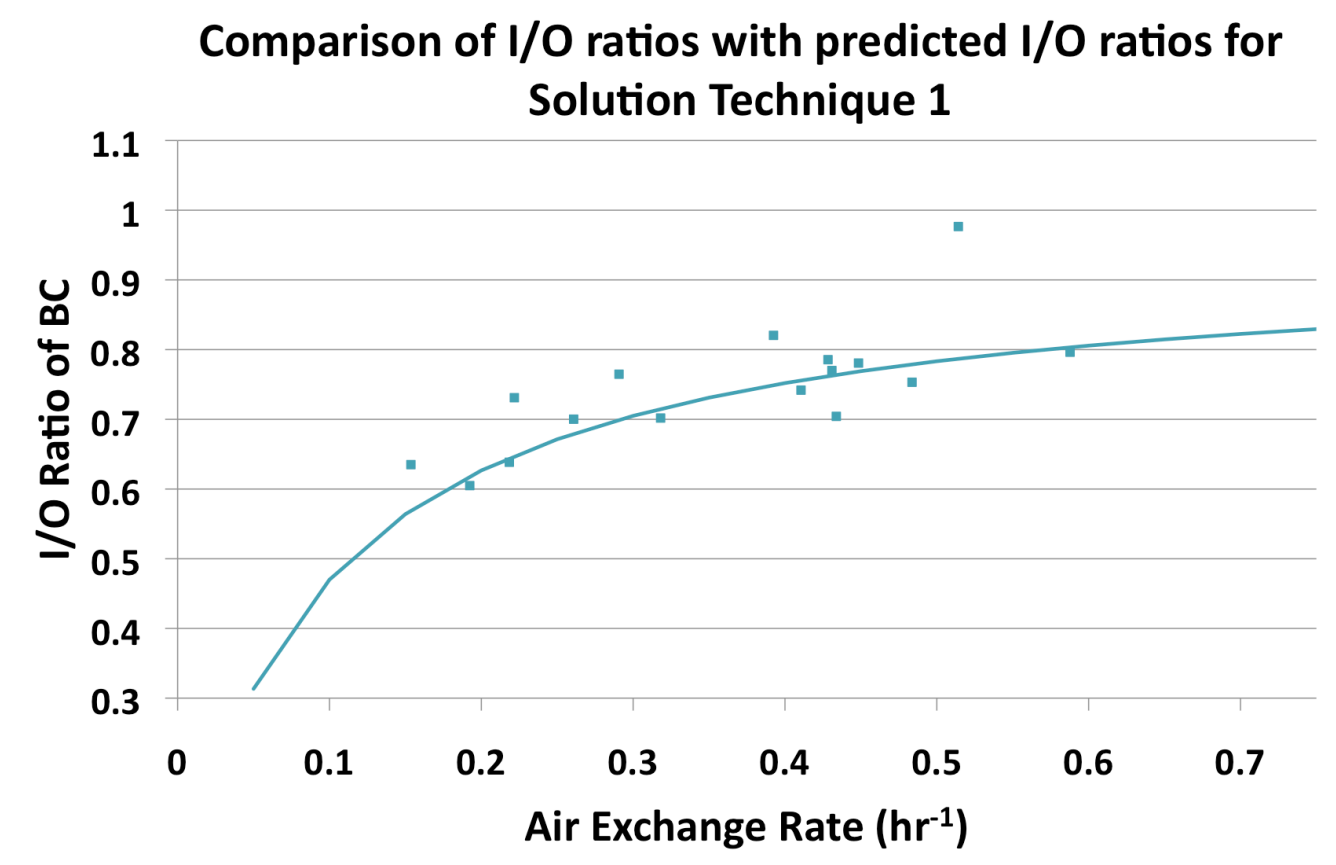

Figure 16: Performance analysis of solution technique 1 for the average penetration factor and depositon rate.

The solid line makes use of Eq. 10, using the average penetration factor and deposition rate determined through minimization with the air exchange rate as an independent variable to calculate $\mathrm{I} / \mathrm{O}$ ratios. The points in Figure 16 represent the actual 
$\mathrm{I} / \mathrm{O}$ ratios determined with the aethalometers with their respective air exchange rates calculated through minimization. The solid line is not a best-fit line. Repeating the same analysis for all solution techniques could give us an idea on their performance. The closer to zero the sum of the squared differences between the line and the points are, the better the performance of the solution technique.

Figure 17 shows the same analysis for each solution technique as Fig. 16. The lines were truncated in Fig. 17 on both ends because the range of air exchange rates is not likely to exceed these bounds. For this analysis, solution technique 1 performed the best followed by 4,2 , and 3 with values $0.004,0.0083,0.0086$ and 0.012 respectively.

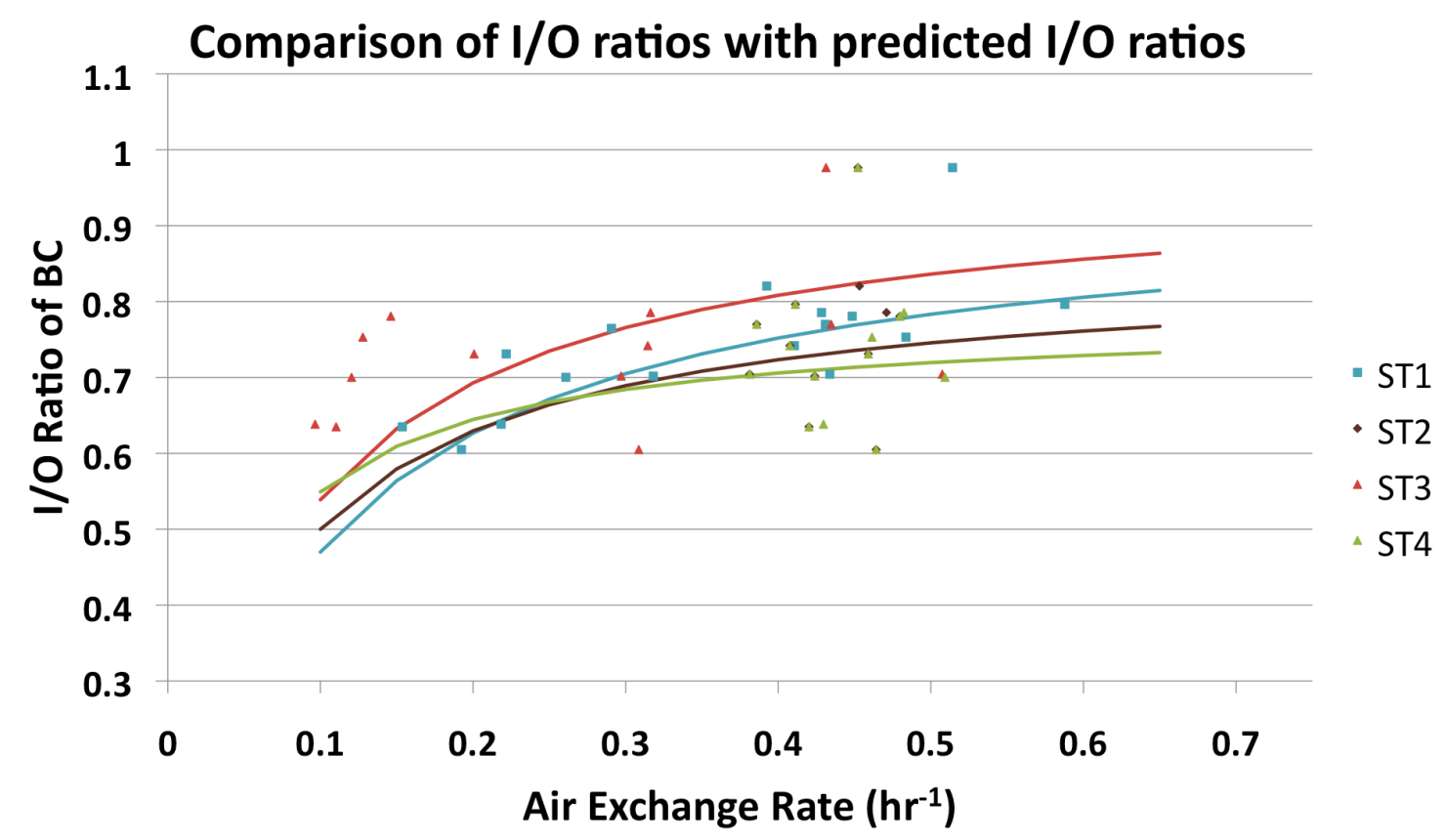

Figure 17: Actual I/O ratios compared with predicted I/O ratios from Eq. 9 with the air exchange rate as the independent variable solution technique

With this approach, solution technique 3 appears to be the worst performer, however the direct comparison of $\mathrm{I} / \mathrm{O}$ ratios in the preceding analysis shows that it is the best. This discrepancy probably arose because of the fluctuations in deposition rate that 
exist in solution technique 3. Individual parameters for each burning event can be found in Appendix C. There appears to be two "camps" of deposition rates in ST 3, one camp with an average $0.046 \mathrm{hr}^{-1}$ and another with an average of $0.12 \mathrm{hr}^{-1}$. Because the second performance analysis uses only the average deposition rate and penetration factor, the calculated I/O ratios can differ significantly from the actual I/O ratios.

The model that solution technique 2 and 4's air exchange rate is based on gives a relatively narrow band of values even because wind speeds and outdoor temperatures varied little from night to night. This is shown by the narrow vertical band that both solution techniques 2 and 4 inhabit, while with solution techniques 1 and 3 , the I/O ratios do follow an increasing trend as the air exchange rate is increased.

\subsection{PEM's Analysis}

This section is split into three main analyses. The first analysis examines the comparison between two methods, NIOSH 5040 and LBNL EGA, to determine woodsmoke's carbon aerosols. The second analysis looks at levoglucosan as a chemical tracer for woodsmoke. Finally, the last section analyzes the organic fraction's optical absorbance properties. All of the following analyses were performed on samples taken during the methods comparison IOPs.

\subsubsection{EC/OC Analysis}

A substantial portion of the particulate matter in the atmosphere is composed of carbon-containing compounds. This carbonaceous material has historically been classified as either elemental carbon (EC) or organic carbon (OC) by the atmospheric science community. Since the 1970's, several analytical methods have been developed to quantify the amount of EC and OC in samples of particulate matter collected on (usually 
quartz) filters. These methods employ one or a combination of thermal, chemical, and optical techniques.

One of the most widely used methods is known as thermal-optical analysis (TOA). In this method, the amount of light transmitted through or reflected from a sample is monitored while the sample is heated to thermally drive off the carbonaceous material. Many variations of the TOA method have been developed, which differ most notably in their heating protocol, the composition of the atmosphere surrounding the sample, and whether or not reflectance or transmittance is measured. Owing partly to the chemical complexity of the carbonaceous material and to variations in the TOA methods, these methods tend to differ in their quantification of the amount of EC and OC present in a given sample of particulate matter (Watson et al., 2001). Thus, estimates of EC and OC are operationally defined by the method of analysis rather than uniquely determined, and it has become common practice to compare the results of different analytical methods.

In this study, samples were analyzed using two TOA methods, the NIOSH method 5040, which measure EC, OC and TC, performed at Sunset Laboratories and the method, historically referred to as evolved gas analysis (EGA), which measures BC and TC, performed at Lawrence Berkeley National Laboratory (LBNL). Both of these methods are described in section 2.3.1.

The samples analyzed by EGA were also analyzed with an optical transmission technique to determine the amount of light attenuated (ATN) by the particles deposited on the quartz filters, from which $\mathrm{BC}$ concentration was estimated. This method of light transmission largely mimics the optical technique employed in the widely used 
aethalometer, the commercially available instrument that measures the concentration of black carbon $(\mathrm{BC})$ in airborne particulate matter.

For each sample number, four PEMs were collocated and operated identically. Each filter was sent to the respective laboratory for analysis of theoretically the same sample of air. The bar chart below (Figure 18) shows the comparison between total carbon (TC) concentrations from the two TOA methods. Here, TC is the sum of the EC and OC (without artifact removal) in each sample. The eight samples were taken over the course of two weekends at 4 different sites; samples 1-4 for one weekend and 5-8 for the following. Each sample required 4 PEM's and 1 Aethalometer to collect the necessary comparison data. Samples 1 and 5 were collected at one site; 2 and 6, 3 and 7, and 4 and 8 were all collected at 3 different sites. All of the samples but 4 and 8 were collected within 1 square mile of each other, while samples 4 and 8 were collected approximately 2 miles to the south.

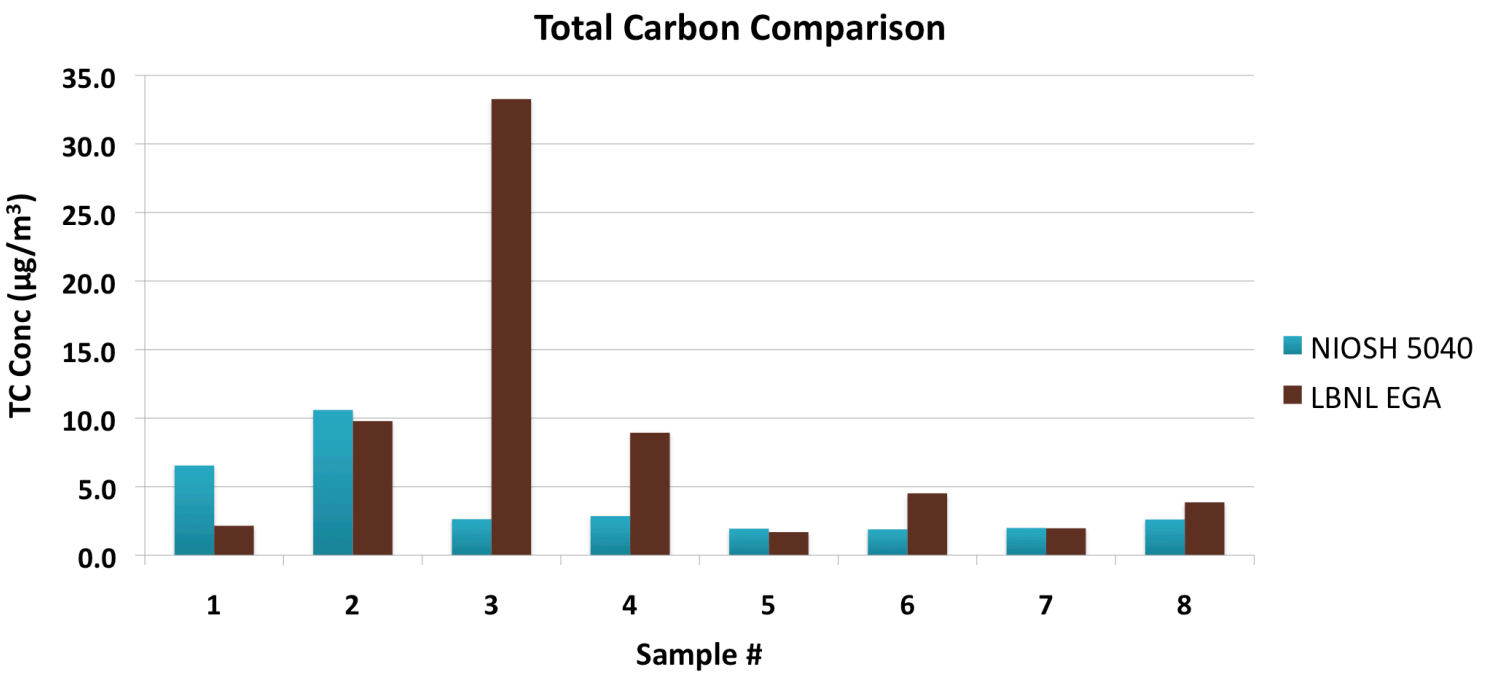

Figure 18: Total Carbon determined from NIOSH 5040 and LBNL TOA method

The two methods produce comparable values in some cases but not in others such as sample 3. It is difficult to assess why these differences exist, however in sample 3 , the 
most likely cause is contamination of the LNBL sample. Discounting sample number 3, the average LBNL TOA/NIOSH 5040 ratio was $1.44 \pm 0.91$ using a $95 \%$ confidence interval.

The elemental (NIOSH 5040) and black carbon (LBNL) concentrations are shown in Figure 19. On average, the LBNL TOA/NIOSH 5040 ratio was $2.11 \pm 0.67$. This discrepancy illustrates the significant uncertainty associated with quantifying particulate carbon concentrations, summarized by Watson et al., (2001). For example, black carbon has been found to be 3.3 times elemental carbon $\left(r^{2}=0.84\right)$ in one location and $2.7\left(r^{2}=\right.$ 0.6) in another (Jeong et al., 2004). During a forest fire event, these relationships dramatically shifted to $\mathrm{BC}$ only being 0.35 and 0.31 times that of $\mathrm{EC}$ for each location. Even when comparing EC determined using two TOA protocols, NIOSH 5040 and IMROVE, the amount of EC detected by each can vary considerably, with the IMRPOVE method typically reporting double the concentration of NIOSH 5040 (Chow et al., 2001).

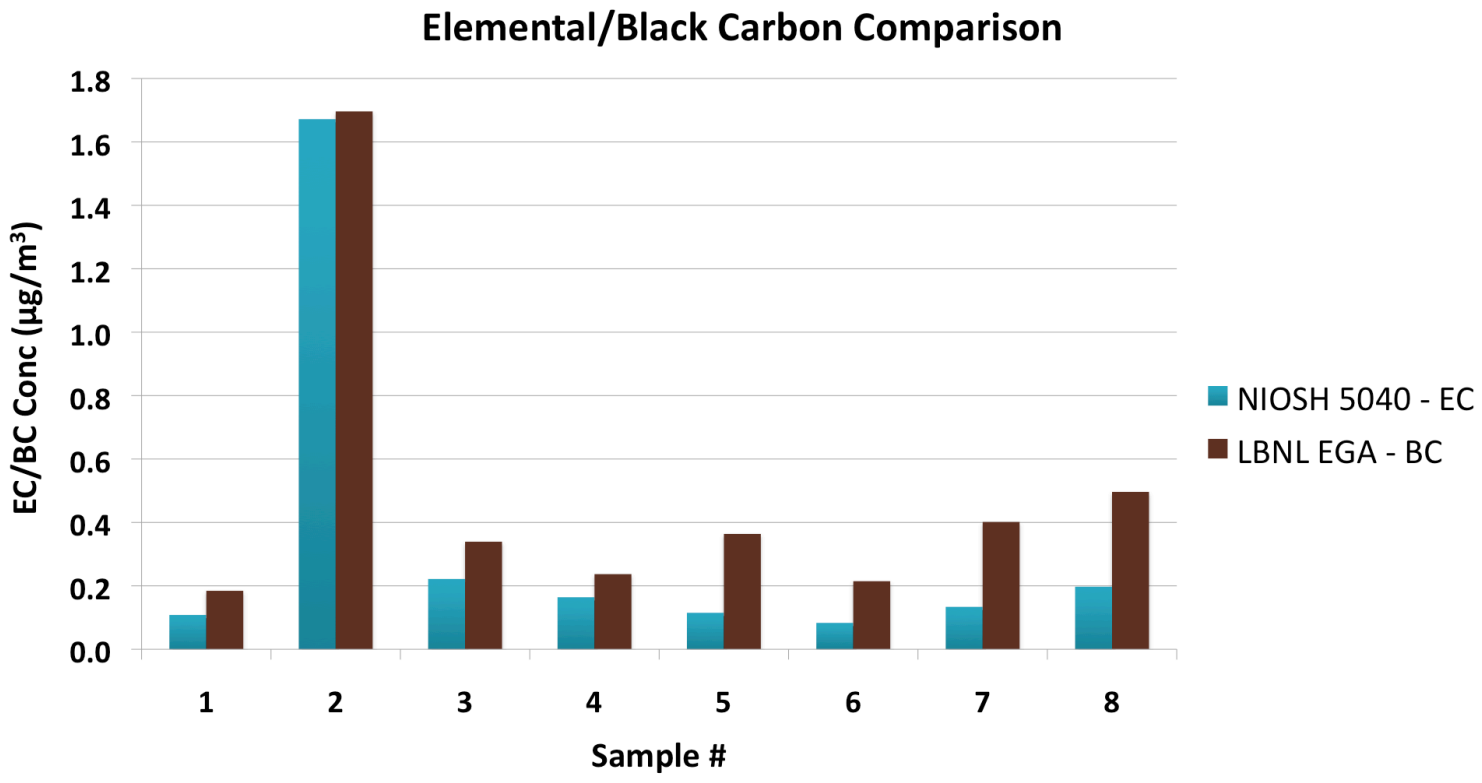

Figure 19: NIOSH 5040 (Elemental Carbon) and LBNL TOA (Black Carbon) comparison 
For samples with a high organic fraction, as in woodsmoke, black carbon concentrations have been reported 50 times greater than actual concentrations due to misidentification of organic carbon as black carbon (Novakov \& Corrigan, 1995). The organic fraction of woodsmoke contains about $6-20 \%$ of refractory organic carbon compounds that have combustion temperatures close to black carbon, which may result in misidentification. Finally, the study found that in the presence of $\mathrm{K}$ and $\mathrm{Na}$, both of which are found in woodsmoke, combustion temperatures of some organics and black carbon are indistinguishable.

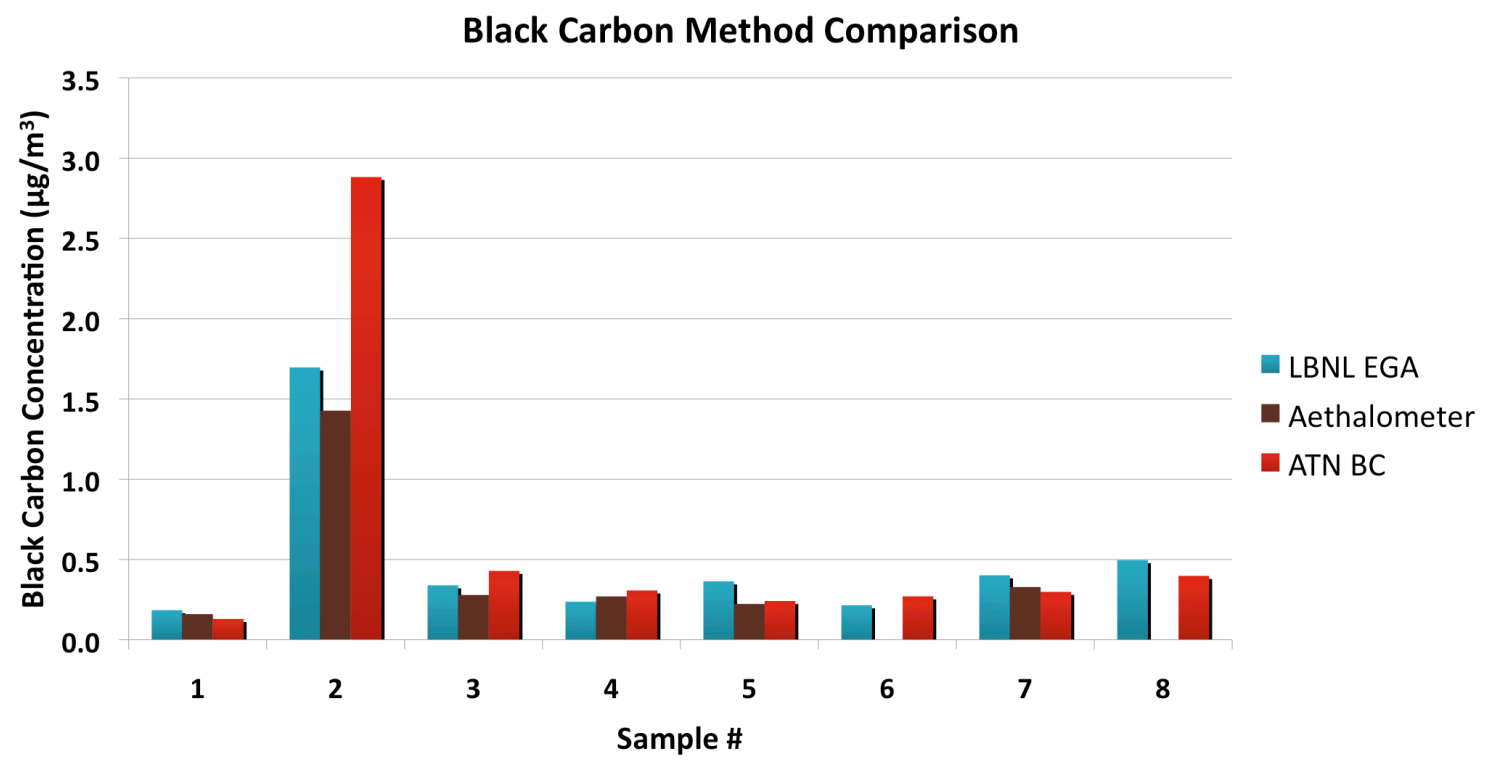

Figure 20: Black carbon comparison with LBNL TOA, the aethalometer and LBNL ATN methods

Figure 20 compares the $\mathrm{BC}$ concentrations we measured using three techniques in this study: the Aethalometer, LNBL light attenuation, and LBNL TOA. The Aethalometer was not present during the comparison of sample 6 and 8 . These three measurements of $\mathrm{BC}$ agreed more closely than did the $\mathrm{BC}$ and $\mathrm{EC}$ measurements discussed above. The LBNL TOA-BC/Aethalometer-BC ratio was $1.21 \pm 0.25$ and the LBNL TOA-BC/LBNL ATN-BC ratio was $1.05 \pm 0.30$. 


\subsubsection{Levoglucosan Analysis}

Levoglucosan has been identified as a tracer for woodsmoke because of its specificity to biomass combustion. Levoglucosan is an abundant compound in the organic carbon fraction of woodsmoke and can be detected even at low OC

concentrations. If levoglucosan emissions were a consistent fraction of total woodsmoke PM or total woodsmoke OC, then its role as a biomass tracer would be validated. Figure 21 compares levoglucosan concentrations to organic carbon from NIOSH 5040 with and without OC artifact removal.

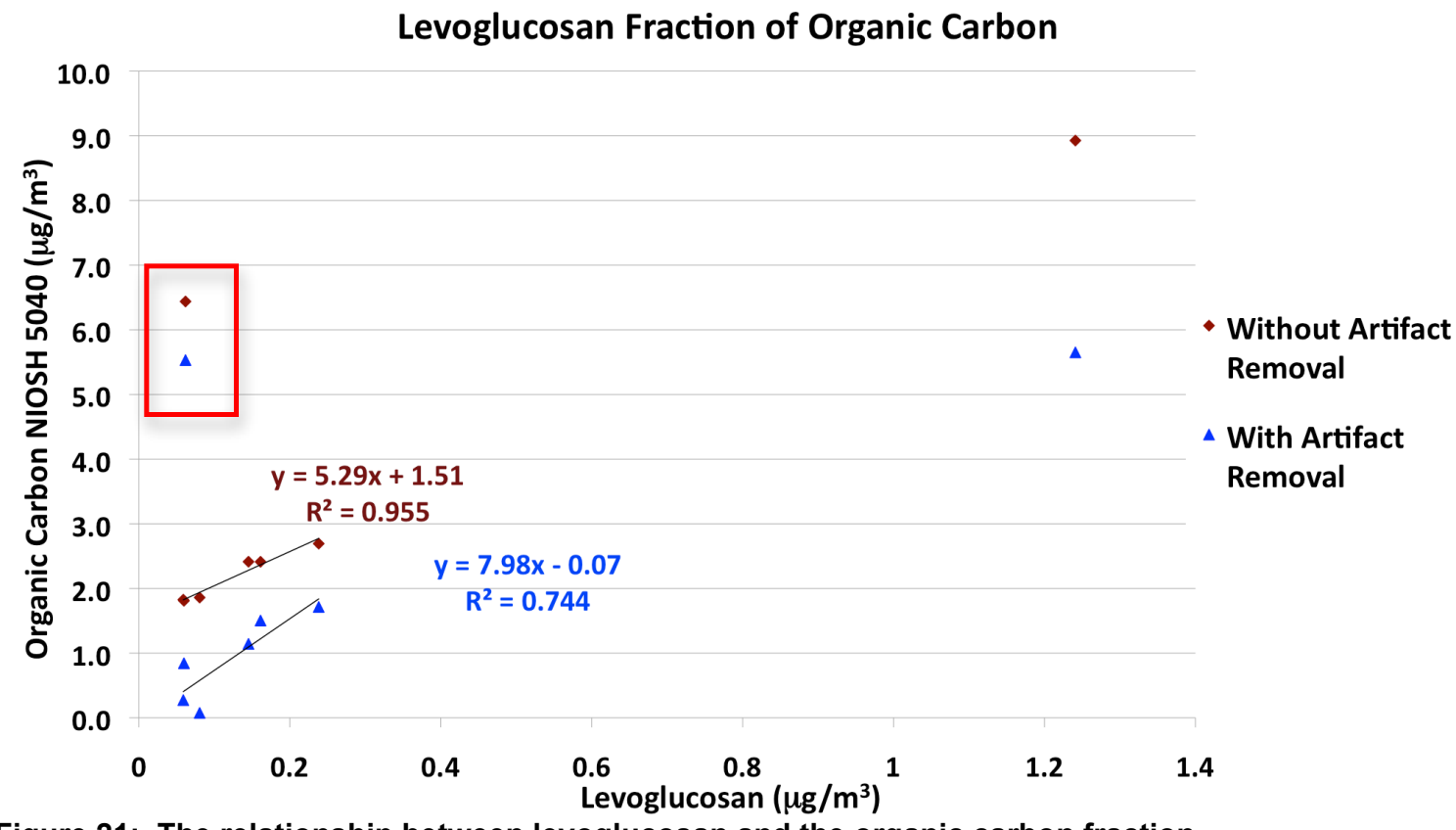

Figure 21: The relationship between levoglucosan and the organic carbon fraction

A fairly linear relationship exists between levoglucosan and organic carbon, regardless of whether the organic artifact was removed or not. The points in the red box were removed from the regression line because of their influence as outliers. The other extreme points to the far right of the graph were also removed because of their heavy leverage on the regression model. Without artifact removal, levoglucosan represents 5.9 
$\pm 3.7 \%$ of the total organic carbon present, while with artifact removal, levoglucosan represents $28 \pm 32 \%$ organic carbon using a 95\% confidence interval. Yan et al., (2007) reported levoglucosan concentrations around $7 \%$ of total organic carbon from a prescribed wildfire episode. The variation was much greater in the artifact removal analysis represented by the much larger confidence interval. From this data, it would appear that levoglucosan was a better predictor of organic carbon without artifact removal. Unfortunately there is a large gap in data between the extreme events and the rest, where the extreme event can heavily influences the slope of the regression. While there is leverage on the regression models from the extreme events, they do not heavily influence the model. This analysis for both organic and total carbon can be seen in appendix B where the extreme points are added. In general, the predictor variable does not change much, indicating that extreme events do not greatly influence the regression models.

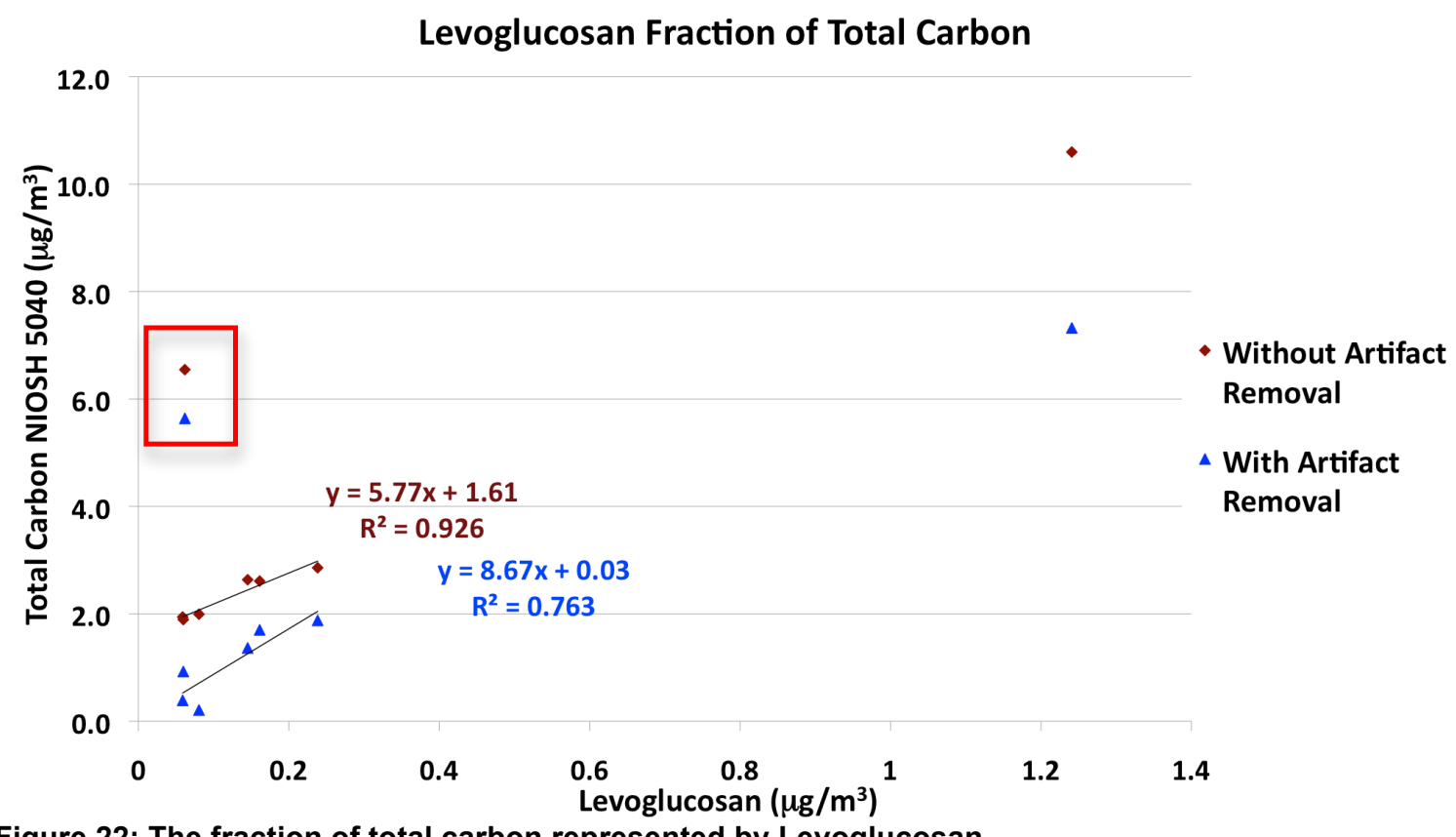

Figure 22: The fraction of total carbon represented by Levoglucosan 
Figure 22 shows the relationship between total carbon and levoglucosan. The graph looks nearly identical to Figure 20 because of the comparatively low elemental to organic carbon ratios and the relatively stable fractions of elemental carbon to total carbon in each sample. This leads to a very similar looking graph, however the slopes are a little bit larger in Figure 21, indicating a smaller overall fraction of levoglucosan to total carbon. Without artifact removal, levoglucosan represents $5.4 \pm 3.1 \%$ of total carbon, while with artifact removal, levoglucosan represents $16 \pm 10 \%$ of total carbon using a $95 \%$ confidence interval. While the percentages in the samples without artifact removal did not significantly change from organic carbon to total carbon, there was a significant reduction from organic carbon to total carbon percentage of levoglucosan with artifact removal. This was due to a few samples with elemental carbon concentrations nearing that of organic carbon after artifact removal.

\subsubsection{Spectral dependence on light absorption}

Biomass smoke contains light-absorbing organic carbon in addition to lightabsorbing black carbon. Unlike black carbon that absorbs light broadly over the solar spectrum, the organic carbon in biomass smoke absorbs light much more strongly in the blue and near ultraviolet spectral region. Consequently the light absorption of biomass smoke exhibits a strong spectral dependence (Kirchstetter et al., 2004).

In our study, an overwhelming majority of our samples displayed this strong spectral dependence on light absorption as shown below in Figure 21. The blue line above is the light attenuation of the third sample over the range of 880 to $350 \mathrm{~nm}$, which dramatically increases with decreasing wavelength, especially for wavelengths less than $600 \mathrm{~nm}$. 
This directly relates to the presence of light absorbing organic carbon that is specific to biomass smoke. In contrast, the light absorption of diesel exhaust particulate exhibits a weak spectral selectivity, as illustrated by the brown line in Figure 21, because the organic carbon in diesel particles does not appreciably absorb light (Kirchstetter et al, 2004).

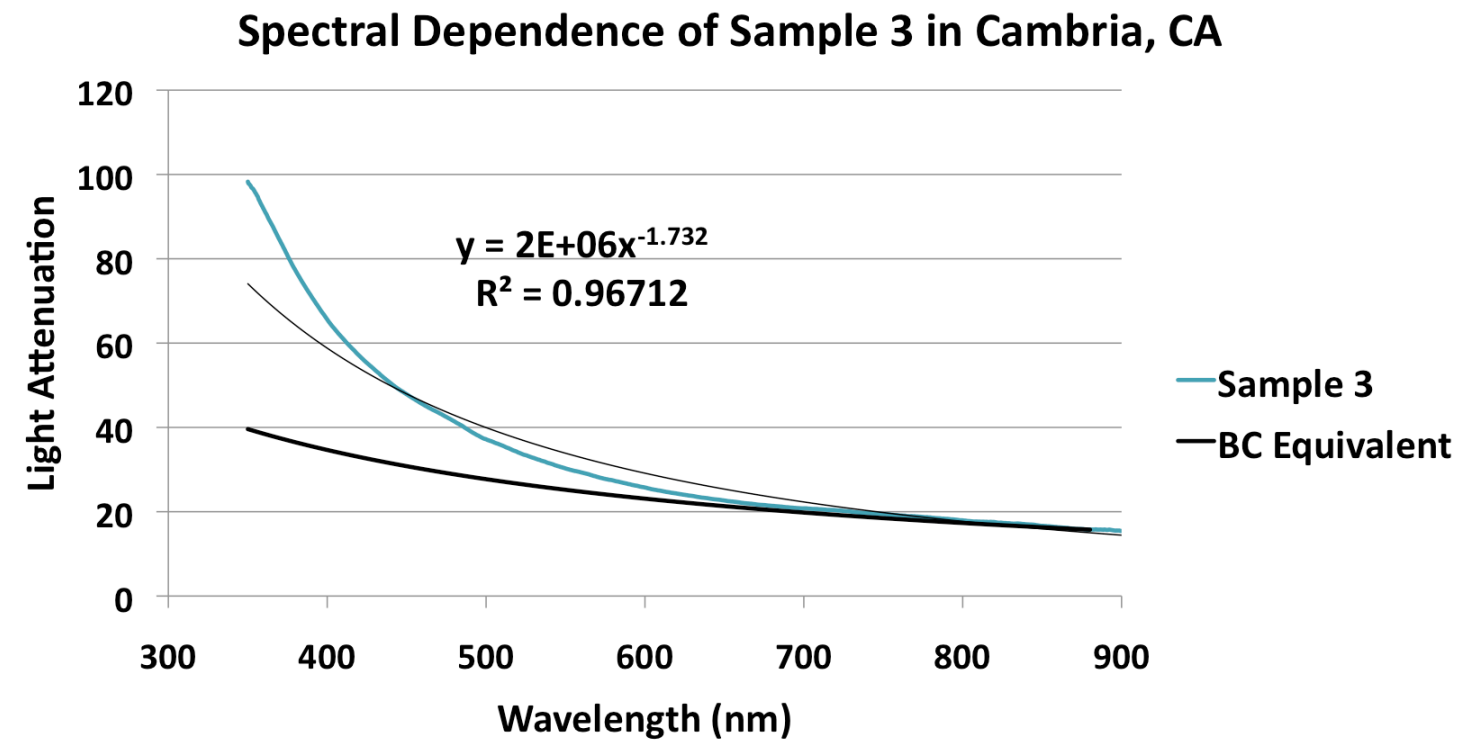

Figure 23: The light attenuation of sample 3 taken in Cambria, CA (blue line) and the attenuation of purely black carbon (black line) extrapolated from the attenuation in the sample at $880 \mathrm{~nm}$. The grey line is the best-fit power law regression for sample 3.

The black line is included in Figure 23 to show how much of the total attenuation is due to black carbon. This line is extrapolated from the biomass smoke sample's attenuation at $880 \mathrm{~nm}$ using the power law described in Section 2.3.2 assuming an Ångström coefficient of 1.1. An Ångström coefficient of 1.1-0.9 has been well documented for traffic aerosols or for pure black carbon (Kirchstetter \& Novakov, 2007; Kirchstetter et al., 2004; Sandradewi et al., 2008; Schnaiter et al., 2003). The sample attenuation above the black line is due to organic carbon as opposed to black carbon. 
As previously stated, for biomass smoke, an absorption Ångström exponent of around 2 is generally observed. The exponents for each sample from the methods comparison are listed on the next page in Table 5. The spectral selectivity of all but one sample, sample 2, resembled woodsmoke rather than traffic-derived aerosols. This can be illustrated by looking at the EC/TC ratio for each sample. Sample 2's EC/TC ratio was double the next highest $\mathrm{EC} / \mathrm{TC}$ ratio. The high ratio along with the spectral data suggests that sample 2's aerosols originated from traffic exhaust.

The spectral variation in attenuation was generally greater than predicted by the power law fit to the data when a wide wavelength region was considered. Restricting the fit to wavelengths less than $600 \mathrm{~nm}$ resulted in an improved fit for most samples, as indicated in the Figure 24.

Table 5: Ångström coefficients for each sample determined from a best-fit power law regression

\begin{tabular}{|c|c|c|c|}
\hline $\begin{array}{c}\text { Sample } \\
\#\end{array}$ & $\begin{array}{c}\text { Angström } \\
\text { Best Fit 350- } \\
1000 \mathrm{~nm}\end{array}$ & $\begin{array}{c}\text { Angström } \\
\text { Best fit } \\
\text { <600nm }\end{array}$ & $\begin{array}{c}\text { EC/TC } \\
\text { Ratio }\end{array}$ \\
\hline \hline $\mathbf{1}$ & 2.0 & 2.5 & 0.02 \\
$\mathbf{2}$ & 1.1 & 1.3 & 0.16 \\
$\mathbf{3}$ & 1.7 & 2.5 & 0.08 \\
$\mathbf{4}$ & 1.9 & 2.6 & 0.06 \\
$\mathbf{5}$ & 1.7 & 2.3 & 0.06 \\
$\mathbf{6}$ & 1.5 & 2.1 & 0.04 \\
$\mathbf{7}$ & 1.7 & 2.3 & 0.07 \\
$\mathbf{8}$ & 1.8 & 2.4 & 0.08 \\
\hline
\end{tabular}

For wavelengths greater than $600 \mathrm{~nm}$, there is little to no difference in attenuation between the sample and that expected for black carbon. However, for wavelengths less 
than $600 \mathrm{~nm}$, the sample attenuation diverges rapidly from the generated traffic attenuation. This implies that black carbon is the dominant species in light absorption for wavelengths greater than $600 \mathrm{~nm}$, however, for wavelengths less than $600 \mathrm{~nm}$, other aerosols, presumably organic carbon, absorbs a significant amount of light. One group of organic compounds that are present in biomass burning aerosols that absorb light at small wavelengths are humic-like substances (HULIS), which have been found in isolated form to have Ångström coefficients near 6 and 7 (Hoffer et al., 2006).

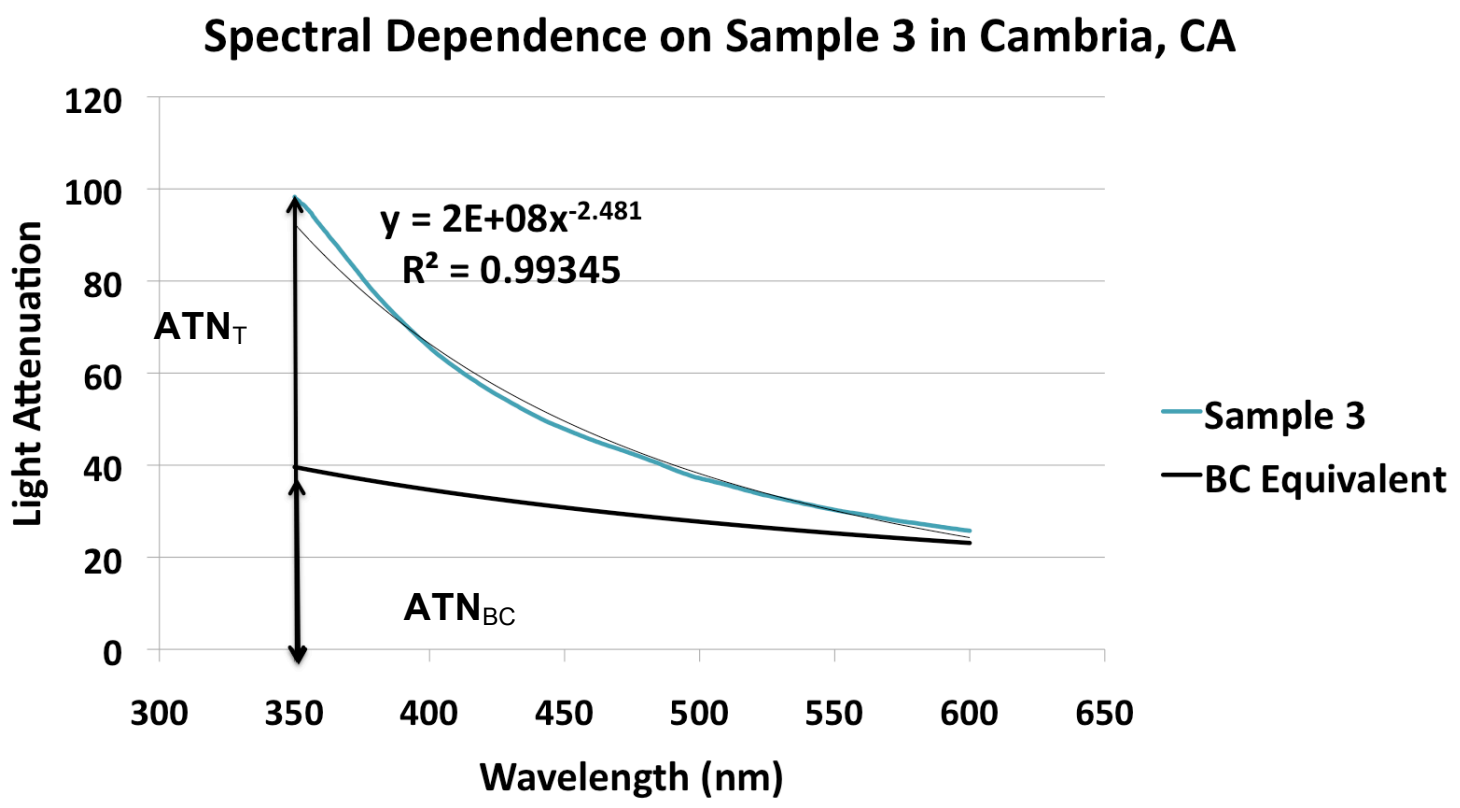

Figure 24: Light attenuation of a sample taken in Cambria, CA (blue line) showing the amount of attenuation due to black carbon in the sample.

The difference in attenuation between the sample and the $\mathrm{BC}$ equivalent lines can be attributed to organic species present in the sample. In Figure 24, the absorbance due to organic carbon is represented by the total attenuation in the sample less the attenuation in the $\mathrm{BC}$ equivalent line, or $\mathrm{ATN}_{\mathrm{OC}}=\mathrm{ATN}_{\mathrm{T}}-\mathrm{ATN}_{\mathrm{BC}}$. For $\mathrm{ATN}_{\mathrm{oc}}$ due only to organic carbon, the specific attenuation coefficient, which relates ATN to concentration is calculated from Eq. 6 in Section 3.3.1, except that instead of BC the calculation is for OC 
and $\mathrm{d}(\mathrm{ATN})$ is now $\mathrm{ATN}_{\mathrm{OC}}$ from the above equation. Table 6 on the next page shows the specific attenuation coefficients for organic carbon for our comparison samples at 370 and $450 \mathrm{~nm}$, which averaged $5.0 \pm 2.2 \mathrm{~m}^{2} / \mathrm{g}$ and $1.6 \pm 0.8 \mathrm{~m}^{2} / \mathrm{g}$, respectively. Samples 1 and 2 have significantly lower coefficients. Based on the Ångström coefficient and the $\mathrm{EC} / \mathrm{TC}$ ratio, sample 2 is more representative of black-carbon dominated aerosols, such as emitted from a diesel vehicle, versus biomass aerosols so the attenuation difference between the black carbon equivalent line and sample line was small compared to the amount of OC present in the sample.

Table 6: Specific Attenuation Coefficients for comparison samples at $370 \mathrm{~nm}$ and $450 \mathrm{~nm}$ for the organic fraction

\begin{tabular}{|c|c|c|}
\hline $\begin{array}{c}\text { Sample } \\
\#\end{array}$ & $370 \mathrm{~nm}$ & $450 \mathrm{~nm}$ \\
\hline \hline $\mathbf{1}$ & 1.2 & 0.5 \\
$\mathbf{2}$ & 2.0 & 0.1 \\
$\mathbf{3}$ & 8.8 & 3.2 \\
$\mathbf{4}$ & 6.0 & 1.8 \\
$\mathbf{5}$ & 5.1 & 1.9 \\
$\mathbf{6}$ & 3.8 & 1.0 \\
7 & 5.8 & 2.1 \\
8 & 7.4 & 2.5 \\
\hline
\end{tabular}

For sample 1, it is possible that some contamination was present in the NIOSH 5040 analysis, shown by the higher TC concentration in the NIOSH 5040 over the TOA (Fig. 18) while the $\mathrm{BC}$ and EC concentrations were similar (Fig. 19), leading to a higher OC concentration and a lower specific attenuation coefficient. If those two samples are removed, then the new averaged specific attenuation coefficients for 370 and $450 \mathrm{~nm}$ become $6.1 \pm 1.4 \mathrm{~m}^{2} / \mathrm{g}$ and $2.1 \pm 0.6 \mathrm{~m}^{2} / \mathrm{g}$, respectively. Kirchstetter et al., (2004) found 
similar values of around $7 \mathrm{~m}^{2} / \mathrm{g}$ at $370 \mathrm{~nm}$ and $3 \mathrm{~m}^{2} / \mathrm{g}$ at $450 \mathrm{~nm}$ for specific attenuation coefficients in biomass samples. There is nothing to indicate that the differences in attenuation could be attributed to the different site locations or on which weekend the samples were taken

Light attenuation is different from light absorption largely because of multiple scatterings that occur with the quartz filter. The fibers in the filter provide a medium for the light to refract off of and become absorbed by the particle matter that otherwise would not have. As a consequence, atmospheric light absorption is less than light attenuation from a filter, typically by factor of 2 . That is, light absorption from organic carbon at $370 \mathrm{~nm}$ and $450 \mathrm{~nm}$ would be $3 \mathrm{~m}^{2} / \mathrm{g}$ and $1 \mathrm{~m}^{2} / \mathrm{g}$ respectively. While it appears that organic carbon does contribute to light absorption in wavelengths lower than $600 \mathrm{~nm}$, black carbon is still the more dominant absorbing species throughout all wavelengths. Figure 25 below shows the light absorption of both black and organic carbon from the method comparison samples.

Immediately apparent in Fig. 25 are the two differing black carbon absorbance groups. It is unknown why this disparity exists. Site location and sampling weekend can be ruled out of reasons for the two groups. The black carbon concentrations used for calculating the optical absorbance were from LBNL EGA method. Although there are inherent uncertainties when separating the black carbon, which require some subjective interpretation, the discrete separation of optical absorbance into two groups cannot be attributed to the methodology. 


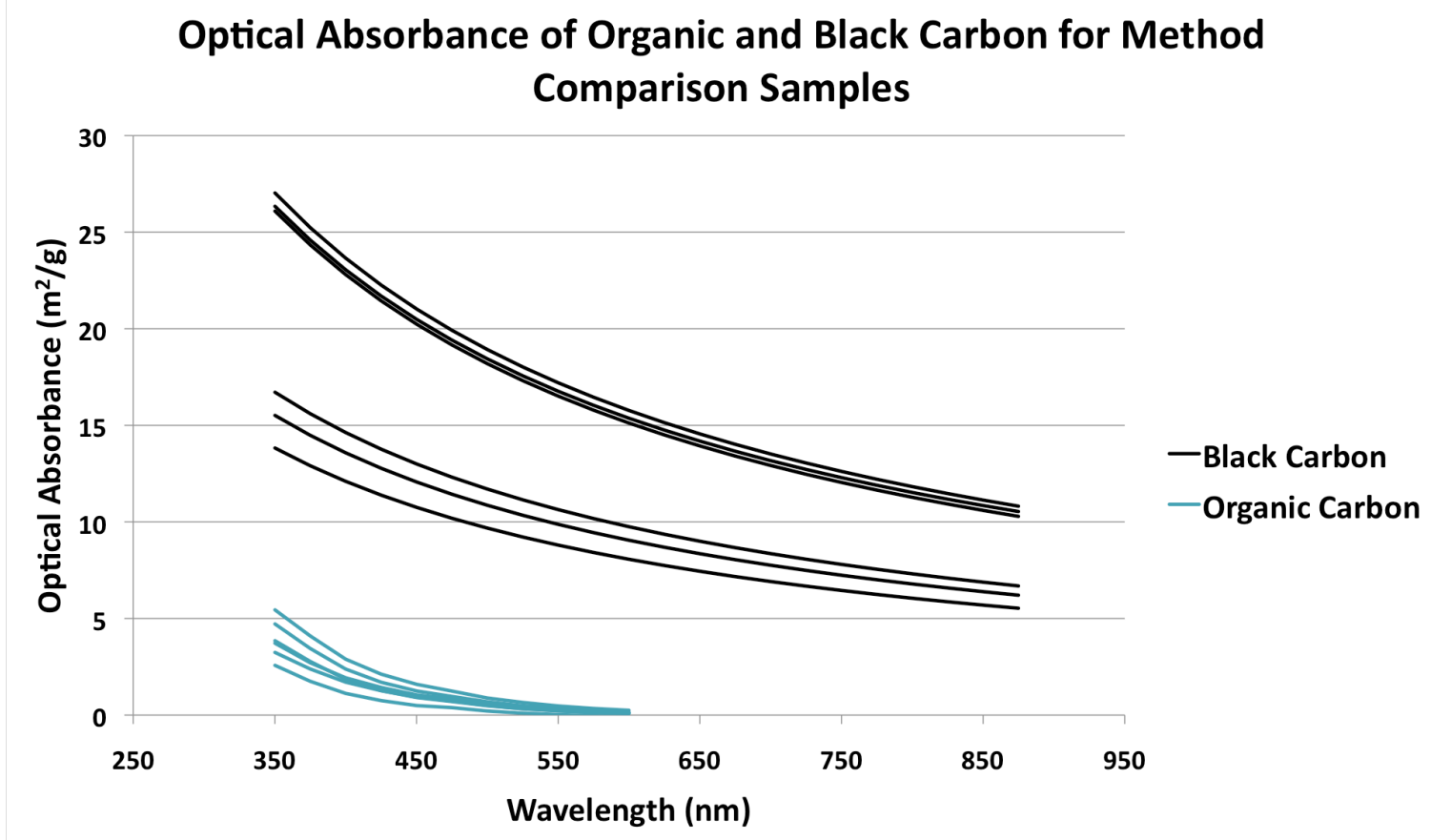

Figure 25: Optical Absorbance of Organic and Black Carbon for samples 3 through 8 . Samples 1 and 2 were excluded because of the uncertainty previously discussed.

Regardless of the differences in black carbon absorbance, it is clear that black carbon is the dominant absorbing species. However, as wavelengths approach the blue-UV range, organic carbon begins to absorb light. At $350 \mathrm{~nm}$, the ratio of light absorbed, $\alpha_{\mathrm{OC}} / \alpha_{\mathrm{BC}}$, is $0.2 \pm 0.07$. This ratio is likely to increase as the wavelength of the light becomes smaller because of the power law relationship. Because black carbon absorbance follows a $\lambda^{-1}$ relationship and organic carbon absorbance follows a $\lambda^{-2.4}$ relationship, organic carbon's optical absorption would increase as the wavelength decreases more rapidly than black carbon, possibly contributing to as much light absorption as black carbon in the far UV range. 


\section{Chapter 5: Conclusion}

\subsection{Experimental Conclusion}

This paper discussed two main topics (1) the parameters that affect the indoor concentration of aerosols of outdoor origin and (2) the comparison of carbon aerosol measurement methods and the effect organic carbon has on optical absorbance. From the assessment of the four solution techniques for calculating the infiltration parameters, it appears that both solution technique 1 and 3 provide the closest approximation for the infiltration rate, deposition rate, and penetration factor for black carbon, a proxy for woodsmoke. Using the infiltration rate model in solution techniques 2 and 4 often resulted in deposition rates constrained by zero. To compensate, the penetration factors were reduced to minimize the sum of squared differences. In addition, the infiltration rates determined from the model were often too constrained to a narrow range, which may have been the result of poor atmospheric data or of bad assumptions. Both solution techniques 1 and 3 provided good approximations and neither seemed better than the other. However, without directly measuring at least one parameter, it is difficult to separate the effects of all three parameters and the results of all 4 solution techniques can only go as far as close approximations.

With penetration factors approaching unity and deposition rates nearing zero, the overall exposure to newly generated woodsmoke particles of an individual inside is close to the exposure of an individual outside. Because the predominant source of black carbon was from newly generated woodsmoke, an average indoor/outdoor ratio of 0.75 shows the minimal shielding a home provides. This is an important conclusion for sensitive individuals who try to avoid inhalation by seeking protection inside a home. 
For the second main topic, the results from the comparison show the need for better methods to determine carbon measurements. All thermal methods use the difference in evolution temperature to separate elemental and organic carbon; however chemical species present in the sample can have a huge effect on the temperature at which each fraction oxidizes. This is readily seen in Fig. 17, where elemental carbon measured on average half of black carbon, when they should represent the same fraction. On average, the different instruments that measured black carbon were comparable, but far from identical. In spite of this disparity, neither method is better than the other at measuring the carbon fractions. Each method provides its own operational definition of organic and black or elemental carbon but since the "true" concentration is unknowable, no one method can be considered to more closely represents this 'true' value than the others.

Woodsmoke was more spectrally dependent than diesel aerosols, which is consistent with previous observations. The most likely cause is light absorbing organic carbon that is present in woodsmoke and not in diesel exhaust. The average spectral dependence was $\lambda^{-1.7}$ across all wavelengths and $\lambda^{-2.25}$ for wavelengths less than $600 \mathrm{~nm}$, as determined through power law regression. This is significantly greater than the spectral dependence of $\lambda^{-1.1}$ that is found for diesel exhaust. At wavelengths less than 600 $\mathrm{nm}$ organic carbon begins to absorb light. At $350 \mathrm{~nm}$, the ratio of organic carbon/black carbon light absorption, $\alpha_{\mathrm{OC}} / \alpha_{\mathrm{BC}}$, was $0.2 \pm 0.07$. This ratio is also likely to increase as the wavelength decreases across the electromagnetic spectrum. This can have implications on estimations for climate change. It is generally believed that only black 
carbon absorbs light, however shown here and other studies, it is apparent that organic carbon also absorbs a significant amount of light.

\subsection{Future Studies}

This study was the first year in a two-year study to examine woodsmoke variation and properties in Cambria, CA. The indoor portion of this study concluded with this paper, however measuring at least one of the indoor parameters, easiest being the infiltration rate, is critical to determining accurate penetration factors and deposition rates. In future studies, simultaneously measuring infiltration rate with a tracer gas would be ideal. If the infiltration rate cannot be determined, then only close approximations can be obtained. Additionally, organic carbon could be measured directly using NIOSH 5040, to find the indoor/outdoor ratios. Studying indoor/outdoor ratios for organic carbon would be unique in Cambria because woodsmoke would be the primary source of organic carbon and each night the concentrations would return to low background levels.

For the comparison section, additional samples are greatly needed. The samples were too variable and there were too few samples to make definitive conclusions. Levoglucosan analysis, however may not need future study as the analysis is expensive and it is now known that woodsmoke is the predominate contributor to local atmospheric particulate matter in Cambria. To replace levoglucosan, other measurement instruments

or methods, like the IMPROVE method, could be used to obtain a better understanding of woodsmoke derived aerosols. Additionally, measuring gravimetric $\mathrm{PM}_{2.5}$ could give a reference to the total concentration of aerosols in Cambria. A field EC/OC analyzer, which measures elemental carbon and organic carbon semi-continuously, running along 
side an aethalometer would also provide a sample base that could yield more definitive conclusions about the light absorbing properties of organic carbon. 


\section{References}

Andreae, M. O., \& Gelencser, A. (2006). Black carbon or brown carbon? The nature of lightabsorbing carbonaceous aerosols. Atmospheric Chemistry and Physics, 6(10), 31313148 .

Birch, M. E., \& Cary, R. A. (1996). Elemental carbon-based method for monitoring occupational exposures to particulate diesel exhaust. Aerosol Science and Technology, 25(3), 221-241.

Bond, T. C., \& Sun, H. (2005). Can reducing black carbon emissions counteract global warming? Environ. Sci. Technol, 39(16), 5921-5926.

Browning, K. G., Koenig, J. Q., Checkoway, H., Larson, T. V., \& Pierson, W. E. (1990). A questionnaire study of respiratory health in areas of high and low ambient wood smoke pollution. Pediatric Asthma, Allergy \& Immunology, 4(3), 183-191.

Cadle, S. H., Groblicki, P. J., \& Mulawa, P. A. (1983). Problems in the sampling and analysis of carbon particulate. Atmospheric Environment, 17, 593-600.

Cambria Weather. (2008). . U.S. Department of Sate. Retrieved from http://countrystudies.us/united-states/weather/California/cambria.htm

Charlson, R. J., Schwartz, S. E., Hales, J. M., Cess, R. D., Coakley, J. A., Hansen, J. E., et al. (1992). Climate forcing by anthropogenic aerosols. Science, 255(5043), 423-430.

Chow, J. C., Watson, J. G., Crow, D., Lowenthal, D. H., \& Merrifield, T. (2001). Comparison of IMPROVE and NIOSH carbon measurements. Aerosol Science and Technology, 34(1), $23-34$.

Chow, J. C., Watson, J. G., Lowenthal, D. H., Chen, L. W., \& Magliano, K. L. (2006). Particulate carbon measurements in California's San Joaquin Valley. Chemosphere, 62(3), 337-348.

Chow, J. C., Watson, J. G., Pritchett, L. C., Pierson, W. R., Frazier, C. A., \& Purcell, R. G. (1993). The DRI thermal/optical reflectance carbon analysis system: Description, evaluation and applications in U. S. air quality studies. Atmospheric Environment; Part 
A, General Topics, 27(8), 1185-1201.

Davy, P. K., Markwitz, A., \& Watherburn, D. C. (2007). Composition, size and Morphological comparison of wood smoke particles from source emissions and in urban air by SEMEDS. In International Union of Air Pollution Prevention and Evironmental Protection Associations. Presented at the 14th IUAPPA World Congress clean air partnerships, Brisbane.

Ellis, E. C., \& Novakov, T. (1982). Application of thermal analysis to the characterization of organic aerosol particles. Sci. Total Environ, 23, 227-238.

Fine, P. M., Cass, G. R., \& Simoneit, B. R. (2004). Chemical characterization of fine particle emissions from the fireplace combustion of wood types grown in the Midwestern and Western United States. Environmental Engineering Science, 21(3), 387-409.

Fine, P. M., Cass, G. R., \& Simoneit, B. R. (2002). Chemical characterization of fine particle emissions from the fireplace combustion of woods grown in the southern united states. Environmental Science \& Technology, 36(7), 1442-1451.

Fine, P. M., Cass, G. R., \& Simoneit, B. R. (2004). Chemical characterization of fine particle emissions from the wood stove combustion of prevalent United States tree species. Environmental Engineering Science, 21(6), 705-721.

Fraser, M. P., \& Lakshmanan, K. (2000). Using Levoglucosan as a Molecular Marker for the Long-Range Transport of Biomass Combustion Aerosols. Environmental Science \& Technology, 34(21), 4560-4564. doi: 10.1021/es9912291

Freijer, J. I., \& Bloemen, H. J. (2000). Modeling relationships between indoor and outdoor air quality. Journal of the Air \& Waste Management Association, 50(2), 292-300.

Gauderman, W. J., Avol, E., Gilliland, F., Vora, H., Thomas, D., Berhane, K., et al. (2004). The effect of air pollution on lung development from 10 to 18 years of age (Vol. 351).

Geller, M. D., Chang, M., Sioutas, C., Ostro, B. D., \& Lipsett, M. J. (2002). Indoor/outdoor relationship and chemical composition of fine and coarse particles in the southern 
California deserts. Atmospheric Environment, 36(6), 1099-1110.

Gray, A., \& Cass, G. R. (1998). Source contributions to atmospheric fine carbon particle concentrations. Atmospheric Environment, 32(22), 3805-3825.

Gundel, L. A., Dod, R. L., Rosen, H., \& Novakov, T. (1984). Relationship between optical attenuation and black carbon concentration for ambient and source particles.

Hansen, A. D. A. (2005). The Aethalometer. Magee Scientific Company.

Hansen, J., \& Nazarenko, L. (2004). Soot climate forcing via snow and ice albedos. Proceedings of the national academy of sciences, 101(2), 423-428.

Hansen, J., Sato, M., Ruedy, R., Nazarenko, L., Lacis, A., Schmidt, G. A., et al. (2005). Efficacy of climate forcings. Journal of Geophysical Research-Atmospheres, 110(D18), D18104.

Hatch, T. F. (1961). Distribution and deposition of inhaled particles in respiratory tract. Microbiology and Molecular Biology Reviews, 25(3), 237-240.

Hering, S. V., Lunden, M. M., Thatcher, T. L., Kirchstetter, T. W., \& Brown, N. J. (2007). Using regional data and building leakage to assess indoor concentrations of particles of outdoor origin. Aerosol Science and Technology, 41(7), 639-654.

Hoffer, A., Gelencser, A., Guyon, P., Kiss, G., Schmid, O., Frank, G. P., et al. (2006). Optical properties of humic-like substances(HULIS) in biomass-burning aerosols. Atmospheric Chemistry and Physics, 6(11), 3563-3570.

Hole, D. J., Watt, G. C. M., Davey-Smith, G., Hart, C. L., Gillis, C. R., \& Hawthorne, V. M. (1996). Impaired lung function and mortality risk in men and women: findings from the Renfrew and Paisley prospective population study. British Medical Journal, 313(7059), $711-715$.

Honicky, R. E., Osborne, J. S., \& Akpom, C. A. (1985). Symptoms of respiratory illness in young children and the use of wood-burning stoves for indoor heating. Pediatrics, 75(3), 587593. 
Huntzicker, J. J., Johnson, R. L., Shah, J. J., \& Cary, R. A. (1982). Analysis of organic and elemental carbon in ambient aerosols by a thermal-optical method. Particulate carbon: Atmospheric life cycle, $79-88$.

Jacobson, M. Z. (2004). Climate response of fossil fuel and biofuel soot, accounting for soot's feedback to snow and sea ice albedo and emissivity. J. Geophys. Res, 109.

Jacobson, M. Z. (2002). Control of fossil-fuel particulate black carbon and organic matter, possibly the most effective method of slowing global warming. J. Geophys. Res, 107(19), 4410.

Jenkins, P. L., Phillips, T. J., Mulberg, E. J., \& Hui, S. P. (1992). Activity patterns of Californians. Use of and proximity to indoor pollutant sources. Atmospheric Environment, 26(12), 2141-2148.

Jeong, C. H., Hopke, P. K., Kim, E., \& Lee, D. W. (2004). The comparison between thermaloptical transmittance elemental carbon and Aethalometer black carbon measured at multiple monitoring sites. Atmospheric Environment, 38(31), 5193-5204.

Jones, G. S., Jones, A., Roberts, D. L., Stott, P. A., \& Williams, K. D. (2005). Sensitivity of global-scale climate change attribution results to inclusion of fossil fuel black carbon aerosol. Geophysical Research Letters, 32(14), L14701.

Kirchstetter, T. W., \& Novakov, T. (2007). Controlled generation of black carbon particles from a diffusion flame and applications in evaluating black carbon measurement methods. Atmospheric Environment, 41(9), 1874-1888.

Kirchstetter, T. W., Novakov, T., \& Hobbs, P. V. (2004). Evidence that the spectral dependence of light absorption by aerosols is affected by organic carbon. Journal of Geophysical Research-Atmospheres, 109(D21), D21208.

Kirchstetter, T. W., Corrigan, C. E., \& Novakov, T. (2001). Laboratory and field investigation of the adsorption of gaseous organic compounds onto quartz filters. Atmospheric Environment, 35(9), 1663-1671. doi: 10.1016/S1352-2310(00)00448-9 
Kleeman, M. J., Schauer, J. J., \& Cass, G. R. (1999). Size and composition distribution of fine particulate matter emitted from wood burning, meat charbroiling, and cigarettes. Environ. Sci. Technol, 33(20), 3516-3523.

Kleindienst, T. E., Shepson, P. B., Edney, E. O., Claxton, L. D., \& Cupitt, L. T. (1986). Wood smoke: measurement of the mutagenic activities of its gas-and particulate-phase photooxidation products. Environmental Science \& Technology, 20(5), 493-501.

Kocbach, A., Johansen, B. V., Schwarze, P. E., \& Namork, E. (2005). Analytical electron microscopy of combustion particles: a comparison of vehicle exhaust and residential wood smoke. Science of the Total Environment, The, 346(1-3), 231-243.

Koenig, J. Q., Larson, T. V., Hanley, Q. S., Rebolledo, V., Dumler, K., Checkoway, H., et al. (1993). Pulmonary function changes in children associated with fine particulate matter. Environmental research, 63(1), 26-38.

LaRosa, L. E., Buckley, T. J., \& Wallace, L. A. (2002). Real-time indoor and outdoor measurements of black carbon in an occupied house: an examination of sources. Journal of the Air \& Waste Management Association(1995), 52(1), 41-49.

Lewtas, J. (1993). Complex mixtures of air pollutants: characterizing the cancer risk of polycyclic organic matter. Environmental health perspectives, 100, 211-218.

Liousse, C., Cachier, H., \& Jennings, S. G. (1993). Optical and thermal measurements of black carbon aerosol content in different environments: Variation of the specific attenuation cross-section, sigma( sigma). Atmospheric Environment; Part A, General Topics, 27(8), $1203-1211$.

Locker, H. B. (1988). The use of levoglucosan to assess the environmental impact of residential wood-burning on air quality.

Lunden, M. M., Kirchstetter, T. W., Thatcher, T. L., Hering, S. V., \& Brown, N. J. (2008). Factors affecting the indoor concentrations of carbonaceous aerosols of outdoor origin. 
Atmospheric Environment, 42(22), 5660-5671.

Lunden, M. M., Thatcher, T. L., Hering, S. V., \& Brown, N. J. (2003). Use of time-and chemically resolved particulate data to characterize the infiltration of outdoor PM2. 5 into a residence in the San Joaquin Valley. Environmental Science and Technology-

Washington DC-, 37(20), 4724-4732.

Nazaroff, W. W., \& Cass, G. R. (1986). Mathematical modeling of chemically reactive pollutants in indoor air. Environmental Science \& Technology, 20(9), 924-934.

NIOSH. (2003). Method 5040 Elemental Carbon (Diesel Exhaust), Issue 3. In Manual of Analytical Methods. Cincinnati, OH: National Institue of Occupational Safety and Health.

Novakov, T., \& Corrigan, C. E. (1995). Thermal characterization of biomass smoke particles. Microchimica Acta, 119(1), 157-166.

Particulate Matter (PM-2.5) Nonattainment State/Area/County Report (1997 Standard) | Green Book | US EPA. (n.d.). . Retrieved from http://www.epa.gov/oaqps001/greenbk/qncs.html\#CALIFORNIA

Petzold, A., Kopp, C., \& Niessner, R. (1997). The dependence of the specific attenuation crosssection on black carbon mass fraction and particle size. Atmospheric Environment, 31(5), $661-672$.

Polidori, A., Turpin, B., Meng, Q. Y., Lee, J. H., Weisel, C., Morandi, M., et al. (2006). Fine organic particulate matter dominates indoor-generated PM2.5 in RIOPA homes. $J$ Expos Sci Environ Epidemiol, 16(4), 321-331.

Poore, M. W. (2002). Levoglucosan in PM2. 5 at the Fresno supersite. Journal of the Air \& Waste Management Association(1995), 52(1), 3-4.

Rau, J. A. (1989). Composition and size distribution of residential wood smoke particles. Aerosol Science and Technology, 10(1), 181-192.

Rosen, H., Hansen, A. D. A., Gundel, L., \& Novakov, T. (1978). Identification of the optically absorbing component in urban aerosols. Applied Optics, 17(24), 3859-3861. 
Rosen, H., \& Novakov, T. (1977). Raman scattering and the characterisation of atmospheric aerosol particles.

Sandradewi, J., Prévôt, A. S. H., Weingartner, E., Schmidhauser, R., Gysel, M., \& Baltensperger, U. (2008). A study of wood burning and traffic aerosols in an Alpine valley using a multi-wavelength Aethalometer. Atmospheric Environment, 42(1), 101-112.

Sandradewi, J., Prévôt, A. S., Szidat, S., et al. (2008). Using aerosol light absorption measurements for the quantitative determination of wood burning and traffic emission contributions to particulate matter. Environmental Science \& Technology, 42(9), 33163323.

Schnaiter, M., Horvath, H., Möhler, O., Naumann, K. -., Saathoff, H., \& Schöck, O. W. (2003). UV-VIS-NIR spectral optical properties of soot and soot-containing aerosols. Journal of Aerosol Science, 34(10), 1421-1444. doi: 10.1016/S0021-8502(03)00361-6

Schroeder, E. B., Welch, V. L., Couper, D., Nieto, F. J., Liao, D., Rosamond, W. D., et al. (2003). Lung Function and Incident Coronary Heart Disease The Atherosclerosis Risk in Communities Study. American journal of epidemiology, 158(12), 1171-1181.

Sherman, M. H., \& Dickerhoff, D. J. (1998). Air-tightness of US dwellings. TransactionsAmerican Society of Heating Refrigerating and Air Conditioning Engineers, 104, 1359 1367.

Sherman, M. H., \& Grimsrud, D. T. (1980). Infiltration-Pressurization Correlations: Simplified Physical Modeling. In Conference of the American Society of Heating, Refrigeration and Air Conditioning Engineers (Vol. 22).

Simoneit, B. R., Schauer, J. J., Nolte, C. G., Oros, D. R., Elias, V. O., Fraser, M. P., et al. (1999). Levoglucosan, a tracer for cellulose in biomass burning and atmospheric particles. Atmospheric Environment, 33(2), 173-182. 
State of the Air: 2007. (n.d.). . American Lung Association. Retrieved from http://lungaction.org/reports/sota07exec_summ.html

Thatcher, T. L., Lai, A. C., Moreno-Jackson, R., Sextro, R. G., \& Nazaroff, W. W. (2002). Effects of room furnishings and air speed on particle deposition rates indoors. Atmospheric Environment, 36(11), 1811-1819.

Thatcher, T. L., \& Layton, D. W. (1995). Deposition, resuspension, and penetration of particles within a residence. Atmospheric Environment, 29(13), 1487-1497.

Thatcher, T. L., Lunden, M. M., Revzan, K. L., Sextro, R. G., \& Brown, N. J. (2003). A concentration rebound method for measuring particle penetration and deposition in the indoor environment. Aerosol Science and Technology, 37(11), 847-864.

Thatcher, T. L., McKone, T. E., Fisk, W. J., Sohn, M. D., Delp, W. W., Riley, W. J., et al. (2001). Factors affecting the concentration of outdoor particles indoors (COPI): Identification of data needs and existing data. Retrieved from http://www.osti.gov/energycitations/servlets/purl/820780-8m21pL/native/

US Census Bureau. (2007). Census Bureau. Retrieved October 12, 2009, from http://www.census.gov/

Virkkula, A., Makela, T., Hillamo, R., Yli-Tuomi, T., Hirsikko, A., Hameri, K., et al. (2007). A simple procedure for correcting loading effects of aethalometer data. Journal of the Air \& Waste Management Association, 57(10), 1214-1222.

Ward, C. (2009, June). Assessing Near-Field Outdoor Concentration Variability from Residential Wood Smoke Combustion Sources. California Polytechnique State University San Luis Obispo.

Watson, J. G., Chow, J. C., \& Houck, J. E. (2001). PM2. 5 chemical source profiles for vehicle exhaust, vegetative burning, geological material, and coal burning in Northwestern Colorado during 1995. Chemosphere, 43(8), 1141-1151. 
Weingartner, E., Saathoff, H., Schnaiter, M., Streit, N., Bitnar, B., \& Baltensperger, U. (2003). Absorption of light by soot particles: determination of the absorption coefficient by means of aethalometers. Journal of Aerosol Science, 34(10), 1445-1463.

Yan, B., Zheng, M., Hu, Y. T., Lee, S., Kim, H. K., \& Russell, A. G. (2007). Organic composition of carbonaceous aerosols in an aged prescribed fire plume. Atmospheric Chemistry and Physics Discussions, 7(6), 18015-18042. 


\title{
Appendix A: GLM Models for Aethalometer Comparison Before and After Specific Attenuation Modification
}

\author{
General Linear Model: BC Raw (ug/m3) versus Aeth Num, Interval \\ Factor \\ Type Levels Values \\ Aeth Num fixed \\ Interval fixed \\ Aeth 1, Aeth 2, Aeth 3, Aeth 4, Aeth 5 \\ $1911,2,3,4,5,6,7,8,9,10,11,12,13,14,15,16$, \\ $17,18,19,20,21,22,23,24,25,26,27,28,29$, \\ $30,31,32,33,34,35,36,37,38,39,40,41,42$, \\ $43,44,45,46,47,48,49,50,51,52,53,54,55$, \\ $56,57,58,59,60,61,62,63,64,65,66,67,68$, \\ $69,70,71,72,73,74,75,76,77,78,79,80,81$, \\ $82,83,84,85,86,87,88,89,90,91,92,93,94$, \\ $95,96,97,98,99,100,101,102,103,104,105,106$, \\ $107,108,109,110,111,112,113,114,115,116,117$, \\ $118,119,120,121,122,123,124,125,126,127,128$, \\ $129,130,131,132,133,134,135,136,137,138,139$, \\ $140,141,142,143,144,145,146,147,148,149,150$, \\ $151,152,153,154,155,156,157,158,159,160,161$, \\ $162,163,164,165,166,167,168,169,170,171,172$, \\ $173,174,175,176,177,178,179,180,181,182,183$
}

Analysis of Variance for BC (ug/m3), using Adjusted ss for Tests

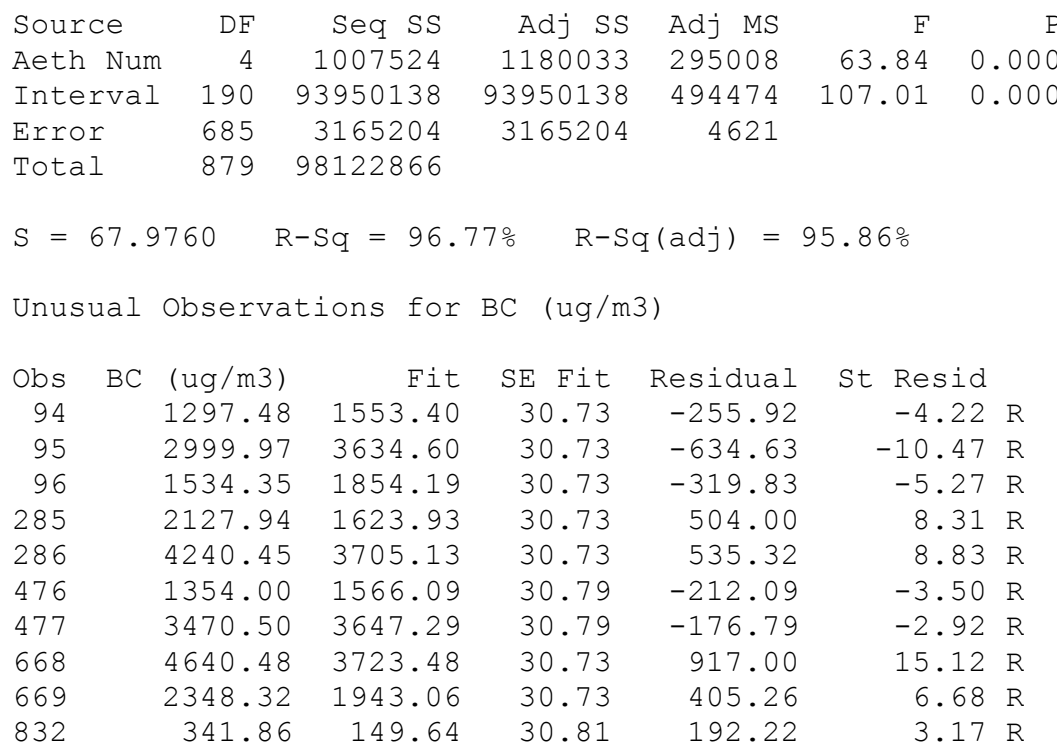

$\mathrm{R}$ denotes an observation with a large standardized residual.

Tukey 95.0\% Simultaneous Confidence Intervals

Response Variable BC (ug/m3)

All Pairwise Comparisons among Levels of Aeth Num

Aeth Num = Aeth 1 subtracted from:

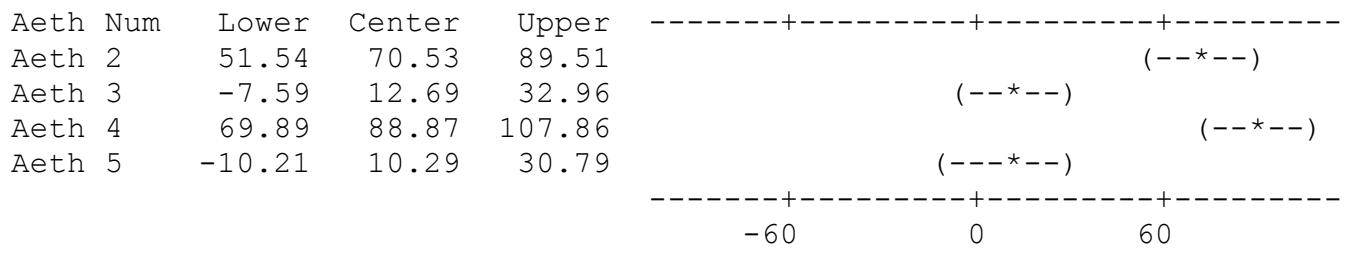




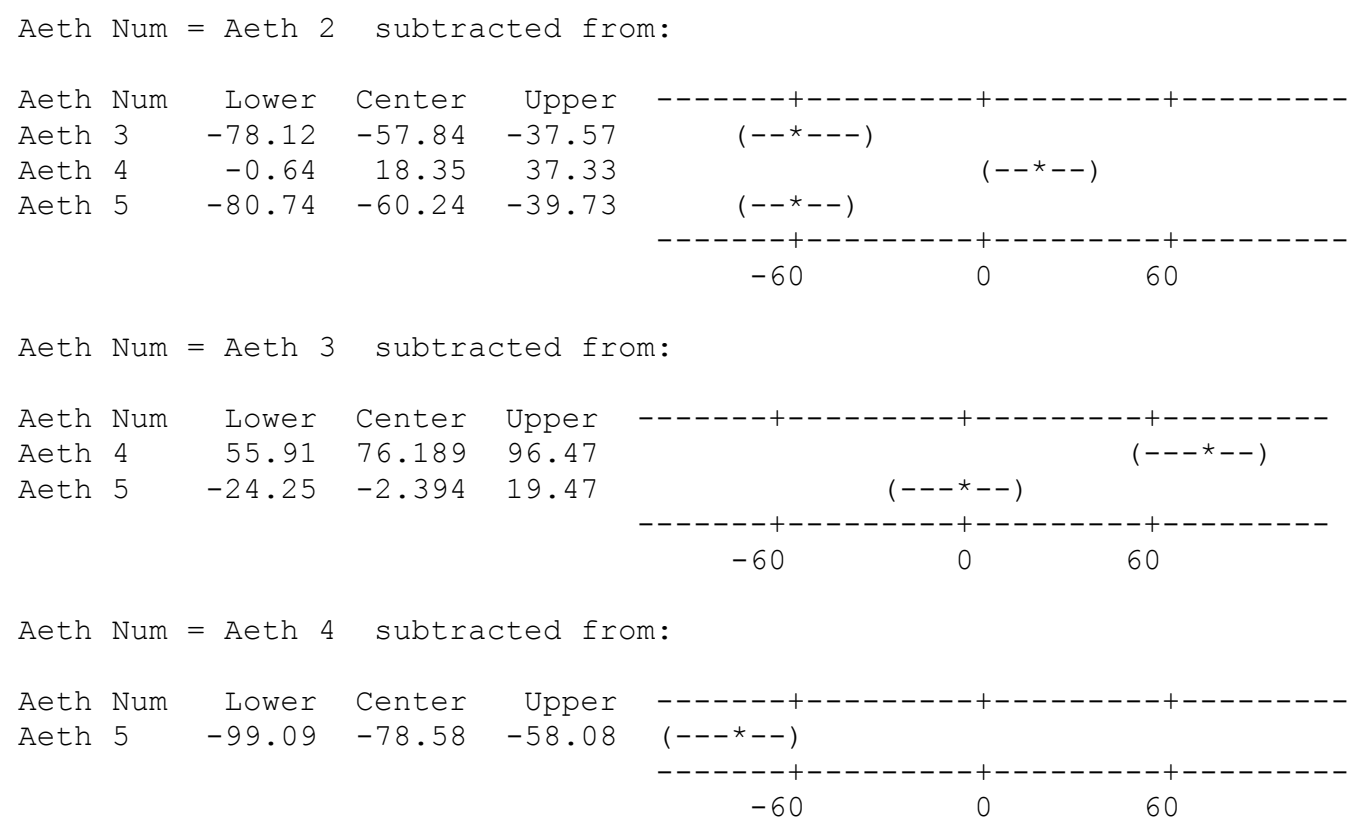

Tukey Simultaneous Tests

Response Variable BC (ug/m3)

All Pairwise Comparisons among Levels of Aeth Num Aeth Num = Aeth 1 subtracted from:

\begin{tabular}{|c|c|c|c|c|}
\hline & Difference & SE of & & Adjusted \\
\hline Aeth Num & of Means & Difference & T-Value & P-Value \\
\hline Aeth 2 & 70.53 & 6.956 & 10.139 & 0.0000 \\
\hline Aeth 3 & 12.69 & 7.429 & 1.708 & 0.4292 \\
\hline Aeth 4 & 88.87 & 6.956 & 12.777 & 0.0000 \\
\hline Aeth 5 & 10.29 & 7.512 & 1.370 & 0.6469 \\
\hline
\end{tabular}

Aeth Num = Aeth 2 subtracted from:

$\begin{array}{lrrrr} & \text { Difference } & \text { SE of } & \text { Adjusted } \\ \text { Aeth Num } & \text { Of Means } & \text { Difference } & \text { T-Value } & \text { P-Value } \\ \text { Aeth 3 } & -57.84 & 7.429 & -7.786 & 0.0000 \\ \text { Aeth 4 } & 18.35 & 6.956 & 2.637 & 0.0638 \\ \text { Aeth 5 } & -60.24 & 7.512 & -8.019 & 0.0000\end{array}$

Aeth Num = Aeth 3 subtracted from:

$\begin{array}{lrrrr} & \text { Difference } & \text { SE of } & \text { Adjusted } \\ \text { Aeth Num } & \text { of Means } & \text { Difference } & \text { T-Value } & \text { P-Value } \\ \text { Aeth 4 } & 76.189 & 7.429 & 10.2552 & 0.0000 \\ \text { Aeth 5 } & -2.394 & 8.009 & -0.2989 & 0.9983\end{array}$

Aeth Num = Aeth 4 subtracted from:

$\begin{array}{lrrrr} & \text { Difference } & \text { SE of } & \text { Adjusted } \\ \text { Aeth Num } & \text { of Means } & \text { Difference } & \text { T-Value } & \text { P-Value } \\ \text { Aeth } 5 & -78.58 & 7.512 & -10.46 & 0.0000\end{array}$




\section{General Linear Model: BC Modified (ug/m3) versus Aeth Num, Interval}

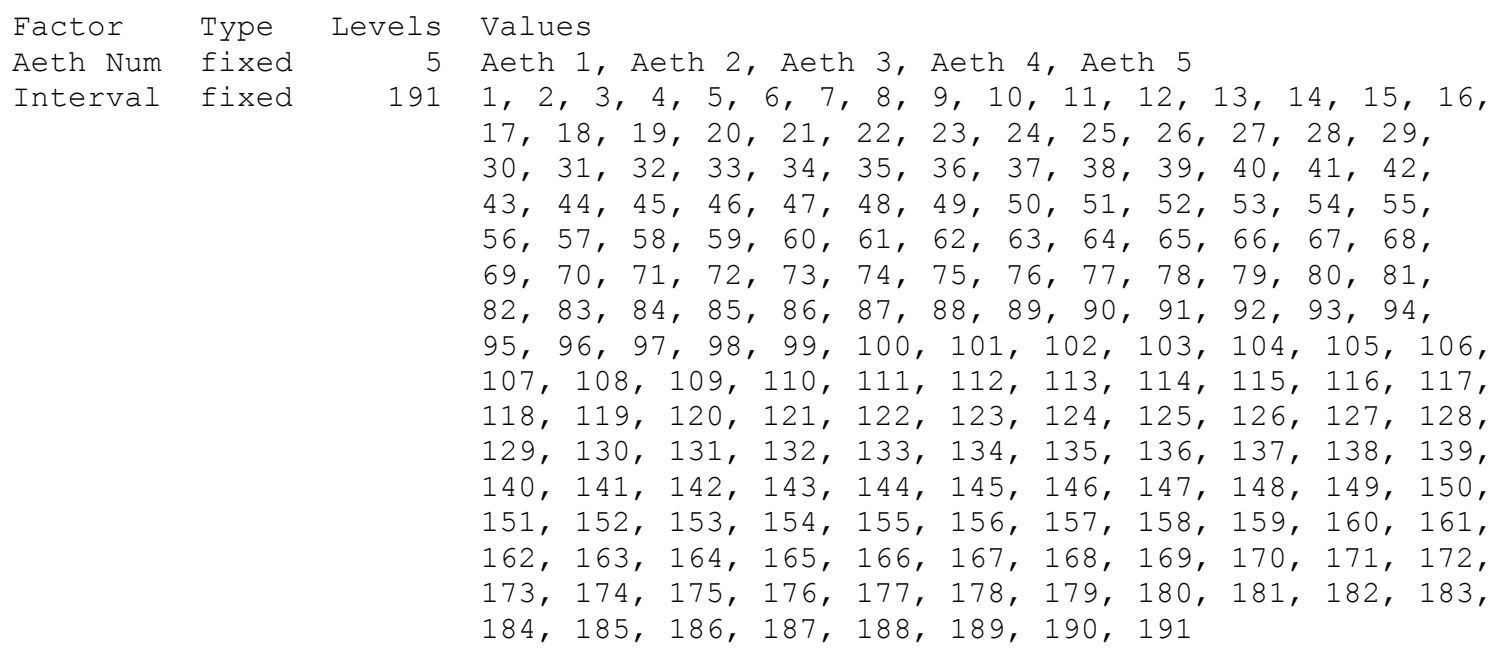

Analysis of Variance for BC (ug/m3), using Adjusted SS for Tests

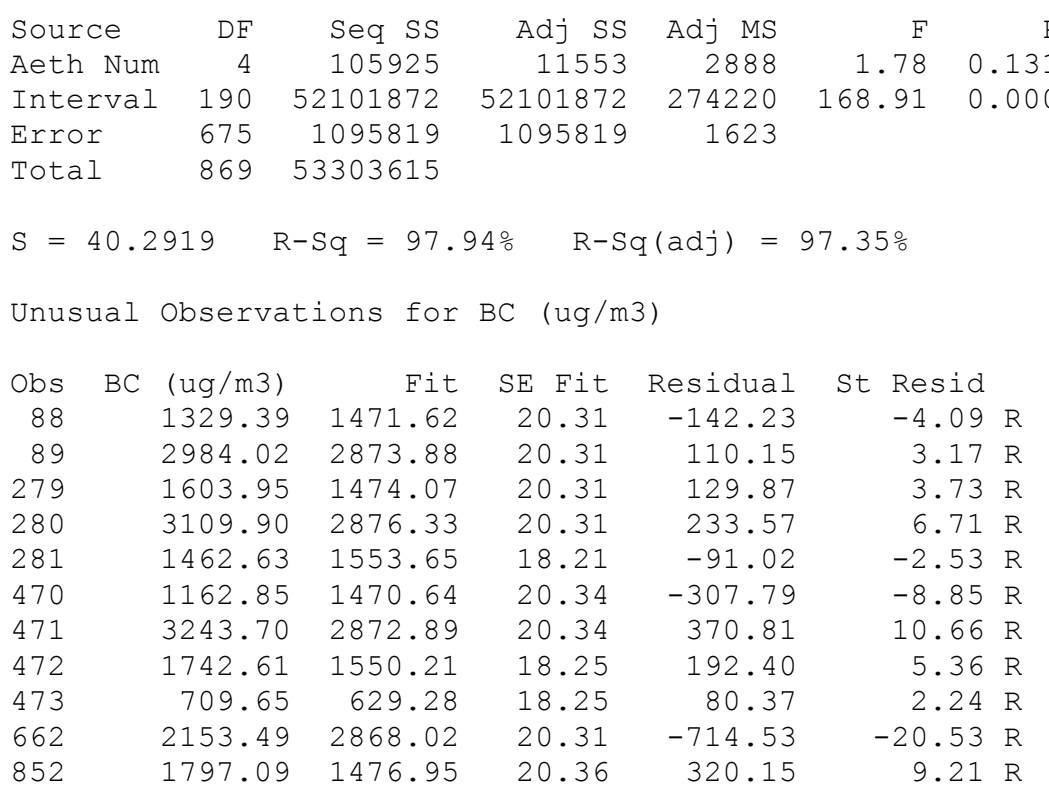

$\mathrm{R}$ denotes an observation with a large standardized residual.

Tukey 95.0\% Simultaneous Confidence Intervals

Response Variable BC (ug/m3)

All Pairwise Comparisons among Levels of Aeth Num

Aeth Num = Aeth 1 subtracted from:

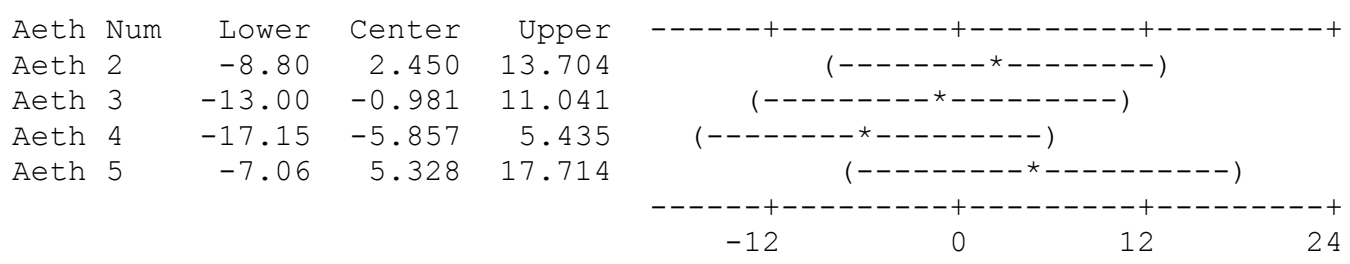




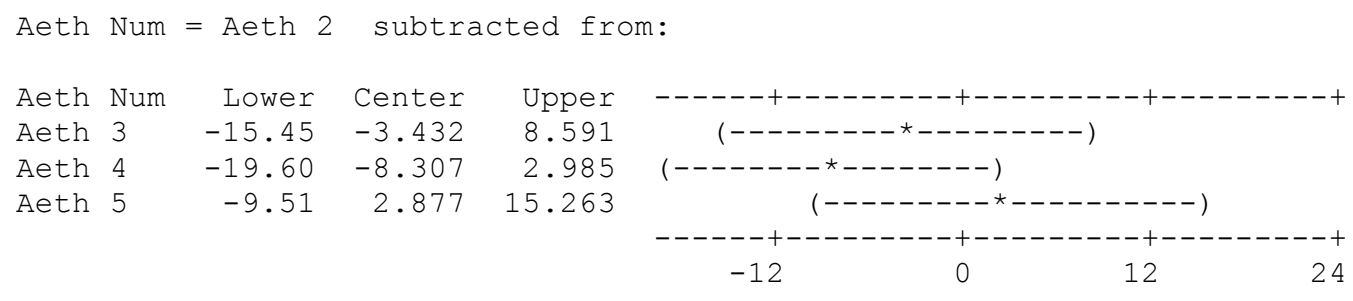

Aeth Num = Aeth 3 subtracted from:

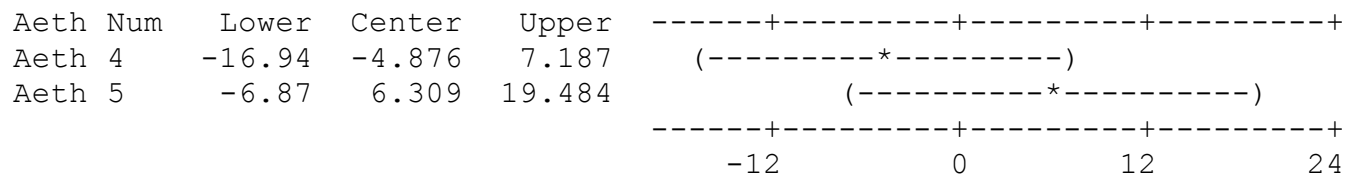

Aeth Num = Aeth 4 subtracted from:

$\begin{array}{lrrrr}\text { Aeth Num } & \text { Lower } & \text { Center } & \text { Upper } & ------+---------+---------+---------+ \\ \text { Aeth } 5 & -1.230 & 11.18 & 23.60 & (---------*----------) \\ & & & -12 & 0\end{array}$

Tukey Simultaneous Tests

Response Variable BC (ug/m3)

All Pairwise Comparisons among Levels of Aeth Num

Aeth Num = Aeth 1 subtracted from:

$\begin{array}{lrrrr} & \text { Difference } & \text { SE of } & \text { Adjusted } \\ \text { Aeth Num } & \text { of Means } & \text { Difference } & \text { T-Value } & \text { P-Value } \\ \text { Aeth 2 } & 2.450 & 4.123 & 0.594 & 0.9760 \\ \text { Aeth 3 } & -0.981 & 4.405 & -0.223 & 0.9995 \\ \text { Aeth 4 } & -5.857 & 4.137 & -1.416 & 0.6175 \\ \text { Aeth 5 } & 5.328 & 4.538 & 1.174 & 0.7663\end{array}$

Aeth Num = Aeth 2 subtracted from:

$\begin{array}{lrrrr} & \text { Difference } & \text { SE of } & & \text { Adjusted } \\ \text { Aeth Num } & \text { of Means } & \text { Difference } & \text { T-Value } & \text { P-Value } \\ \text { Aeth 3 } & -3.432 & 4.405 & -0.779 & 0.9367 \\ \text { Aeth 4 } & -8.307 & 4.137 & -2.008 & 0.2620 \\ \text { Aeth 5 } & 2.877 & 4.538 & 0.634 & 0.9696\end{array}$

Aeth Num = Aeth 3 subtracted from:

$\begin{array}{lrrrr} & \text { Difference } & \text { SE of } & \text { Adjusted } \\ \text { Aeth Num } & \text { of Means } & \text { Difference } & \text { T-Value } & \text { P-Value } \\ \text { Aeth } 4 & -4.876 & 4.419 & -1.103 & 0.8049 \\ \text { Aeth } 5 & 6.309 & 4.827 & 1.307 & 0.6869\end{array}$

Aeth Num = Aeth 4 subtracted from:

$\begin{array}{lrrrr} & \text { Difference } & \text { SE of } & & \text { Adjusted } \\ \text { Aeth Num } & \text { of Means } & \text { Difference } & \text { T-Value } & \text { P-Value } \\ \text { Aeth } 5 & 11.18 & 4.548 & 2.459 & 0.1001\end{array}$




\section{Appendix B: Regression Analysis for Levoglucosan including High Leverage Events}

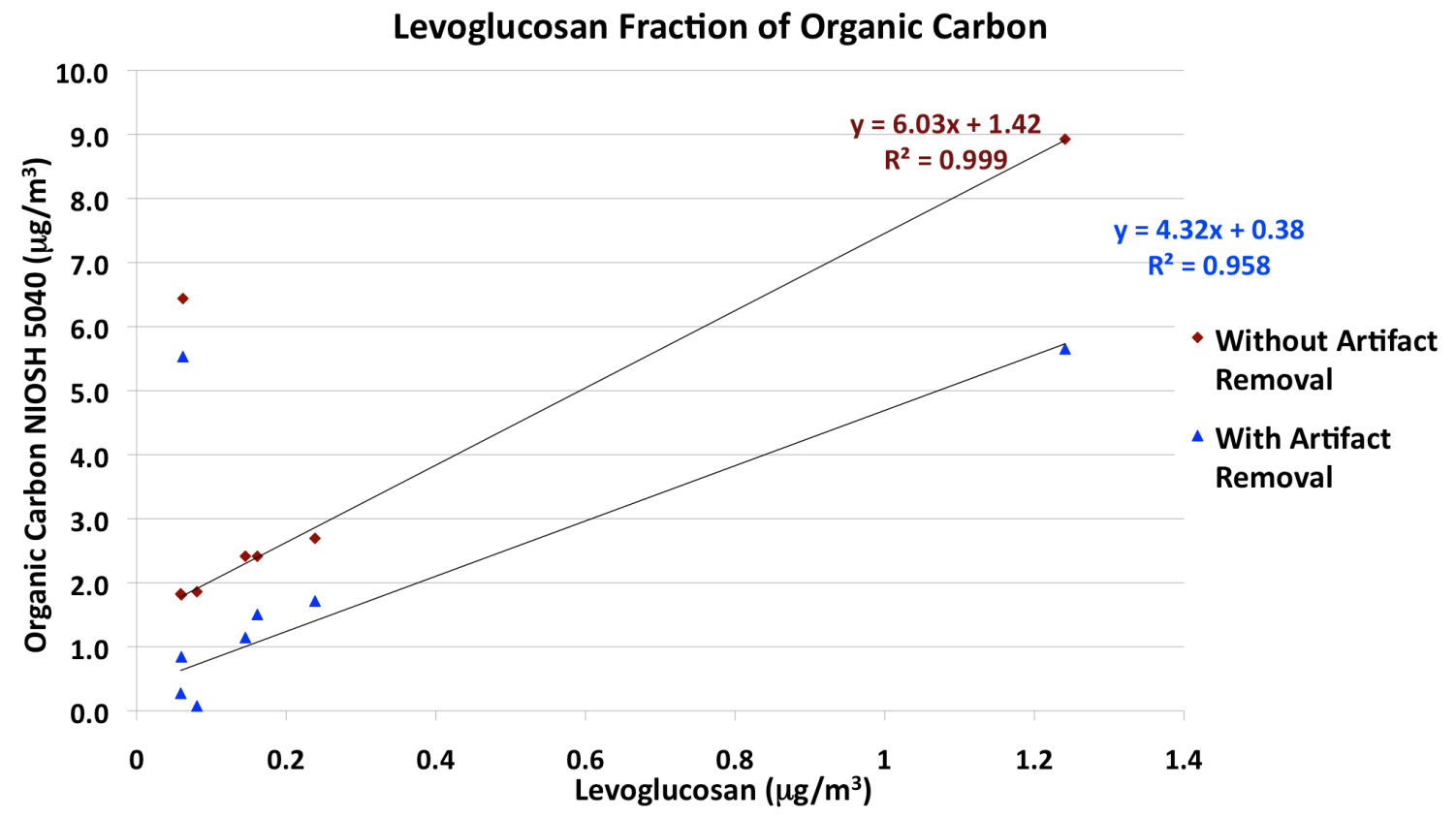

\section{Levoglucosan Fraction of Total Carbon}

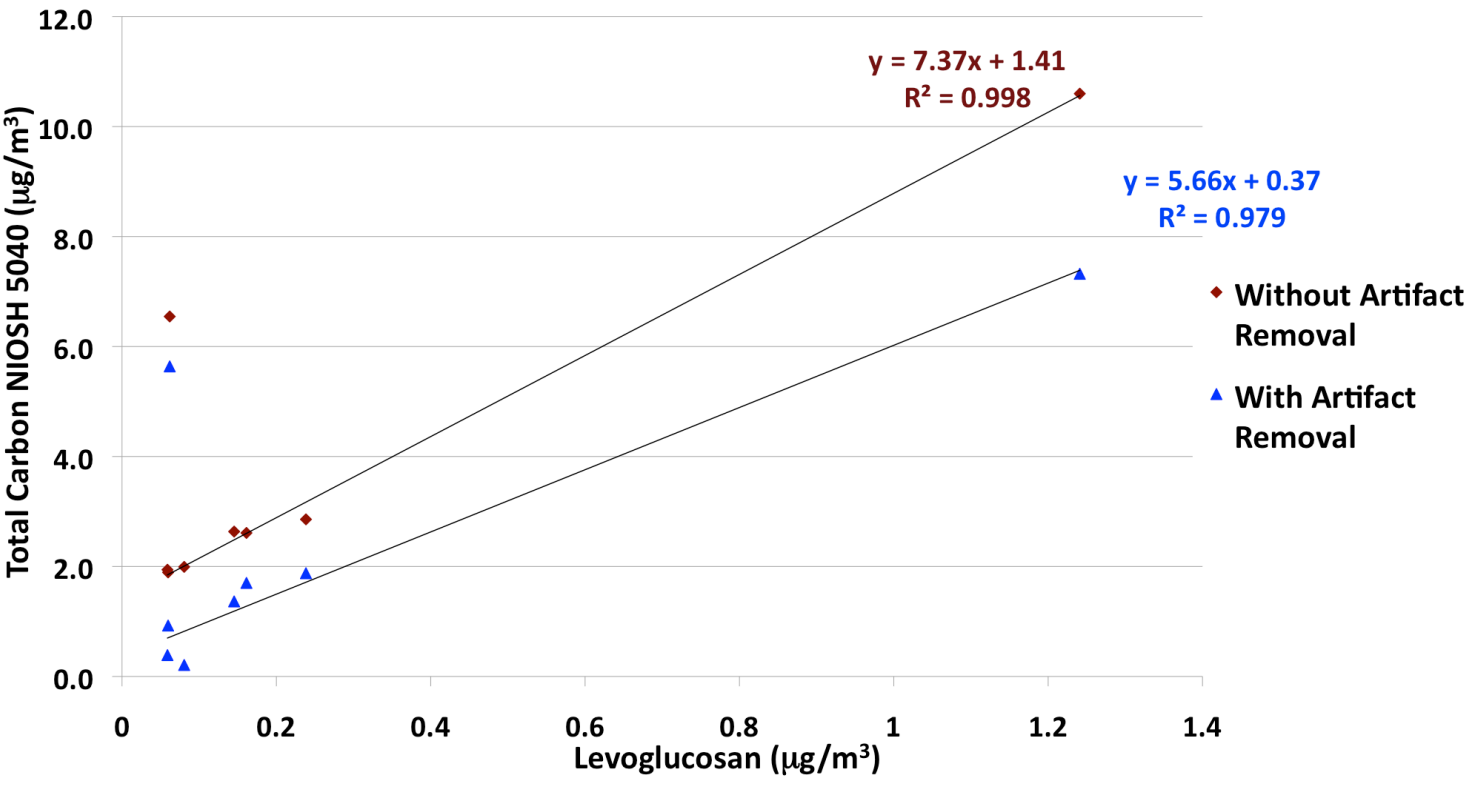


Appendix C: Penetration Factors, Deposition Rates and Air Exchange Rates

\begin{tabular}{|c|c|c|c|c|c|c|}
\hline & Date & $\begin{array}{c}\text { Actual } \\
\text { I/O } \\
\text { Ratio }\end{array}$ & $\begin{array}{l}\text { Predicted } \\
\text { I/O Ratio }\end{array}$ & $\begin{array}{c}\text { Air Exchange } \\
\text { Rate }(1 / \mathrm{hr})\end{array}$ & $\begin{array}{c}\text { Penetration } \\
\text { Factor }\end{array}$ & $\begin{array}{c}\text { Deposition } \\
\text { Rate }(1 / \mathrm{hr})\end{array}$ \\
\hline \multirow{16}{*}{1} & $11 / 30 / 08$ & 0.765 & 0.708 & 0.291 & 1 & 0.120 \\
\hline & $12 / 1 / 08$ & 0.821 & 0.812 & 0.393 & 0.965 & 0.074 \\
\hline & $12 / 2 / 08$ & 0.731 & 0.727 & 0.222 & 0.983 & 0.078 \\
\hline & $12 / 3 / 08$ & 0.781 & 0.770 & 0.448 & 0.940 & 0.099 \\
\hline & $12 / 4 / 08$ & 0.700 & 0.682 & 0.261 & 0.947 & 0.101 \\
\hline & $12 / 5 / 08$ & 0.638 & 0.595 & 0.218 & 0.928 & 0.122 \\
\hline & $12 / 6 / 08$ & 0.753 & 0.739 & 0.484 & 0.849 & 0.072 \\
\hline & $12 / 7 / 08$ & 0.977 & 0.801 & 0.514 & 0.833 & 0.021 \\
\hline & $12 / 8 / 08$ & 0.635 & 0.637 & 0.154 & 0.910 & 0.066 \\
\hline & $1 / 31 / 09$ & 0.742 & 0.747 & 0.411 & 0.854 & 0.059 \\
\hline & $2 / 18 / 09$ & 0.770 & 0.723 & 0.431 & 0.994 & 0.161 \\
\hline & $3 / 11 / 09$ & 0.605 & 0.556 & 0.192 & 1 & 0.154 \\
\hline & $3 / 13 / 09$ & 0.702 & 0.659 & 0.318 & 1 & 0.165 \\
\hline & $3 / 16 / 09$ & 0.786 & 0.848 & 0.428 & 1 & 0.077 \\
\hline & $3 / 17 / 09$ & 0.704 & 0.737 & 0.434 & 1 & 0.155 \\
\hline & $3 / 19 / 09$ & 0.796 & 0.796 & 0.588 & 0.957 & 0.119 \\
\hline \multirow{12}{*}{2} & $12 / 1 / 08$ & 0.821 & 0.777 & 0.453 & 0.777 & 0 \\
\hline & $12 / 2 / 08$ & 0.731 & 0.676 & 0.459 & 0.676 & 0 \\
\hline & $12 / 3 / 08$ & 0.781 & 0.754 & 0.480 & 0.809 & 0.035 \\
\hline & $12 / 7 / 08$ & 0.977 & 0.826 & 0.452 & 0.915 & 0.049 \\
\hline & $12 / 8 / 08$ & 0.635 & 0.710 & 0.420 & 0.710 & 0 \\
\hline & $1 / 31 / 09$ & 0.742 & 0.690 & 0.408 & 0.953 & 0.156 \\
\hline & $2 / 18 / 09$ & 0.770 & 0.704 & 0.386 & 1 & 0.162 \\
\hline & $3 / 11 / 09$ & 0.605 & 0.597 & 0.464 & 0.597 & 0 \\
\hline & $3 / 13 / 09$ & 0.702 & 0.676 & 0.424 & 1 & 0.203 \\
\hline & $3 / 16 / 09$ & 0.786 & 0.854 & 0.471 & 0.854 & 0 \\
\hline & $3 / 17 / 09$ & 0.704 & 0.707 & 0.381 & 0.958 & 0.135 \\
\hline & $3 / 19 / 09$ & 0.796 & 0.742 & 0.411 & 0.980 & 0.132 \\
\hline \multirow{10}{*}{3} & $12 / 2 / 08$ & 0.731 & 0.731 & 0.201 & 1 & 0.074 \\
\hline & $12 / 3 / 08$ & 0.781 & 0.782 & 0.146 & 0.995 & 0.040 \\
\hline & $12 / 4 / 08$ & 0.700 & 0.701 & 0.120 & 1 & 0.051 \\
\hline & $12 / 5 / 08$ & 0.638 & 0.637 & 0.097 & 1 & 0.055 \\
\hline & $12 / 6 / 08$ & 0.753 & 0.752 & 0.128 & 1 & 0.042 \\
\hline & $12 / 7 / 08$ & 0.977 & 0.863 & 0.431 & 0.863 & 0 \\
\hline & $12 / 8 / 08$ & 0.635 & 0.635 & 0.110 & 1 & 0.063 \\
\hline & $1 / 31 / 09$ & 0.742 & 0.741 & 0.315 & 0.968 & 0.096 \\
\hline & $2 / 18 / 09$ & 0.770 & 0.722 & 0.435 & 1 & 0.167 \\
\hline & $3 / 11 / 09$ & 0.605 & 0.620 & 0.309 & 0.917 & 0.148 \\
\hline
\end{tabular}




\begin{tabular}{|r|c|ccccc|}
\hline & Date & $\begin{array}{l}\text { Actual } \\
\text { I/O } \\
\text { Ratio }\end{array}$ & $\begin{array}{l}\text { Predicted } \\
\text { I/O Ratio }\end{array}$ & $\begin{array}{l}\text { Air Exchange } \\
\text { Rate (1/hr) }\end{array}$ & $\begin{array}{l}\text { Penetration } \\
\text { Factor }\end{array}$ & $\begin{array}{l}\text { Deposition } \\
\text { Rate (1/hr) }\end{array}$ \\
\hline Cont 3 & $3 / 11 / 09$ & 0.605 & 0.620 & 0.309 & 0.917 & 0.148 \\
& $3 / 13 / 09$ & 0.702 & 0.702 & 0.297 & 0.988 & 0.121 \\
& $3 / 16 / 09$ & 0.786 & 0.776 & 0.316 & 0.950 & 0.071 \\
& $3 / 17 / 09$ & 0.704 & 0.704 & 0.507 & 0.929 & 0.162 \\
& $3 / 19 / 09$ & 0.796 & 0.797 & 0.183 & 1 & 0.047 \\
\hline \multirow{6}{*}{4} & $12 / 2 / 08$ & 0.731 & 0.560 & 0.459 & 0.560 & 0 \\
& $12 / 3 / 08$ & 0.781 & 0.781 & 0.480 & 0.911 & 0.080 \\
& $12 / 4 / 08$ & 0.700 & 0.679 & 0.509 & 0.679 & 0 \\
& $12 / 5 / 08$ & 0.638 & 0.555 & 0.430 & 0.555 & 0 \\
& $12 / 6 / 08$ & 0.753 & 0.733 & 0.461 & 0.733 & 0 \\
& $12 / 7 / 08$ & 0.977 & 0.930 & 0.452 & 0.930 & 0 \\
& $12 / 8 / 08$ & 0.635 & 0.640 & 0.420 & 0.707 & 0.044 \\
& $1 / 31 / 09$ & 0.742 & 0.741 & 0.408 & 0.741 & 0 \\
& $2 / 18 / 09$ & 0.770 & 0.660 & 0.386 & 0.892 & 0.136 \\
& $3 / 11 / 09$ & 0.605 & 0.687 & 0.464 & 0.687 & 0 \\
& $3 / 13 / 09$ & 0.702 & 0.705 & 0.424 & 0.807 & 0.061 \\
& $3 / 16 / 09$ & 0.786 & 0.789 & 0.482 & 0.907 & 0.072 \\
& $3 / 17 / 09$ & 0.704 & 0.711 & 0.381 & 0.943 & 0.124 \\
$3 / 19 / 09$ & 0.796 & 0.760 & 0.411 & 0.879 & 0.065 \\
\hline
\end{tabular}




\section{Appendix D: LBNL Air Exchange Rate Model}

The Lawrence Berkeley National Laboratory Infiltration model uses atmospheric data, including outside temperature, inside temperature and wind speed, along with topographical data, including whether the area is forested or an unobstructed expanse, to determine the air infiltration into a structure. This section provides a brief introduction into the model and the equations that dominate the forces. Shown below in Eq. D1 is the LBNL model.

$$
\lambda=3600 \frac{A_{\text {Leak }}}{A_{\text {Floor }} H} \sqrt{f_{s}^{2} \Delta T+f_{w}^{2} W^{2}}
$$

$$
\begin{aligned}
& \text { where } A_{\text {leak }}\left(\mathrm{m}^{2}\right) \quad=\text { the total leakage area of the building, } \\
& A_{\text {floor }}\left(\mathrm{m}^{2}\right) \quad=\text { floor area of the building, } \\
& H(\mathrm{~m}) \quad \text { = building height, } \\
& f_{s}\left(\mathrm{~ms}^{-1} \mathrm{~K}^{1 / 2}\right) \quad=\text { the stack parameter determined by the geometry of the } \\
& \Delta T(\mathrm{~K}) \quad=\text { absolute temperature difference, } \\
& f_{w} \text { (unitless) } \quad=\text { the wind factor determined environmental shielding, and } \\
& W(\mathrm{~m} / \mathrm{s}) \quad=\text { the wind speed. }
\end{aligned}
$$

There are two parameters that when multiplied by external factors arrive at an infiltration rate: (1) stack parameter, $f_{s}$ and (2) wind factor, $f_{w}$. An indoor/outdoor temperature difference creates a pressure gradient whose magnitude is related to the geometry of the structure. The stack parameter is determined by the fractions of air 
leakage through the ceiling, floor and walls and the height of the building. Below in Eq. $\mathrm{D} 2$ is the stack parameter equation.

$$
f_{s}=\left(\frac{1+R / 2}{3}\right)\left(1-\frac{X^{2}}{(2-R)^{2}}\right)^{3 / 2}\left(\frac{g H}{T_{o}}\right)^{1 / 2}
$$

$$
\begin{array}{ll}
\text { where } R \text { (unitless) } & =(a+b) /(a+b+w), \\
X \text { (unitless) } & =(a-b) /(a+b+w), \\
a\left(\mathrm{~m}^{2}\right) & =\text { ceiling leakage area, } \\
b\left(\mathrm{~m}^{2}\right) & =\text { floor leakage area, } \\
w\left(\mathrm{~m}^{2}\right) & =\text { wall leakage area, } \\
H(\mathrm{~m}) & =\text { height of the building } \\
g\left(\mathrm{~m} / \mathrm{s}^{2}\right) & =\text { gravitational constant, } 9.81 \\
T_{o}(\mathrm{~K}) & =\text { reference temperature, } 298
\end{array}
$$

Determining the individual leakage areas can be difficult, but can be estimated based on the construction. For example, a slab on grade home is assumed to have no flow through the floor, thus $b=0$ and $X=R$. Wind pressure on a building also creates a pressure gradient between a home and the outside. The terrain around the building determines the extent of the pressure gradient. The wind factor is shown in Eq. D3.

$$
f_{w}=C(1-R)^{1 / 3} A\left(\frac{H}{10}\right)^{B}
$$


where, A and B (unitless), refer to the terrain class surrounding the building and $\mathrm{C}$ (unitless) refers to the shielding provided by obstructions around the home. A table of the values can be found in Table D1.

Table D1: LBNL infiltration model wind factor terrain and shielding constants

\begin{tabular}{|c|c|c|c|}
\hline Class & \multicolumn{2}{|c|}{ Model Constants } & \multirow[t]{2}{*}{ Description } \\
\hline Terrain & $A$ & $\mathrm{~B}$ & \\
\hline 1 & 1.3 & 0.1 & $\begin{array}{l}\text { Ocean or body of water with at } \\
\text { least } 5 \mathrm{~km} \text { of unrestricted } \\
\text { expanse }\end{array}$ \\
\hline 2 & 1 & 0.15 & $\begin{array}{l}\text { Flat terrain with some isolated } \\
\text { obstacles }\end{array}$ \\
\hline 3 & 0.85 & 0.2 & $\begin{array}{l}\text { Rural areas with low } \\
\text { buildings/trees }\end{array}$ \\
\hline 4 & 0.67 & 0.25 & $\begin{array}{l}\text { Urban, industrial or forested } \\
\text { area }\end{array}$ \\
\hline 5 & 0.47 & 0.35 & Center of large city \\
\hline Shielding & $\mathrm{C}$ & & \\
\hline 1 & 0.34 & & $\begin{array}{l}\text { No obstructions or local } \\
\text { shielding }\end{array}$ \\
\hline 2 & 0.3 & & $\begin{array}{l}\text { Light local shielding with few } \\
\text { obstructions }\end{array}$ \\
\hline 3 & 0.25 & & $\begin{array}{l}\text { Moderate local shielding, some } \\
\text { obstructions within two house } \\
\text { heights }\end{array}$ \\
\hline 4 & 0.19 & & $\begin{array}{l}\text { Heavy shielding, obstructions } \\
\text { around most of the perimeter }\end{array}$ \\
\hline 5 & 0.11 & & $\begin{array}{l}\text { Very heavy shielding, large } \\
\text { obstructions surrounding } \\
\text { perimeter within two house } \\
\text { heights }\end{array}$ \\
\hline
\end{tabular}




\section{Sample Calculation}

If leakage area is equal for floor, ceiling and wall, then $\mathrm{a}=\mathrm{b}=\mathrm{w}$ and

$\mathrm{R}=.667$

$\mathrm{X}=0$

Calculating $f_{\underline{s}}$

$$
\begin{gathered}
f_{s}=\left(\frac{1+0.667 / 2}{3}\right)\left(1-\frac{0^{2}}{(2-.667)^{2}}\right)^{3 / 2}\left(\frac{9.81 * 2.5}{298}\right)^{1 / 2} \\
f_{s}=0.129 \mathrm{~m} \cdot \mathrm{s}^{-1} \cdot \mathrm{K}^{-1 / 2}
\end{gathered}
$$

Calculating $f_{\underline{w}}$

$$
\begin{aligned}
& f_{w}=0.19 *(1-0.667)^{1 / 3} * 0.67 *\left(\frac{2.5}{10}\right)^{0.25} \\
& f_{w}=0.0624
\end{aligned}
$$

If the temperature difference between inside and outside is $8^{\circ} \mathrm{C}$ and the wind speed is $6.3 \mathrm{~m} / \mathrm{s}$ then

$$
\begin{gathered}
\lambda=3600 * \frac{(0.00073)}{2.5} \sqrt{0.128^{2} *(8)+0.0624^{2} *(6.3)} \\
\lambda=0.563 \mathrm{hr}^{-1}
\end{gathered}
$$


Appendix E: Detailed Burnina Events and Reqional Data used in LBNL AER Model Actual Indoor and Outdoor BC Concentrations on November $30^{\text {th }}$ -

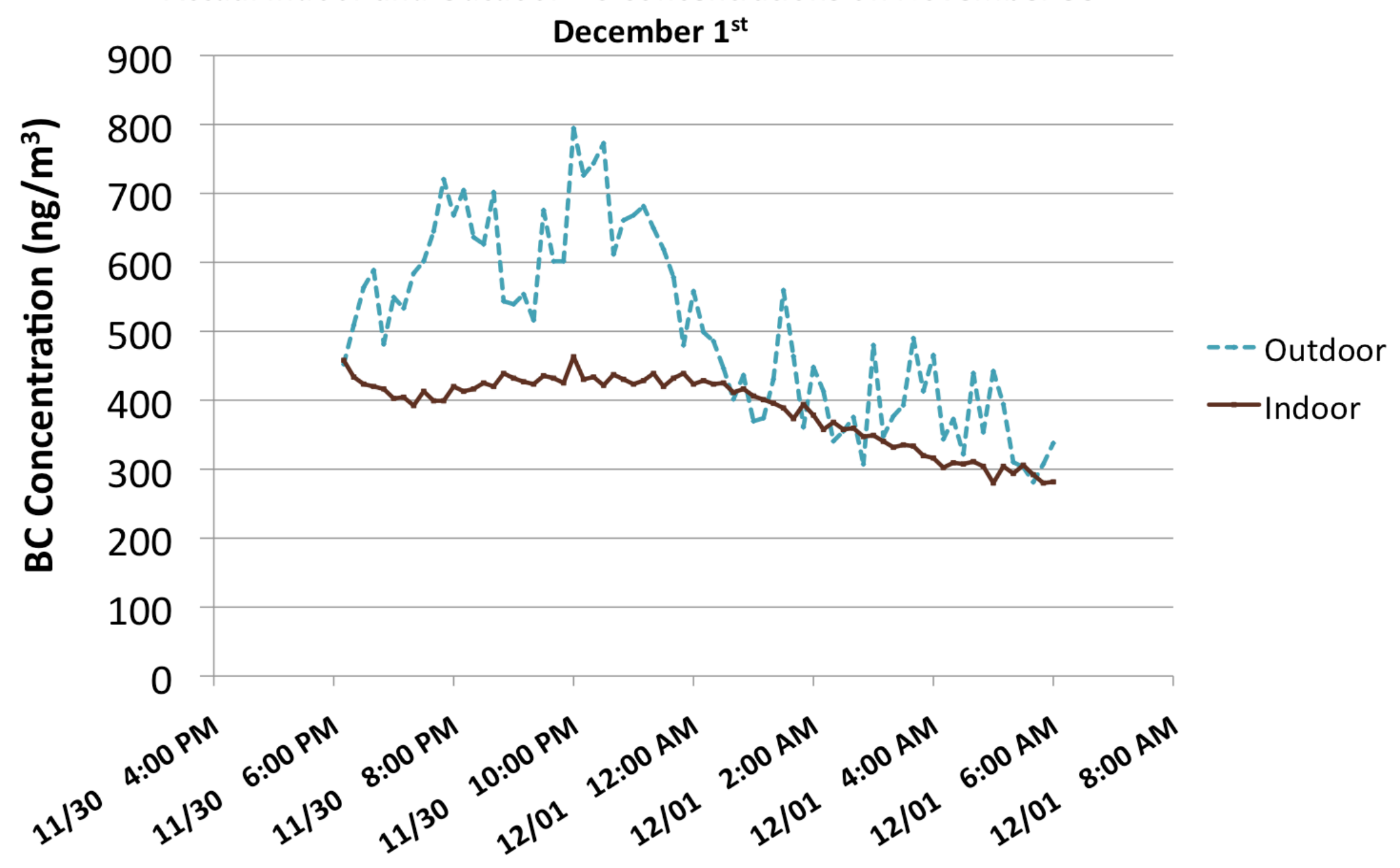


Regional Temperature/Windspeed and the Corresponding Air Exchange Rate for 11/30/08-12/01/08

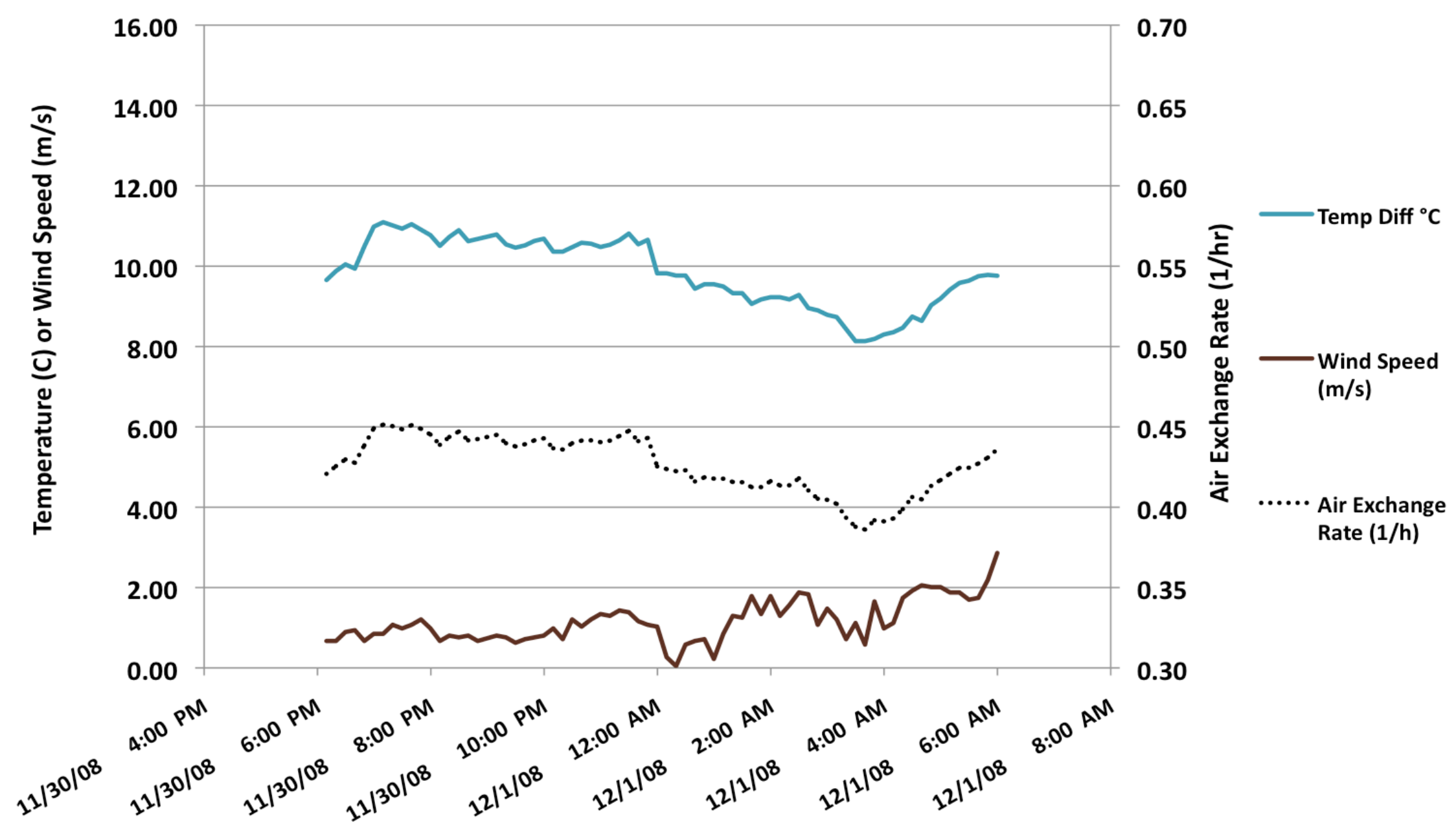


Actual Indoor and Outdoor BC Concentrations on December $1^{\text {st }}-2^{\text {nd }}$

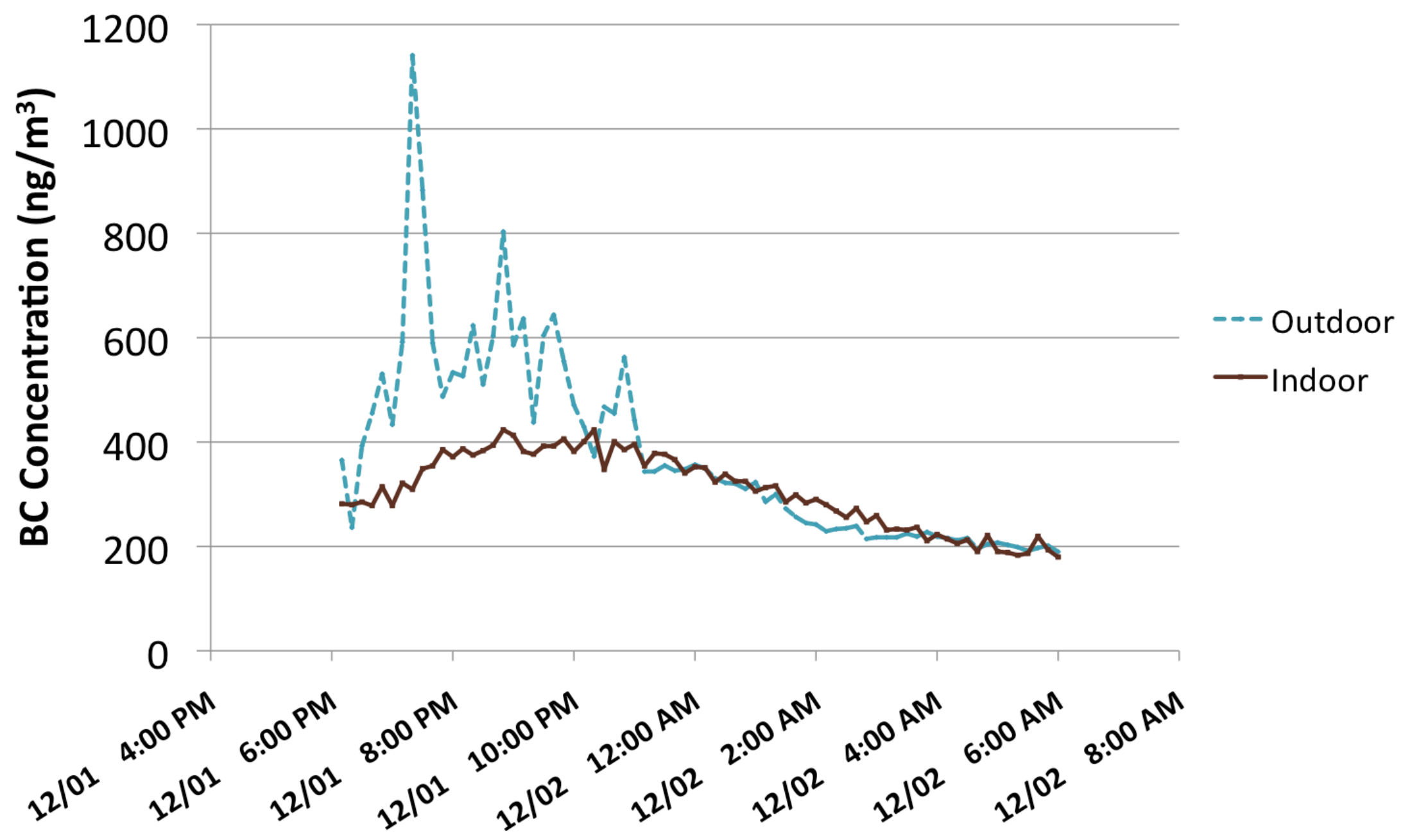


Regional Temperature/Windspeed and the Corresponding Air Exchange Rate for 12/01/08-12/02/08

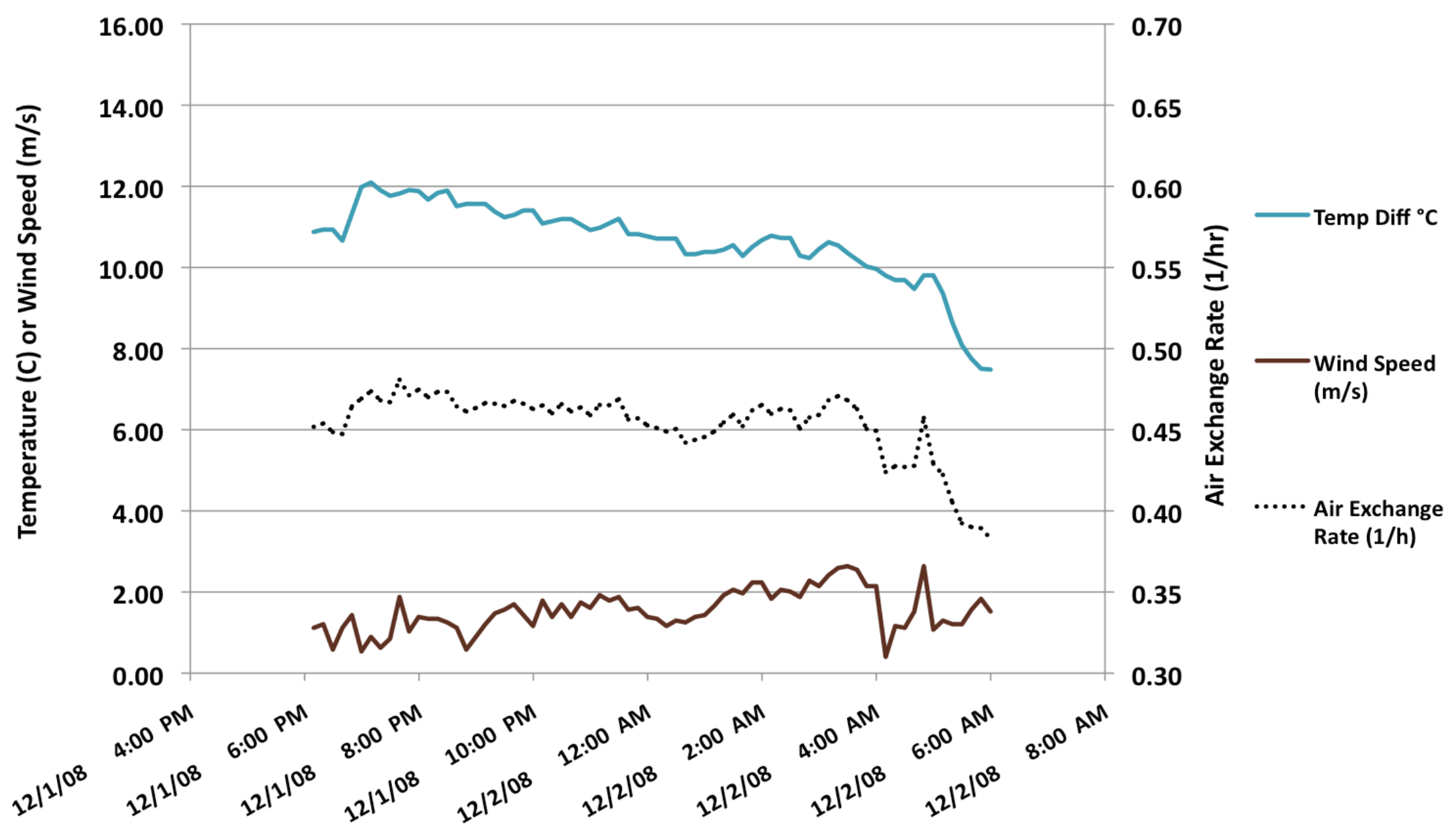


Actual Indoor and Outdoor BC Concentrations on December $2^{\text {nd }}-3^{\text {rd }}$

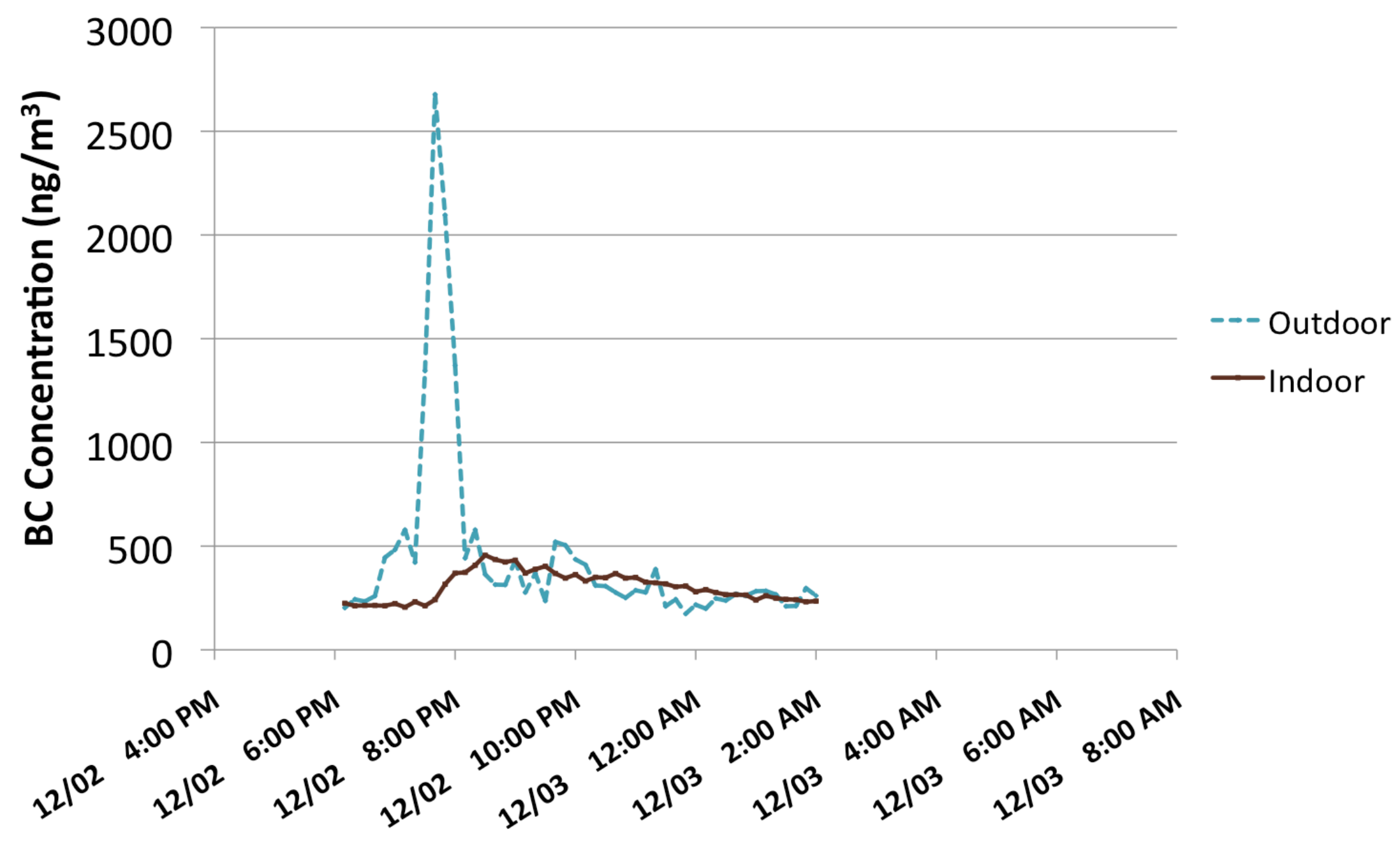


Regional Temperature/Windspeed and the Corresponding Air Exchange Rate for 12/02/08-12/03/08

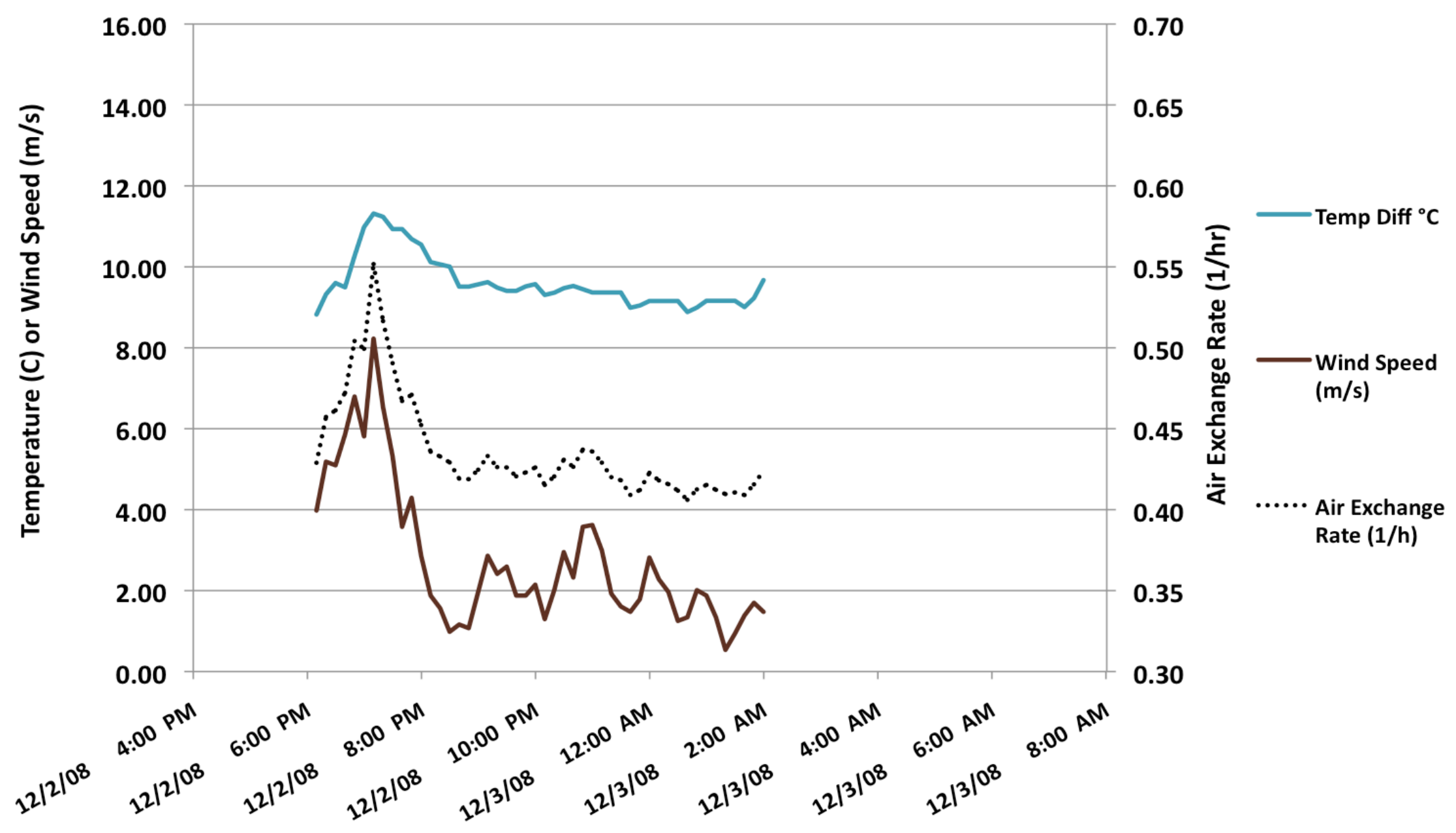


Actual Indoor and Outdoor BC Concentrations on December $3^{\text {rd }} 4^{\text {th }}$

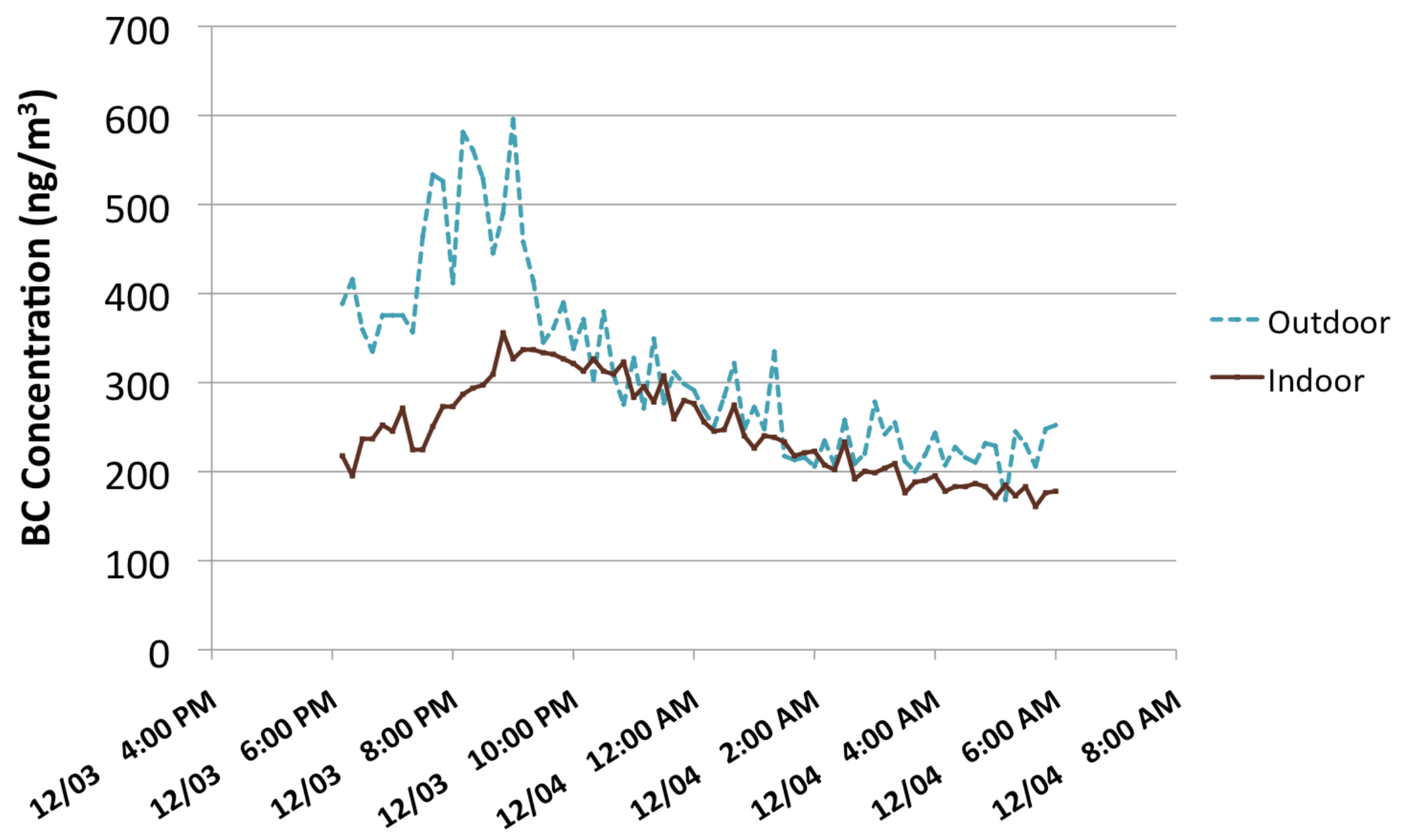


Regional Temperature/Windspeed and the Corresponding Air Exchange Rate for $12 / 03 / 08-12 / 04 / 08$

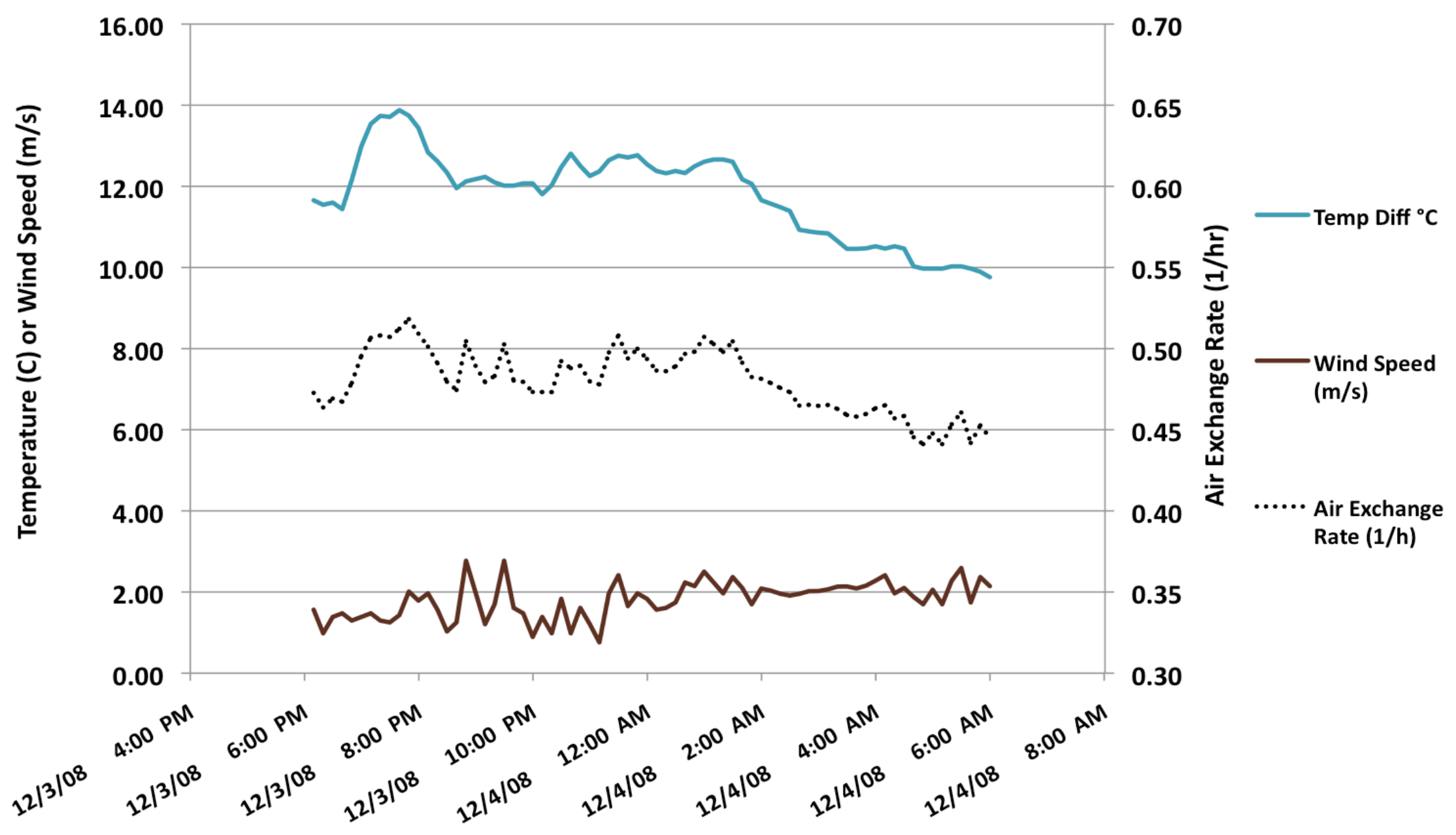


Actual Indoor and Outdoor BC Concentrations on December $4^{\text {th }}-5^{\text {th }}$

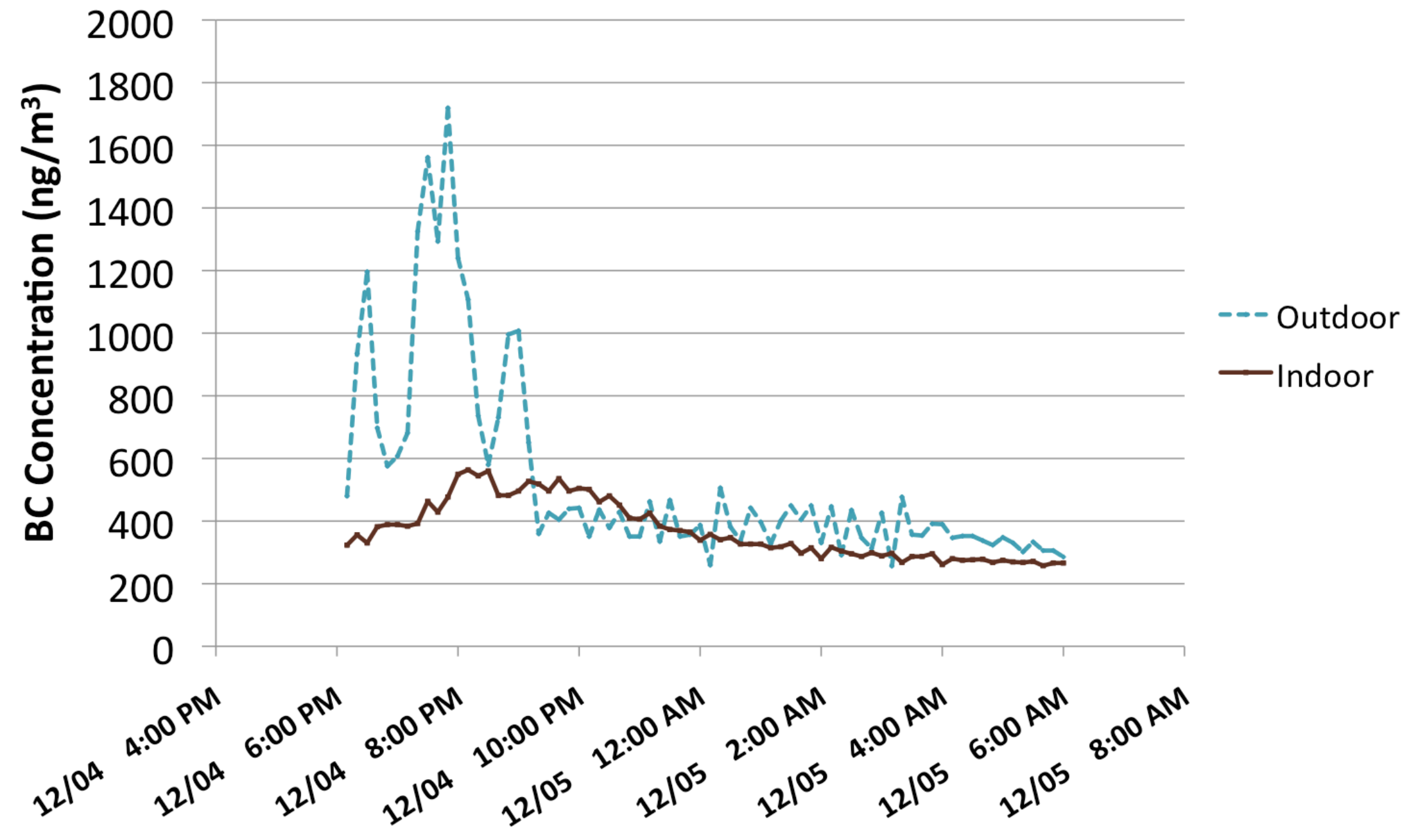


Regional Temperature/Windspeed and the Corresponding Air Exchange Rate for 12/04/08-12/05/08

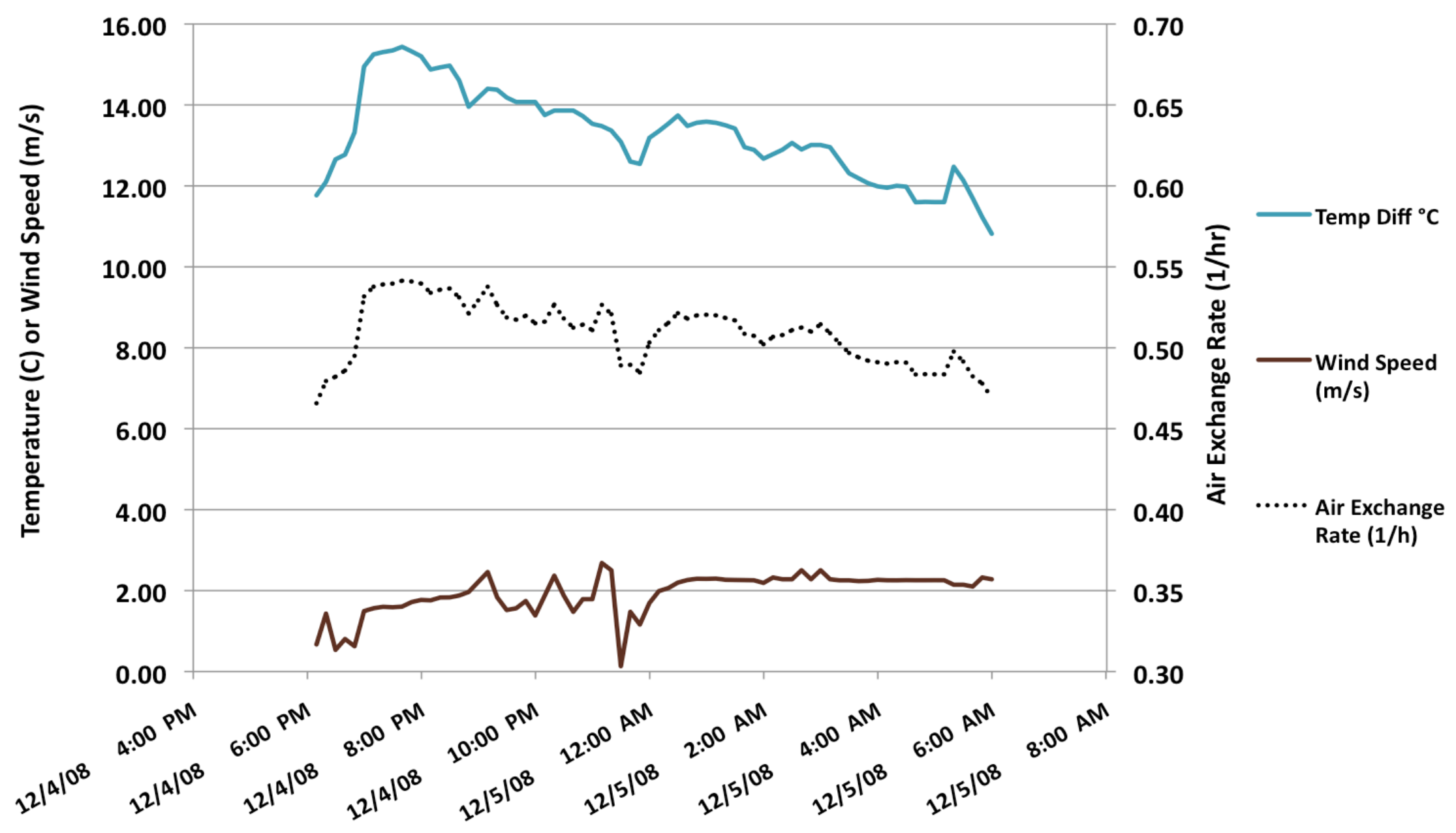


Actual Indoor and Outdoor BC Concentrations on December $5^{\text {th }}-6^{\text {th }}$

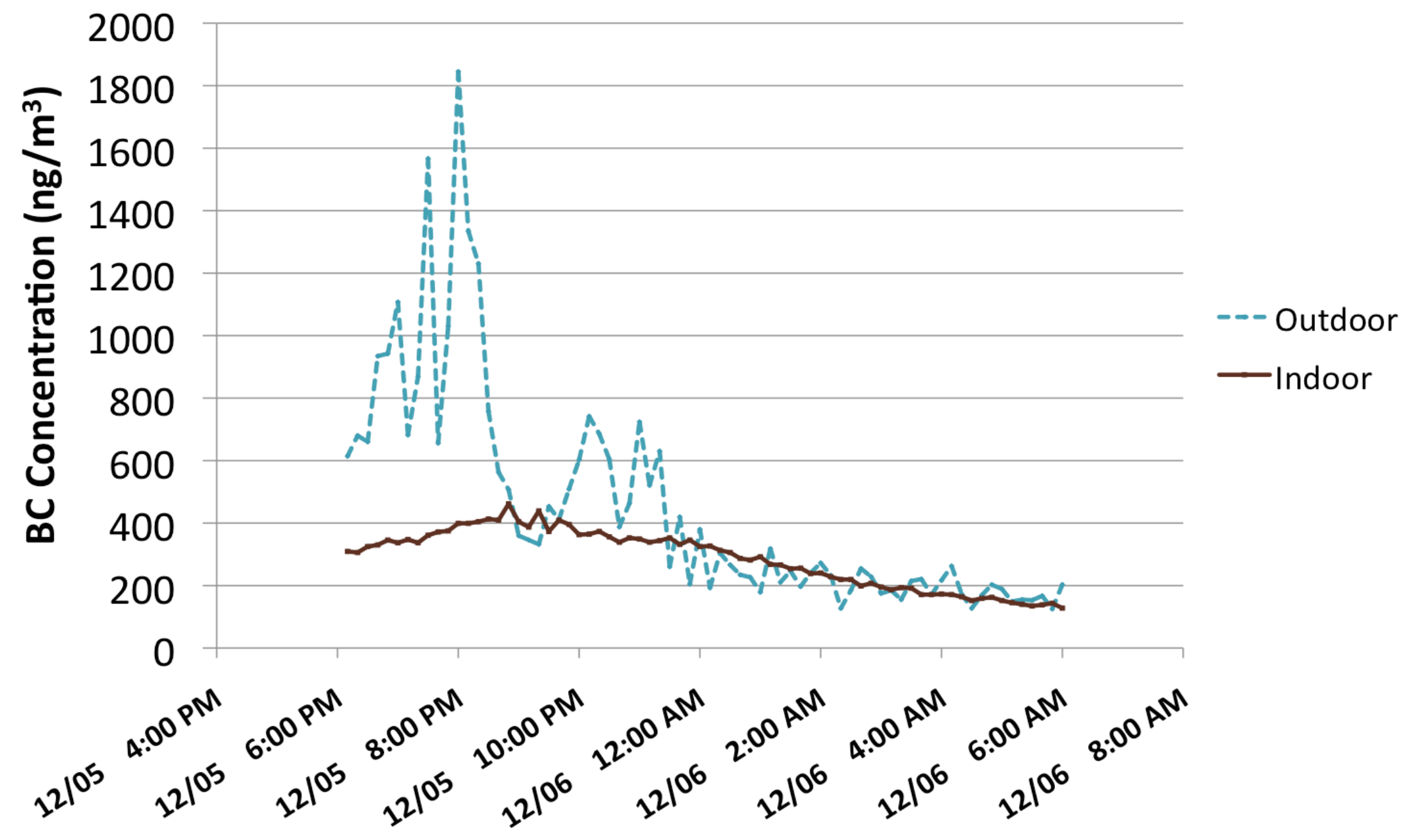


Regional Temperature/Windspeed and the Corresponding Air Exchange Rate for 12/05/08-12/06/08

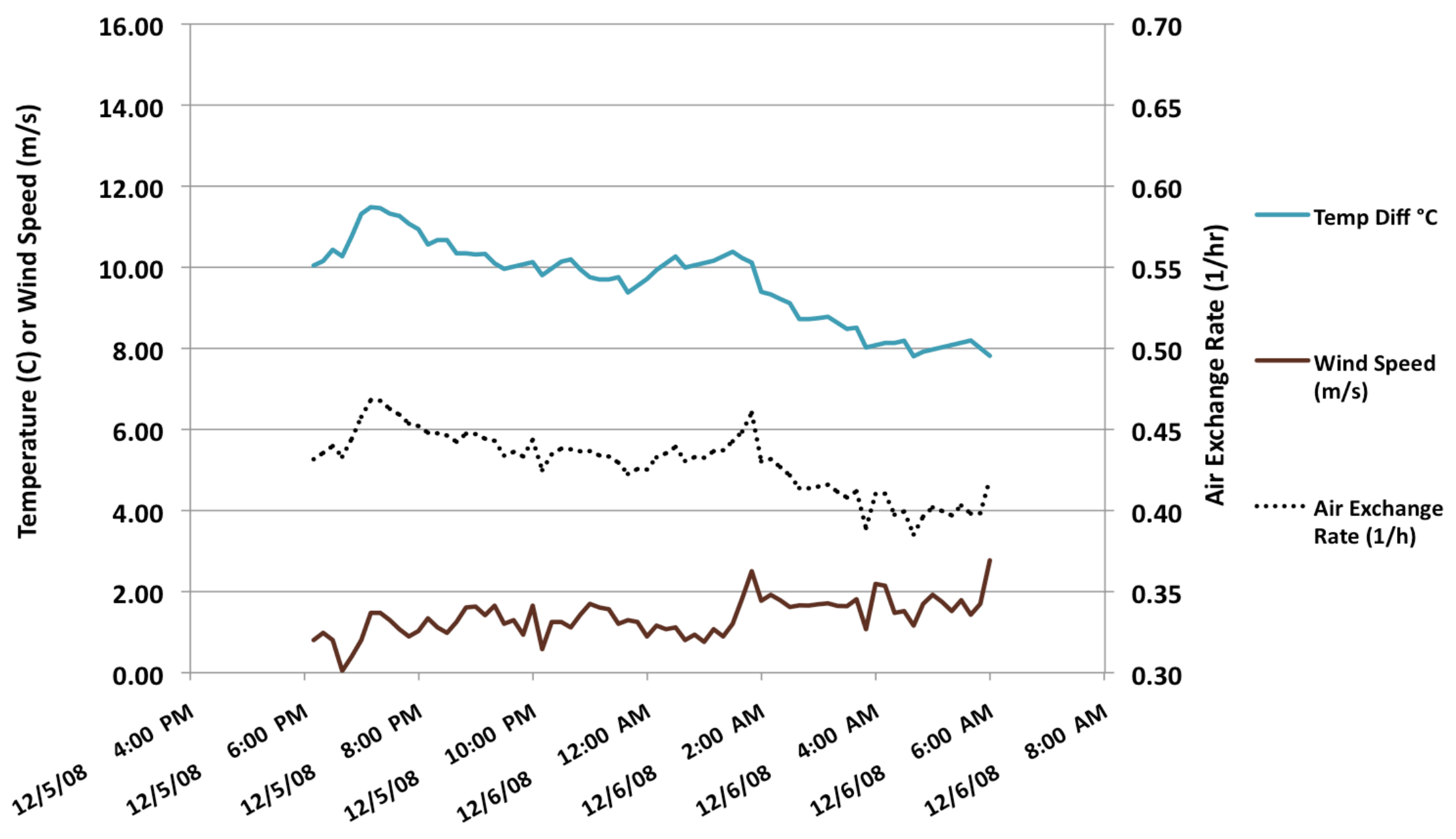


Actual Indoor and Outdoor BC Concentrations on December $6^{\text {th }}-7^{\text {th }}$

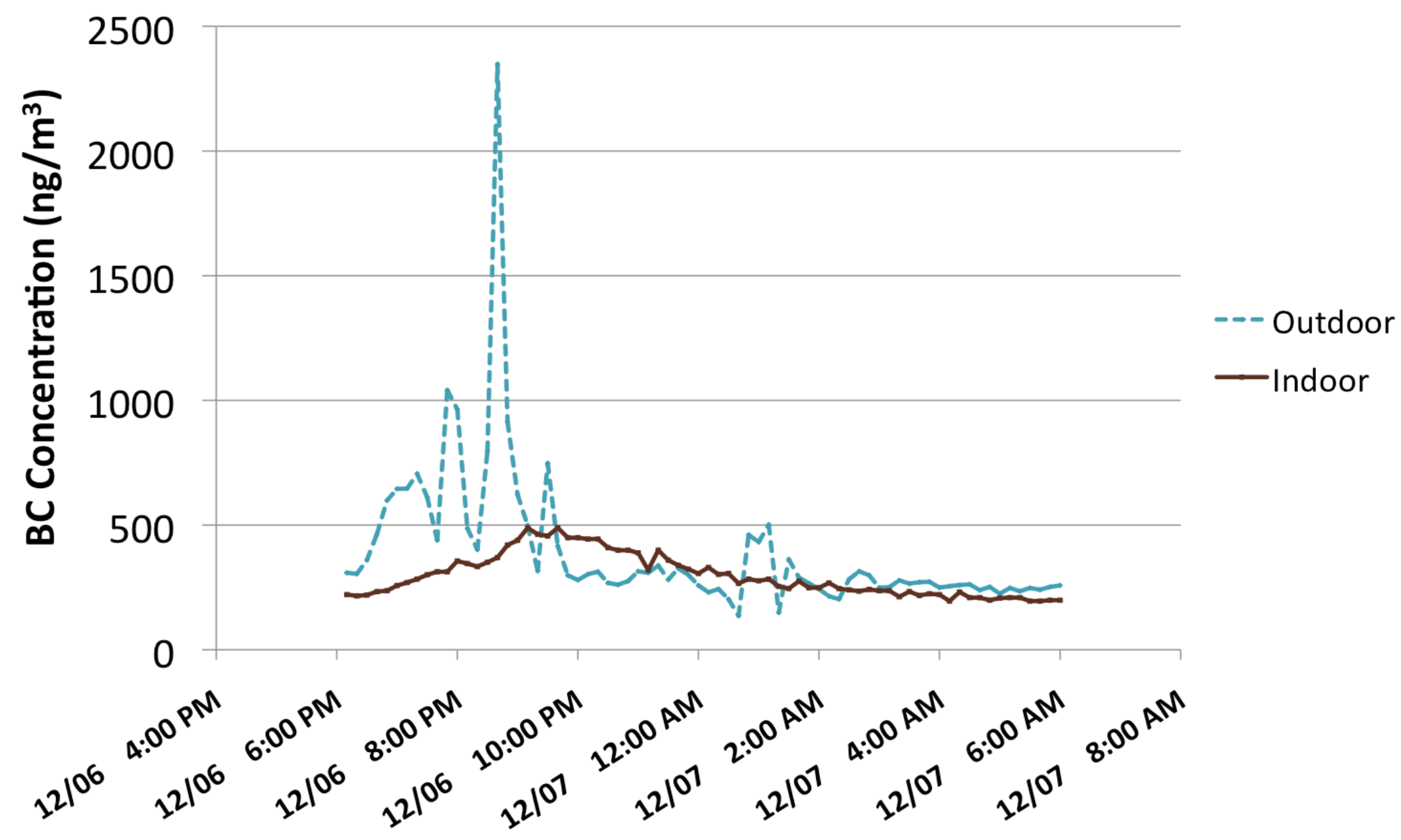


Regional Temperature/Windspeed and the Corresponding Air Exchange Rate for 12/06/08-12/07/08

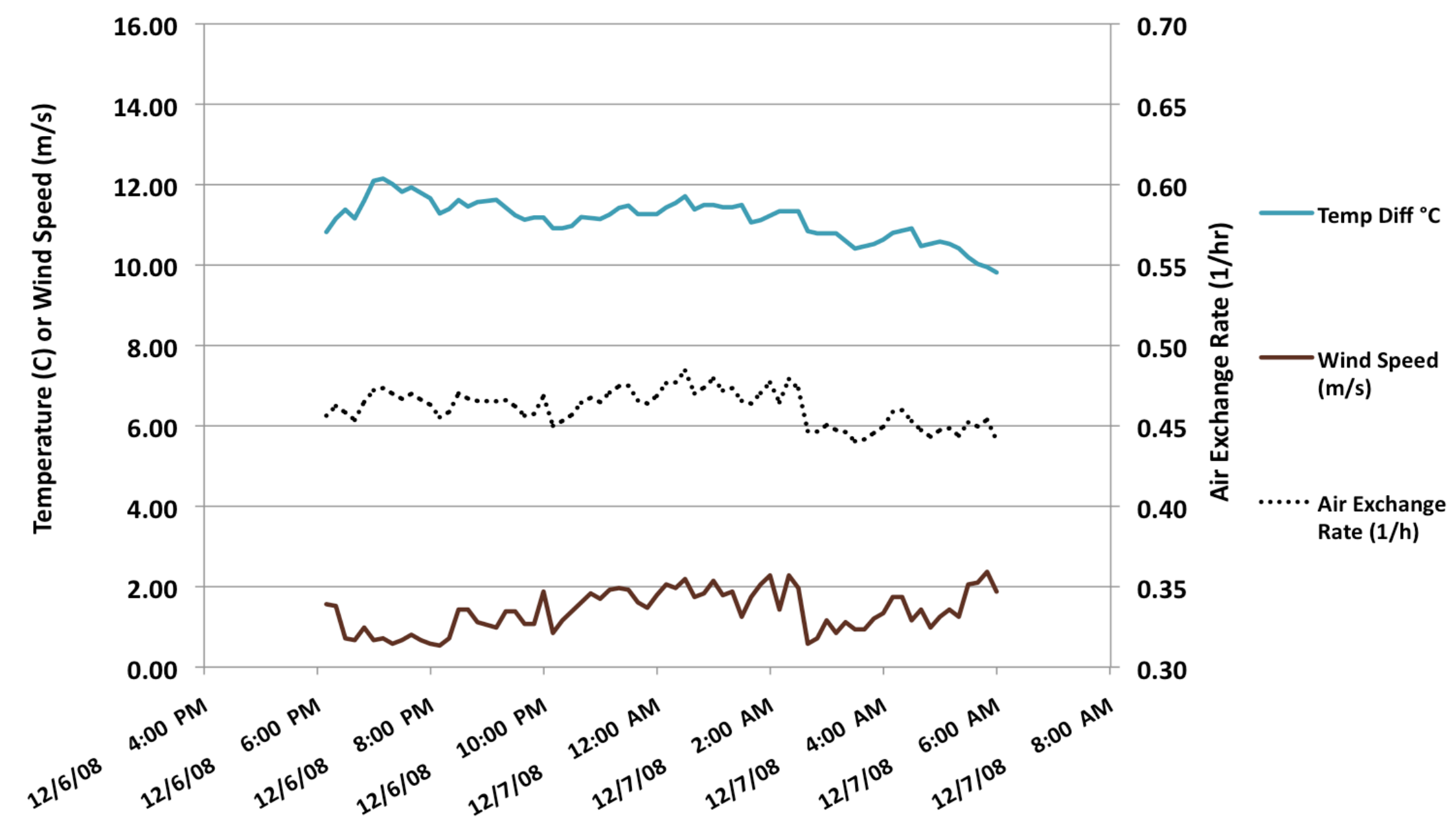


Actual Indoor and Outdoor BC Concentrations on December $7^{\text {th }}-8^{\text {th }}$

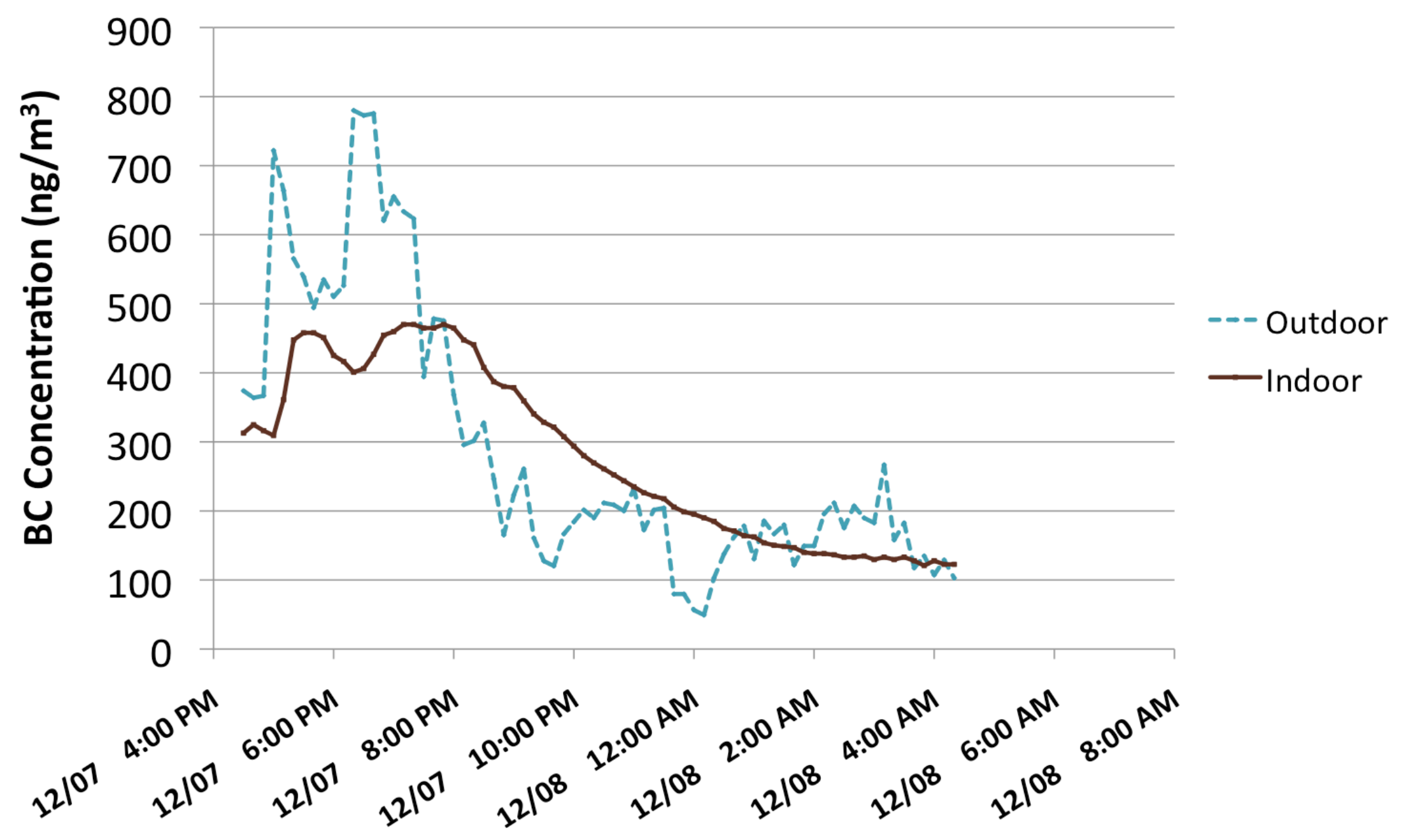


Regional Temperature/Windspeed and the Corresponding Air Exchange Rate for $12 / 07 / 08-12 / 08 / 08$

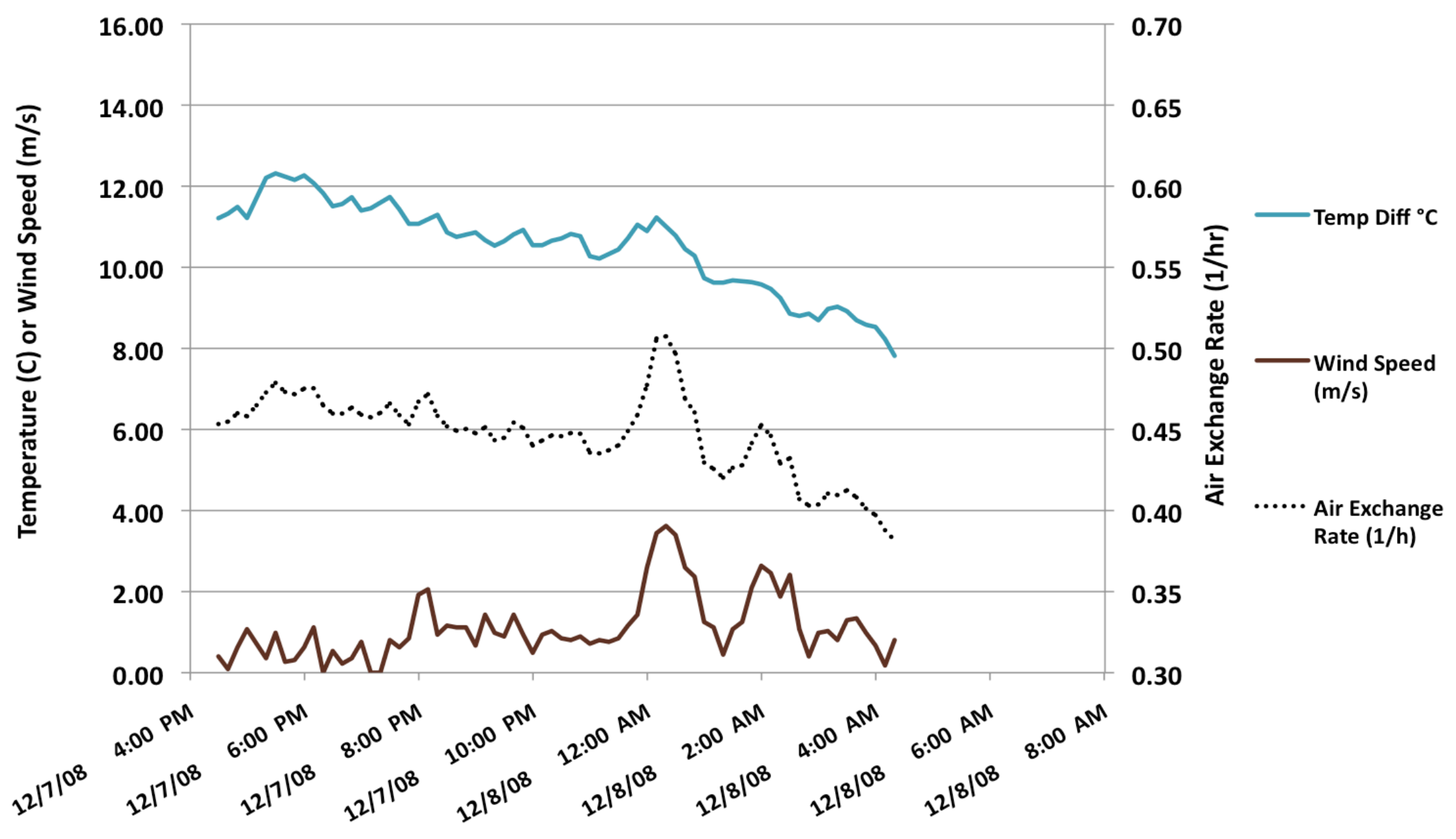


Actual Indoor and Outdoor BC Concentrations on December $8^{\text {th }}-9^{\text {th }}$

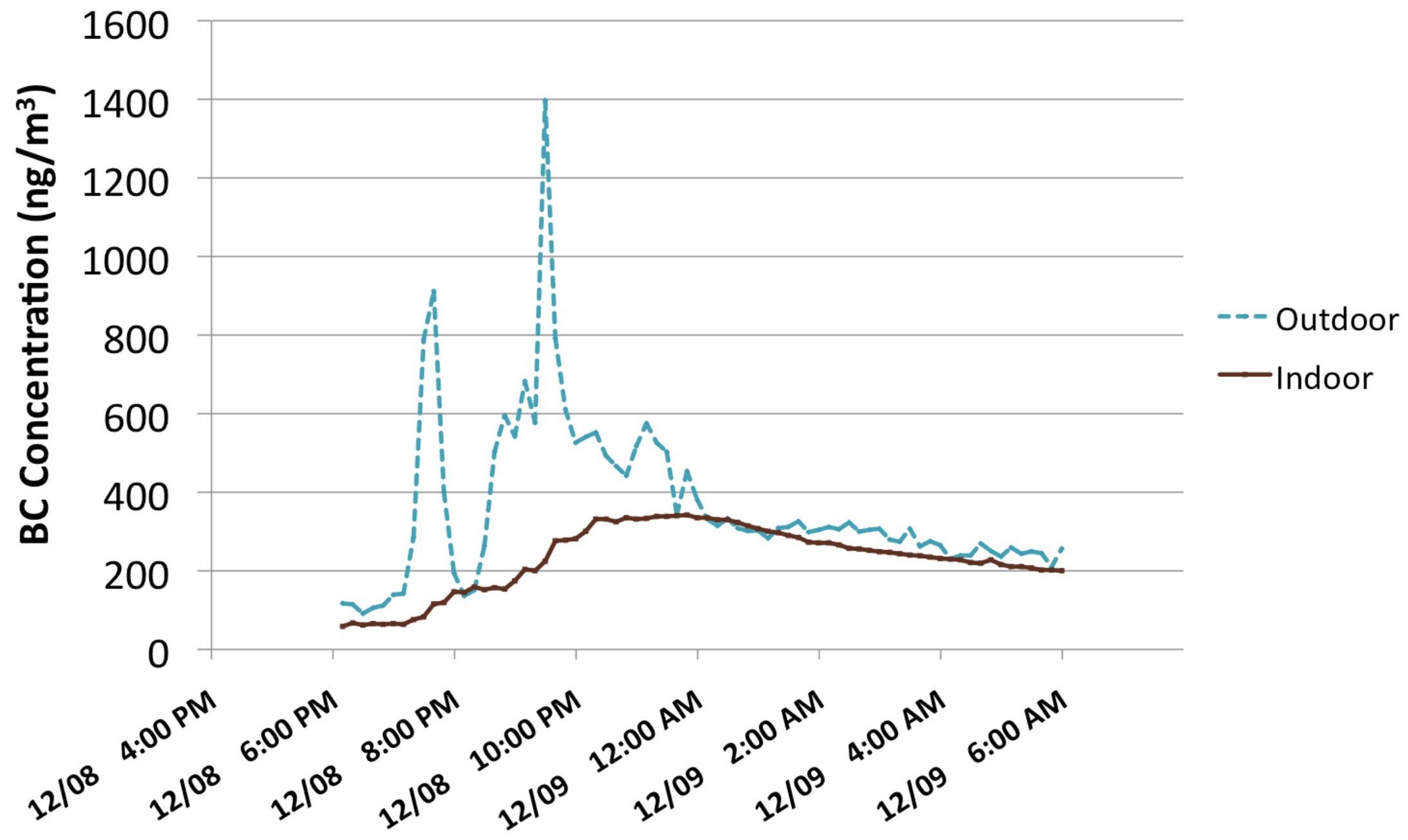


Regional Temperature/Windspeed and the Corresponding Air Exchange Rate for 12/08/08-12/09/08

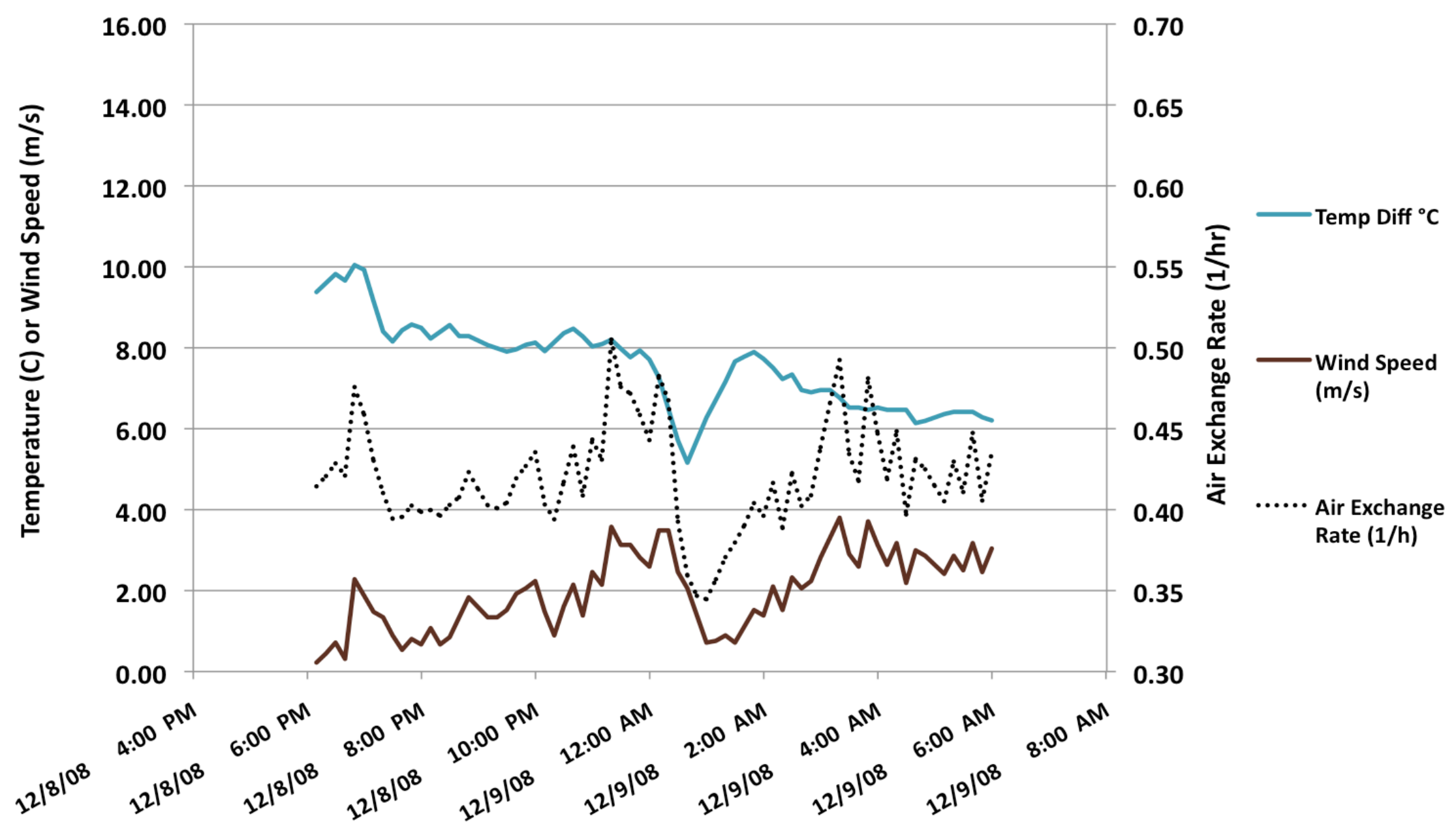


Actual Indoor and Outdoor BC Concentrations on January $31^{\text {st }}$ - February $1^{\text {st }}$

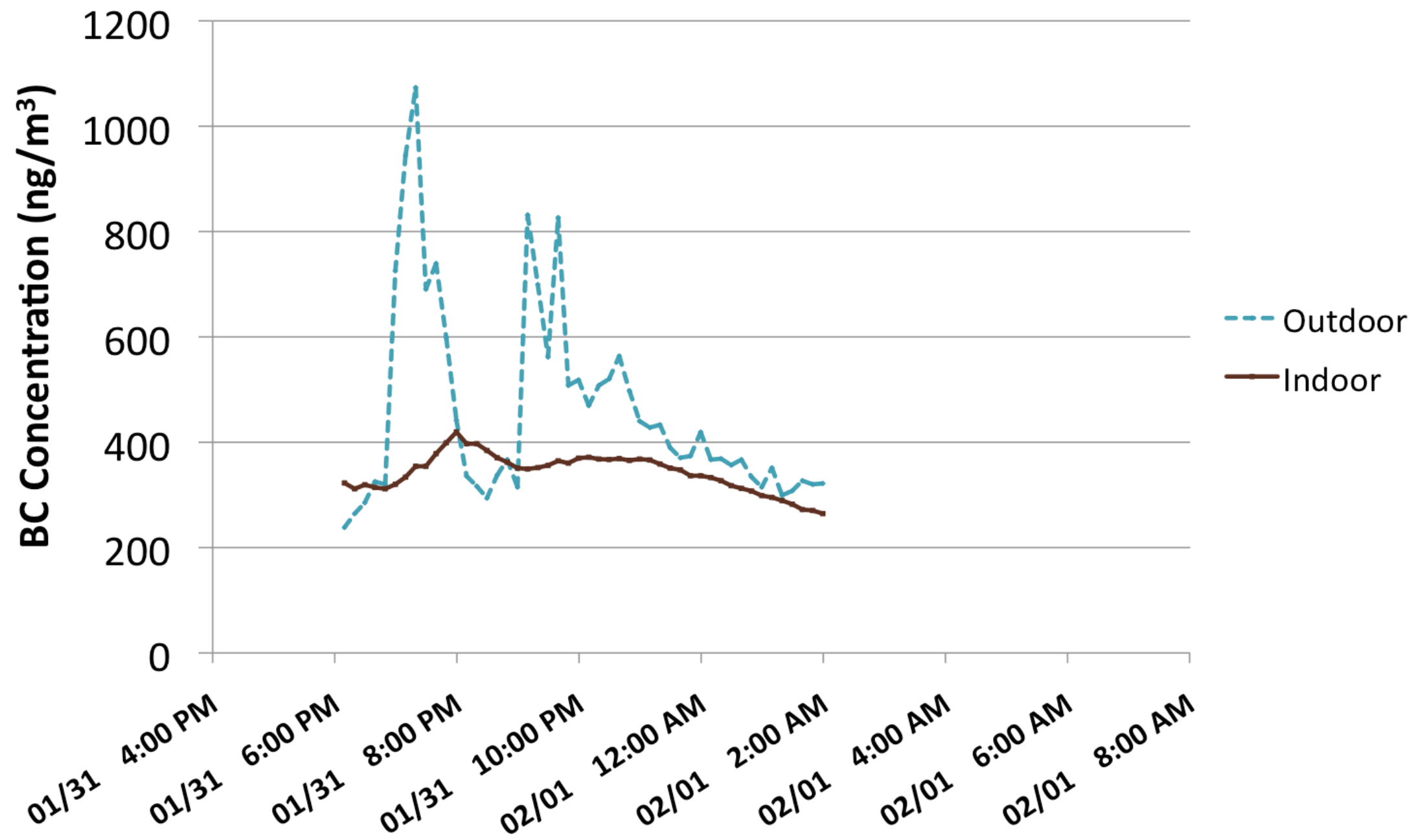


Regional Temperature/Windspeed and the Corresponding Air Exchange Rate for 01/31/09-02/01/09

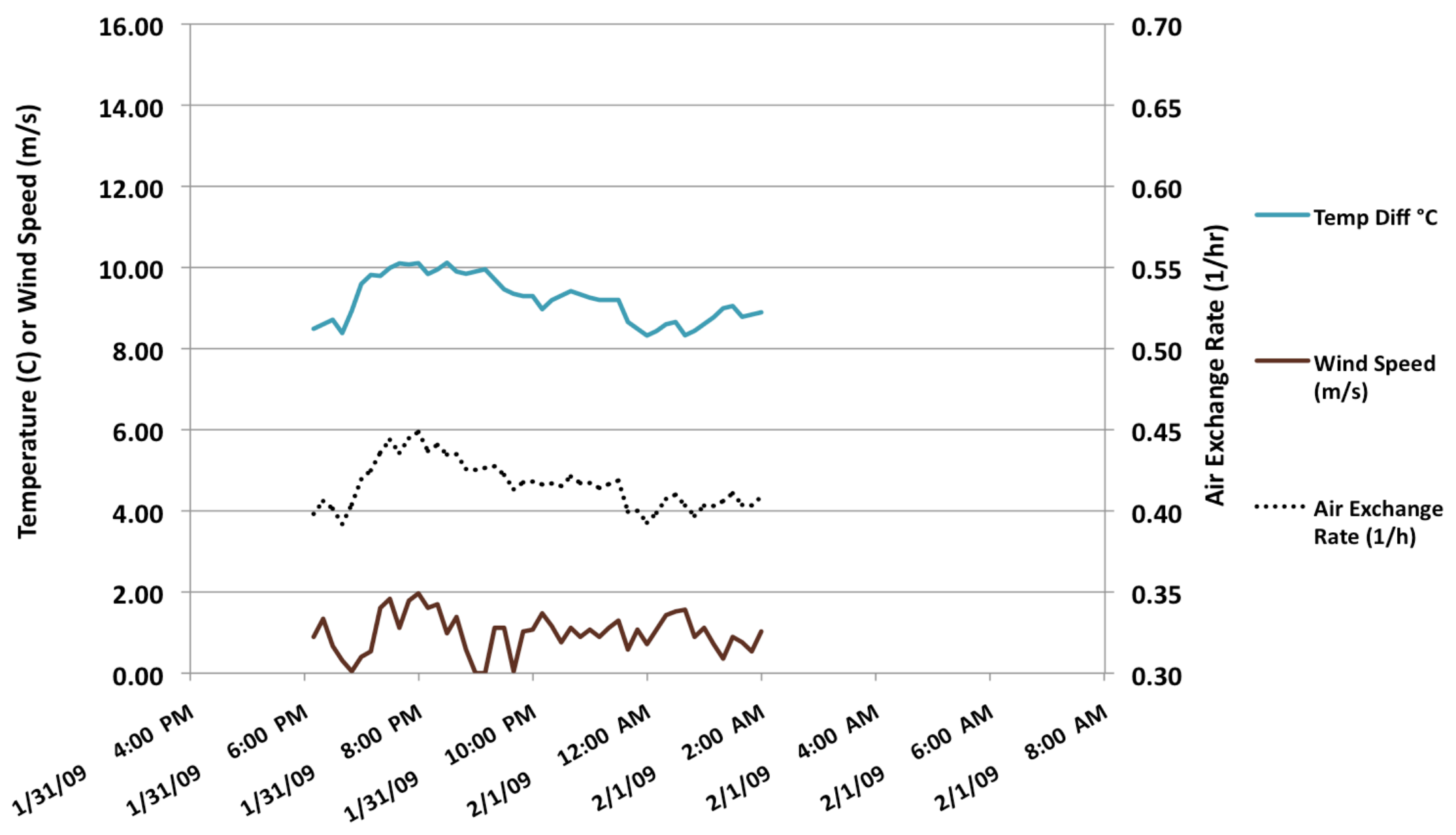


Actual Indoor and Outdoor BC Concentrations on February $18^{\text {th }}-19^{\text {th }}$

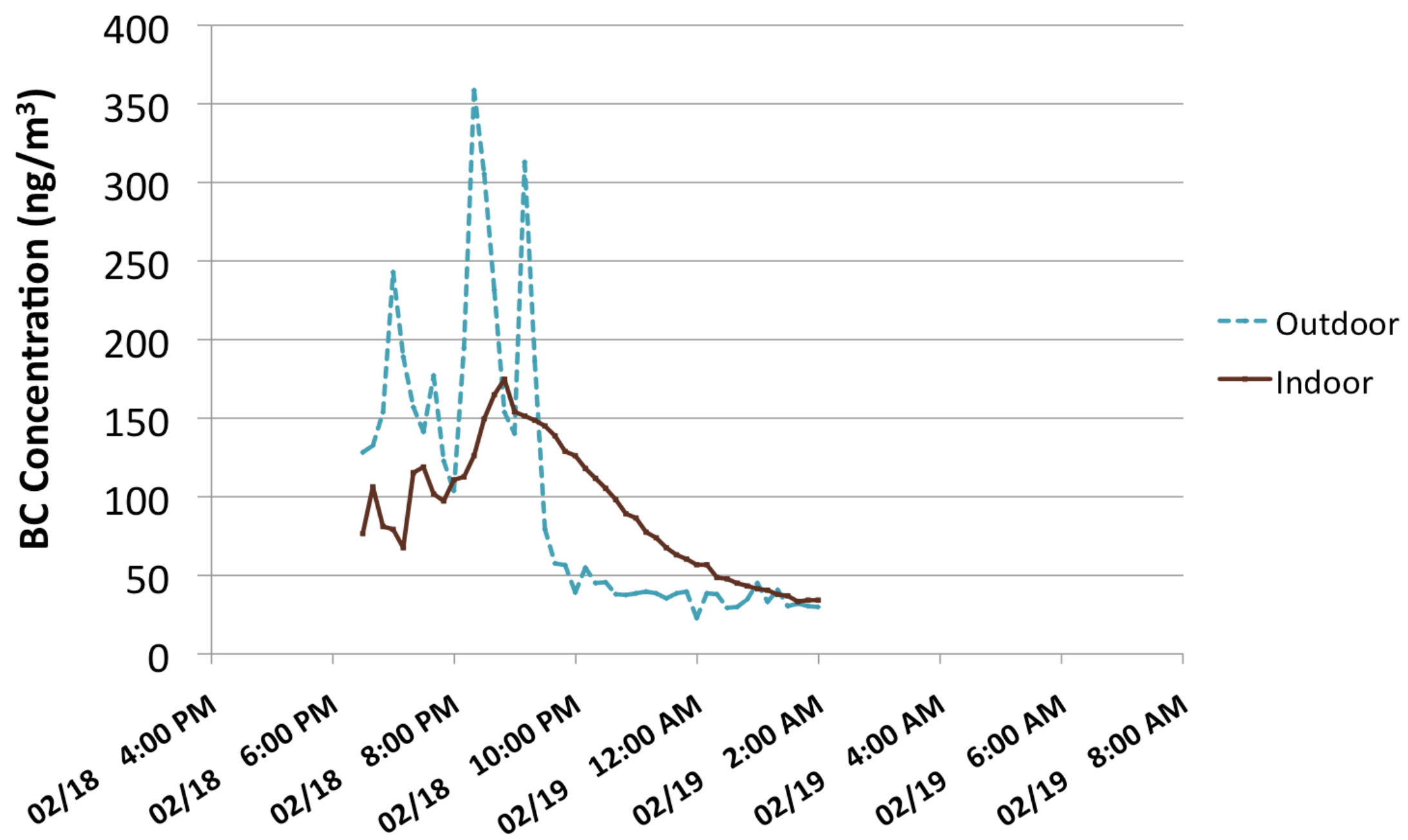


Regional Temperature/Windspeed and the Corresponding Air Exchange Rate for 02/18/09-02/19/09

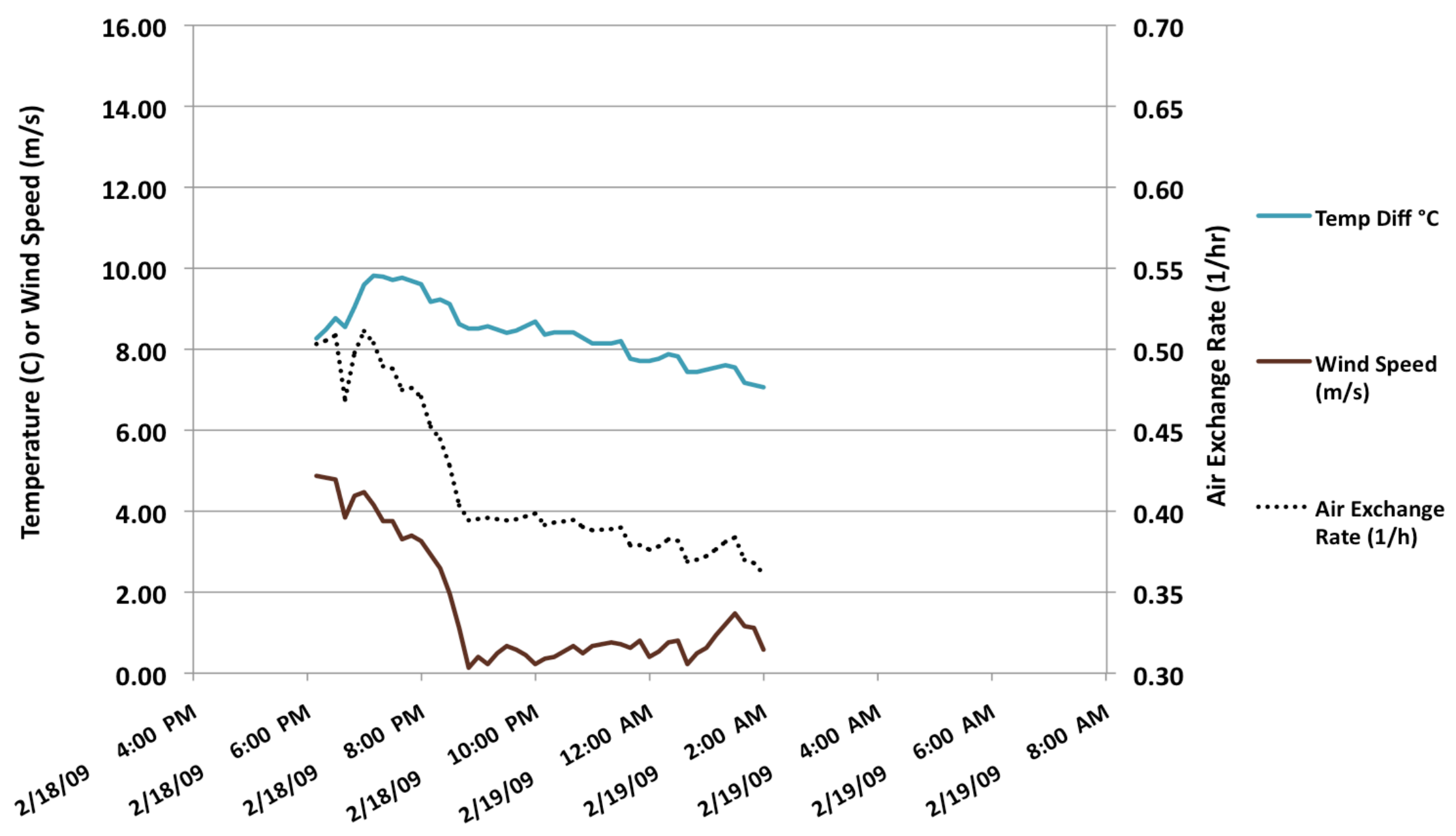


Actual Indoor and Outdoor BC Concentrations on March $11^{\text {th }}-12^{\text {th }}$

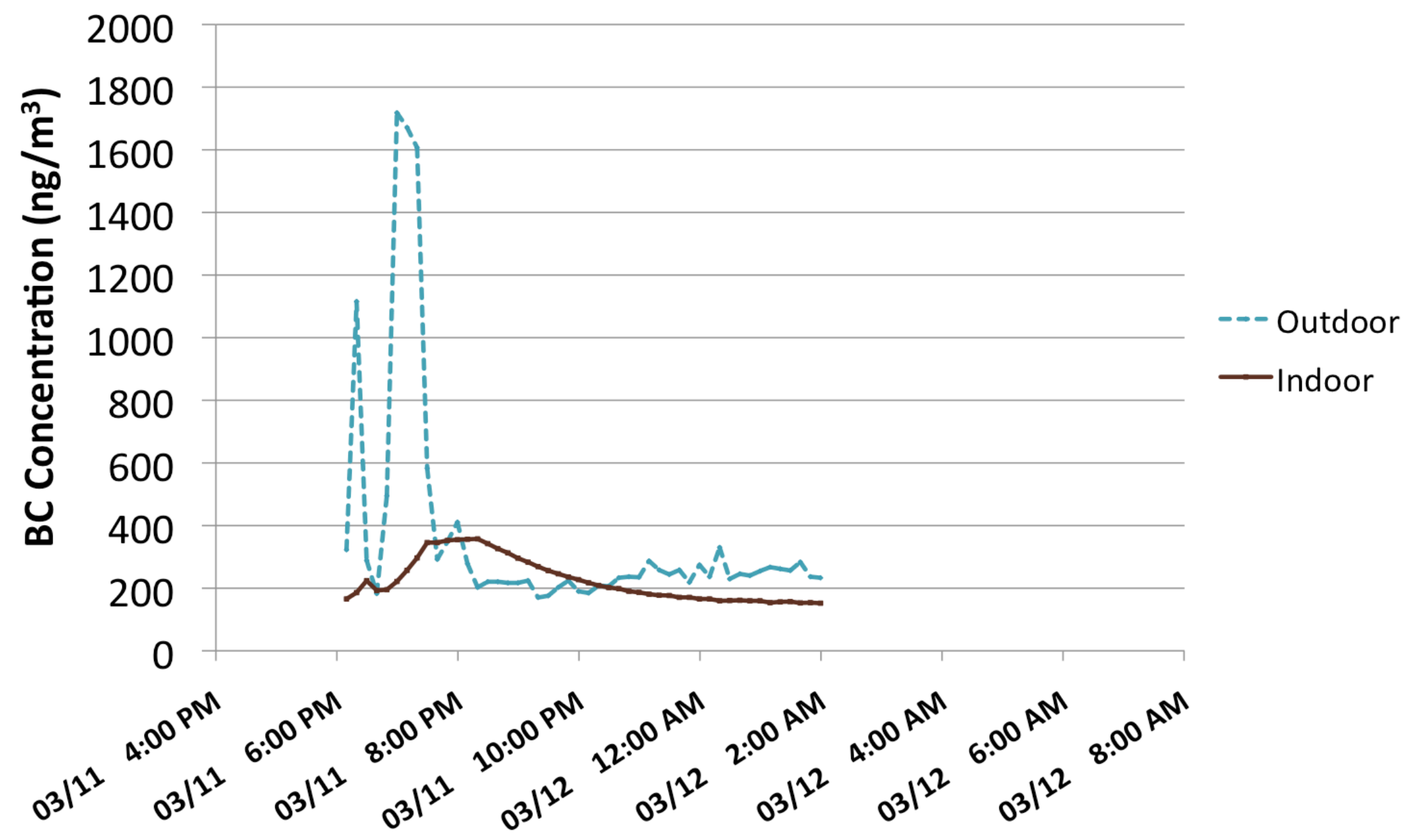


Regional Temperature/Windspeed and the Corresponding Air Exchange Rate for 03/11/09-03/12/09

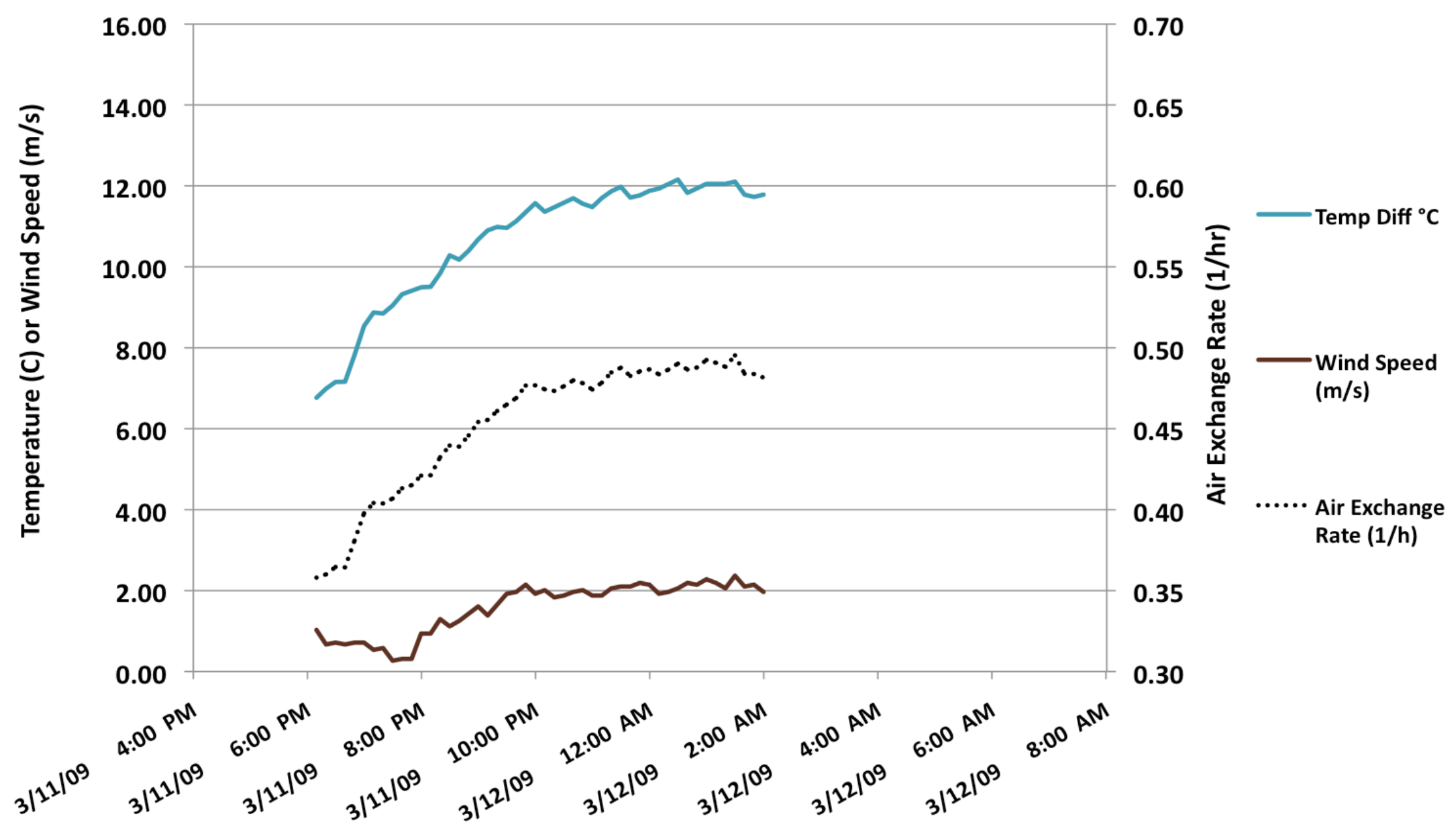


Actual Indoor and Outdoor BC Concentrations on March $13^{\text {th }}-14^{\text {th }}$

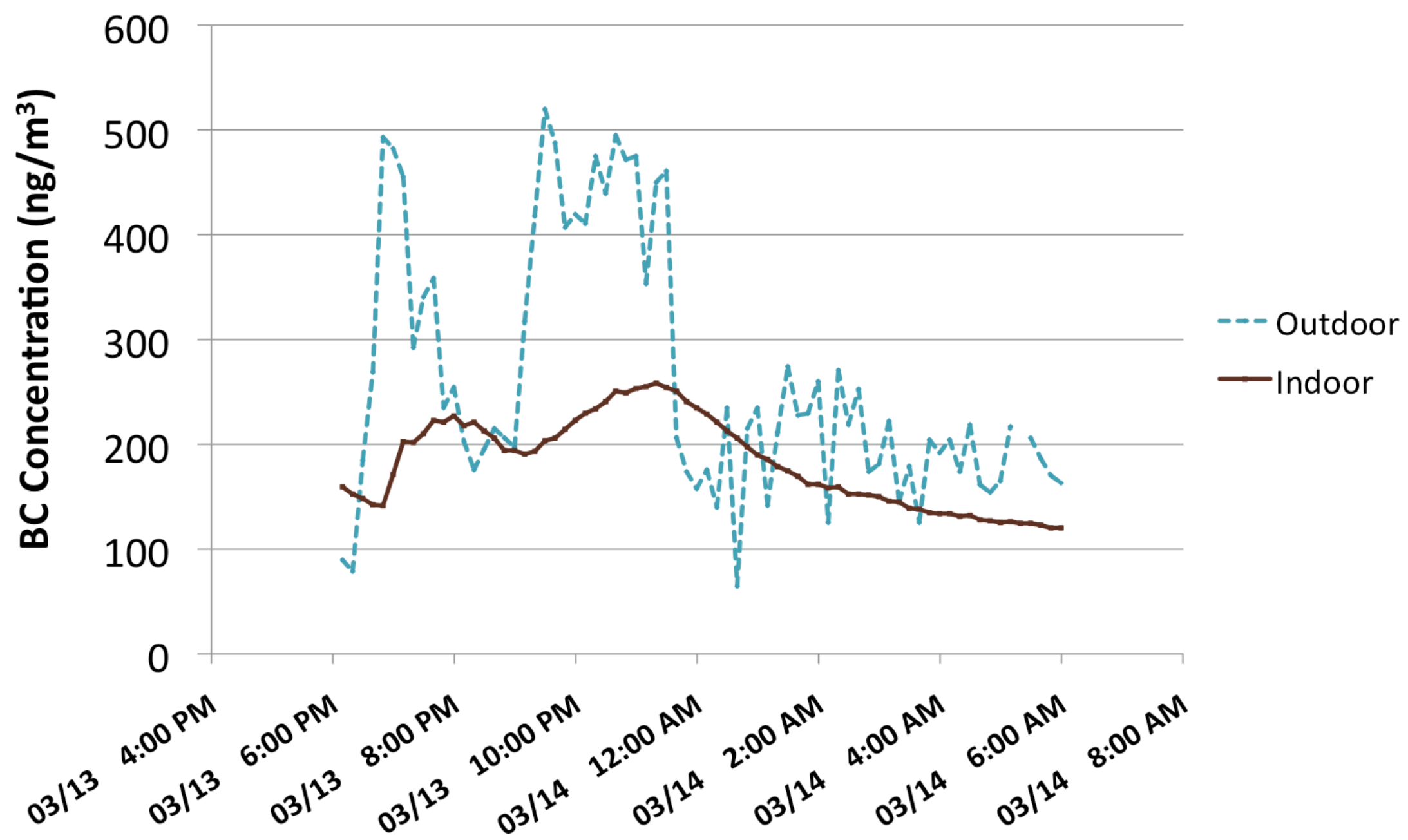


Regional Temperature/Windspeed and the Corresponding Air Exchange Rate for 03/13/09-03/14/09

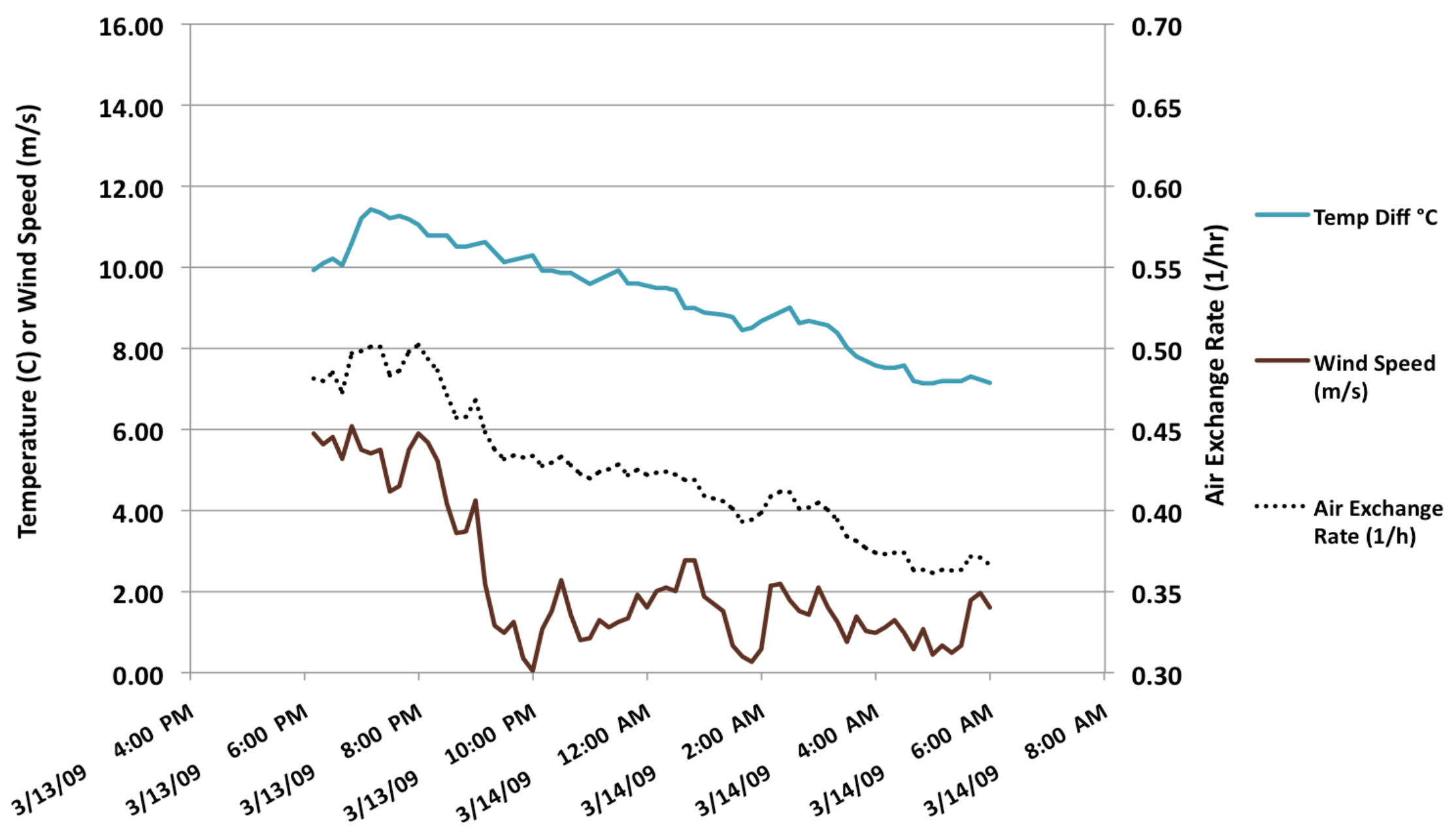


Actual Indoor and Outdoor BC Concentrations on March $16^{\text {th }}-17^{\text {th }}$

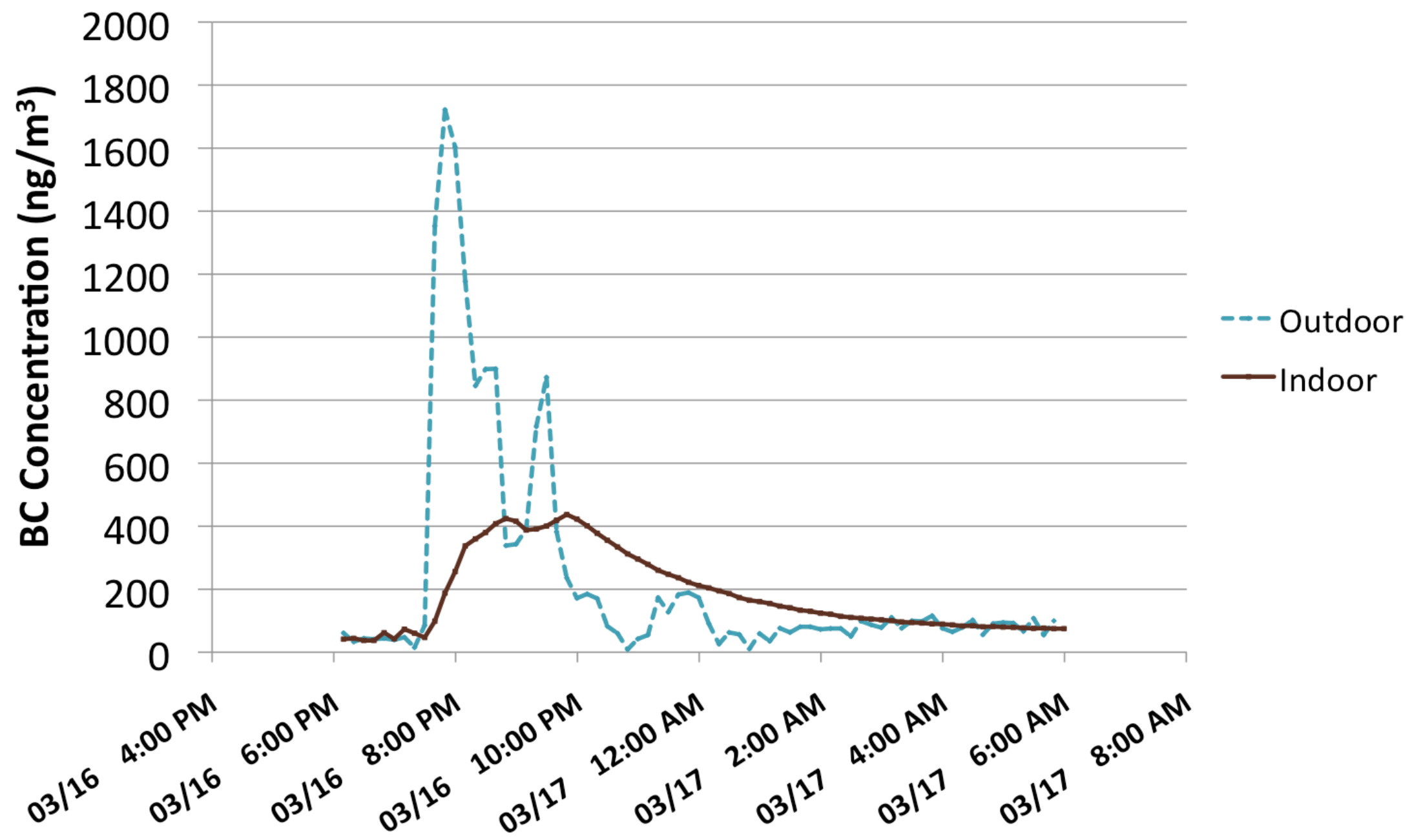


Regional Temperature/Windspeed and the Corresponding Air Exchange Rate for 03/16/09-03/17/09

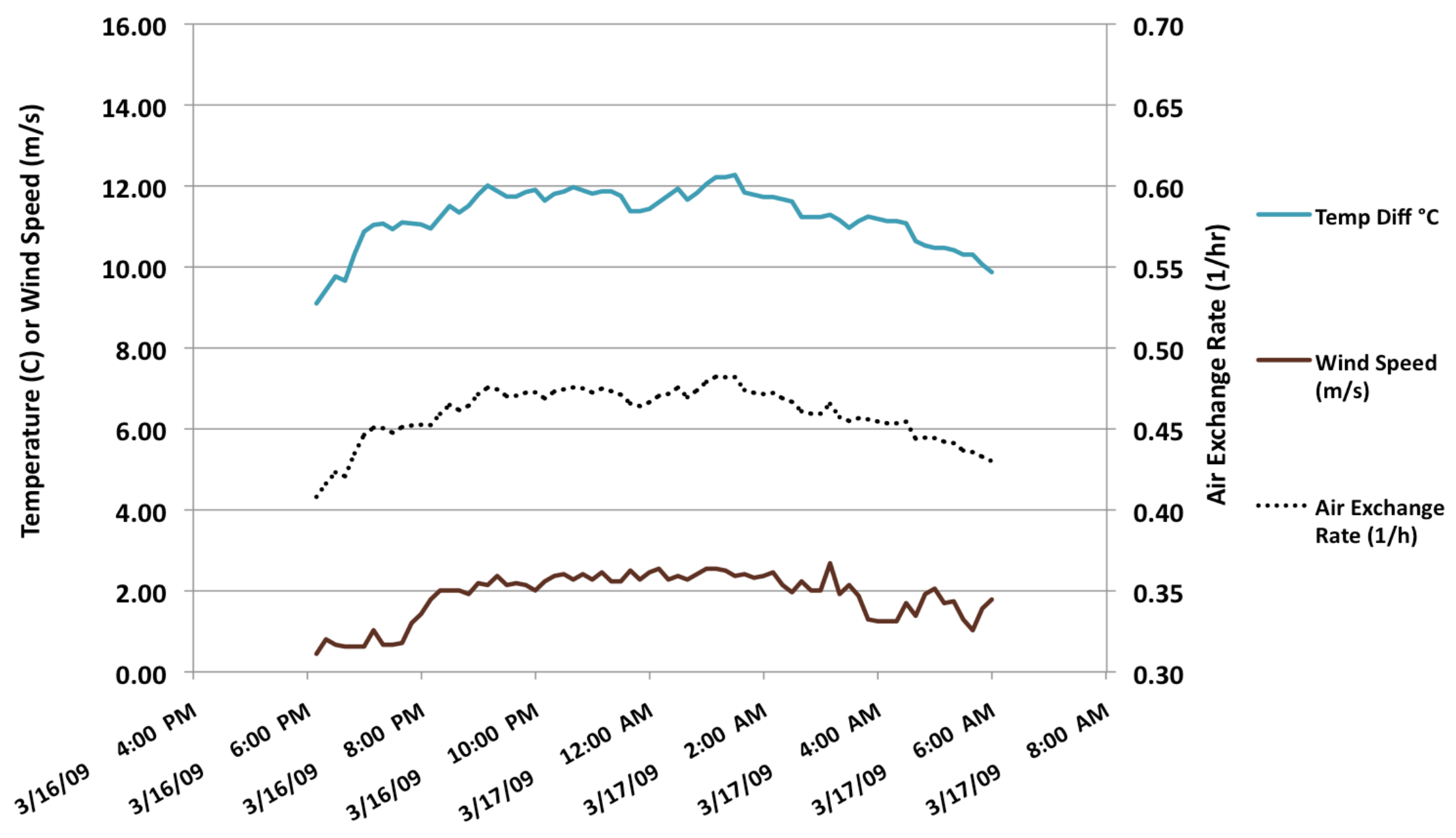


Actual Indoor and Outdoor BC Concentrations on March $17^{\text {th }}-18^{\text {th }}$

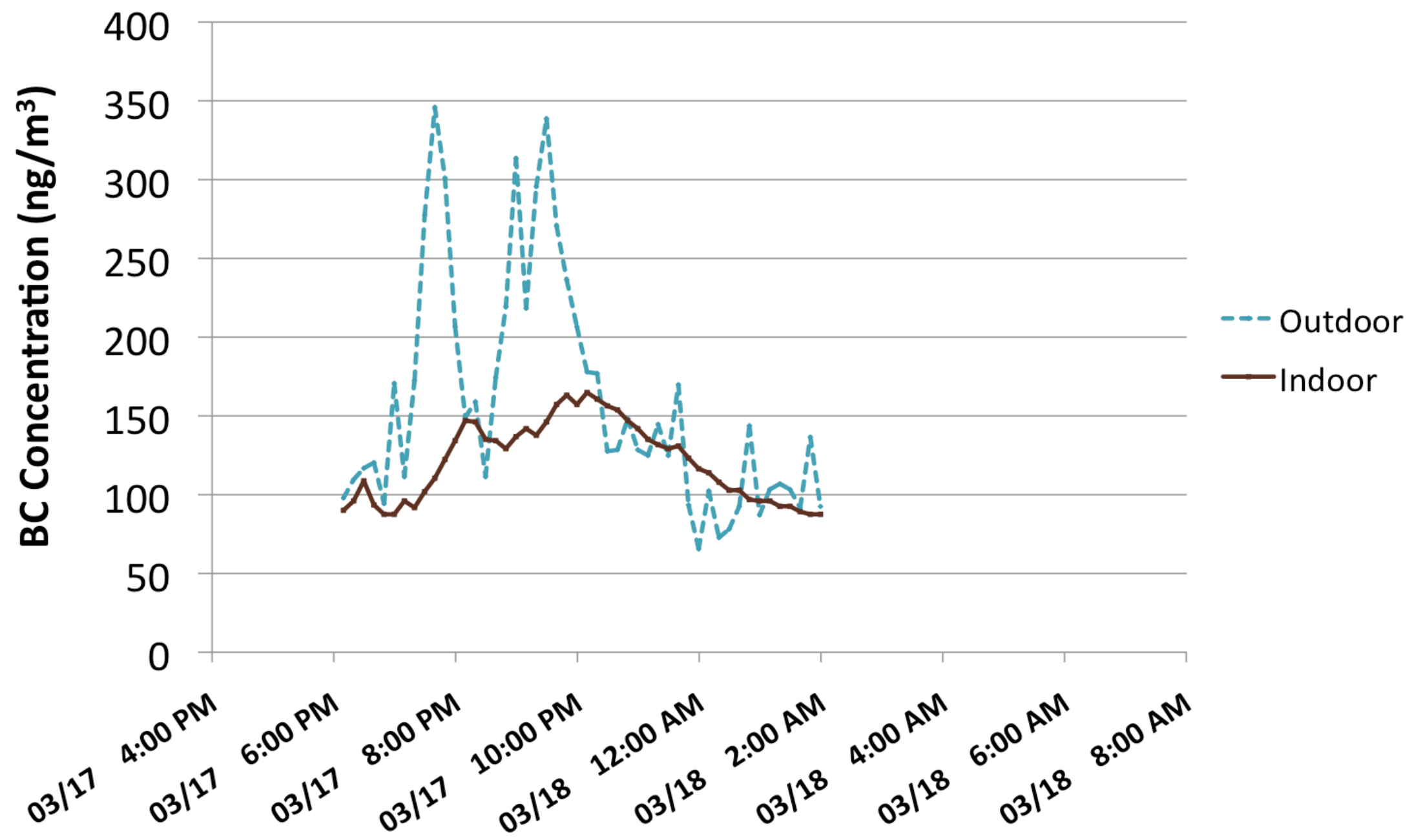


Regional Temperature/Windspeed and the Corresponding Air Exchange Rate for 03/17/09-03/18/09

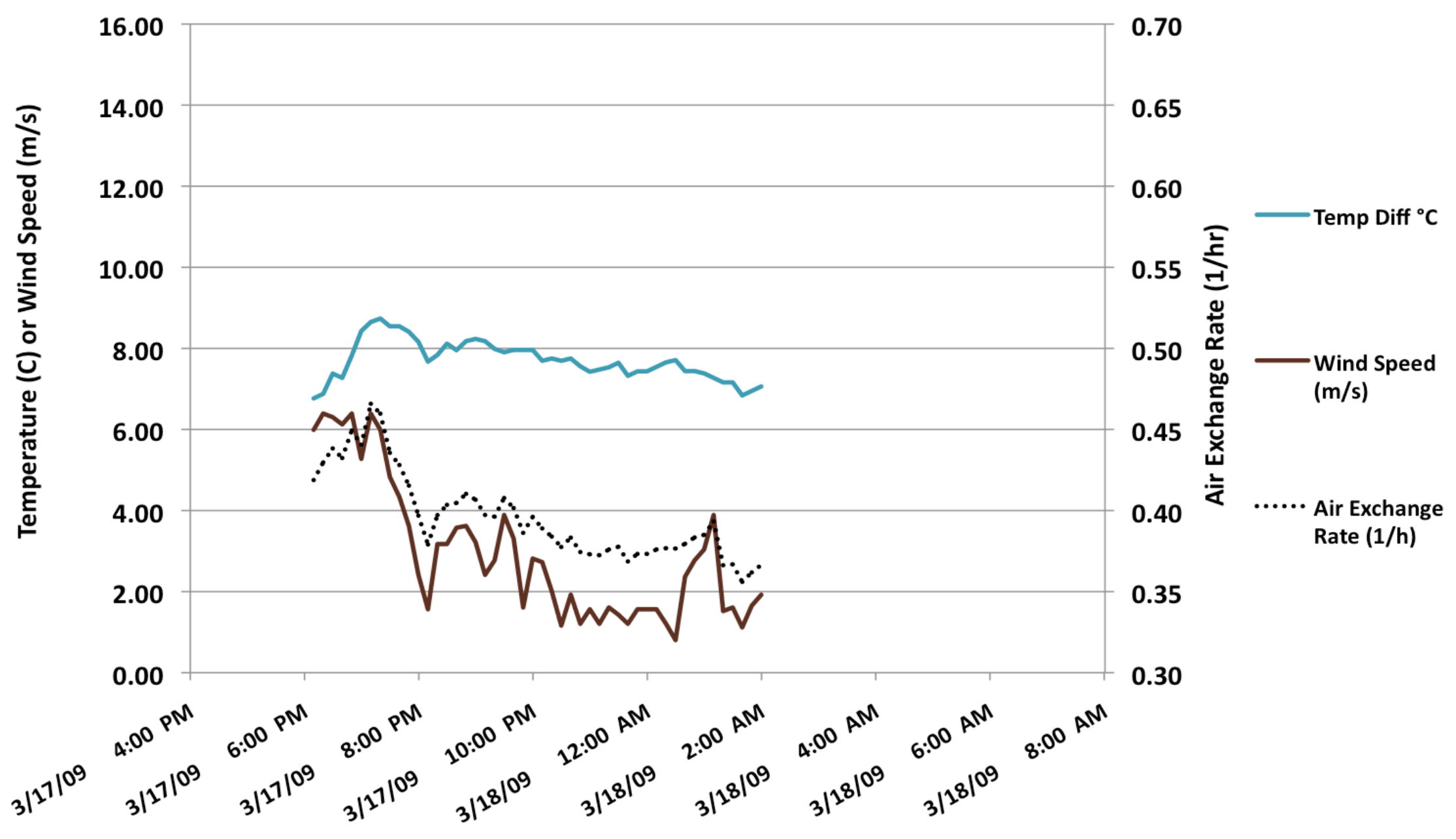


Actual Indoor and Outdoor BC Concentrations on March $19^{\text {th }}-20^{\text {th }}$

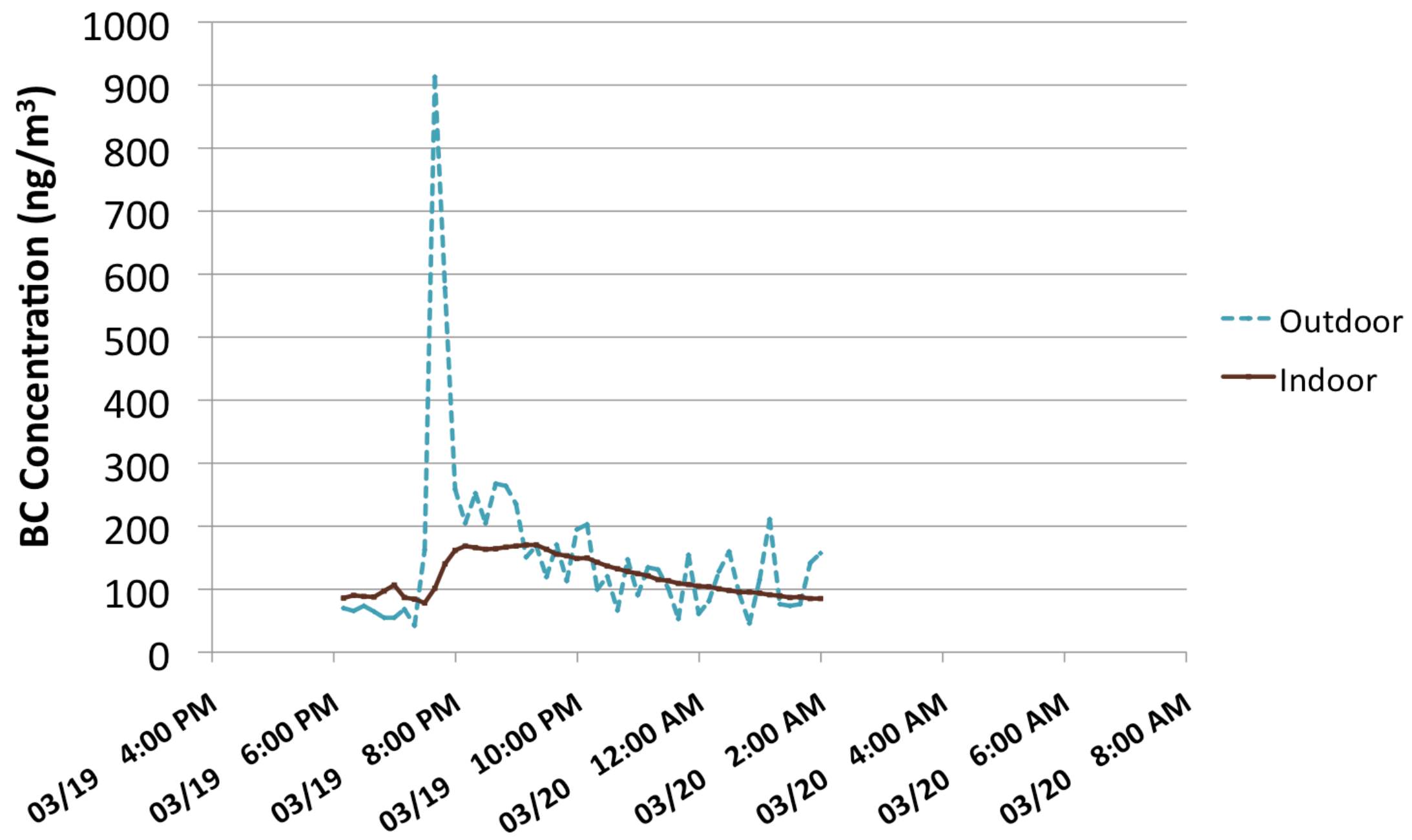


Regional Temperature/Windspeed and the Corresponding Air Exchange Rate for 03/19/09-03/20/09

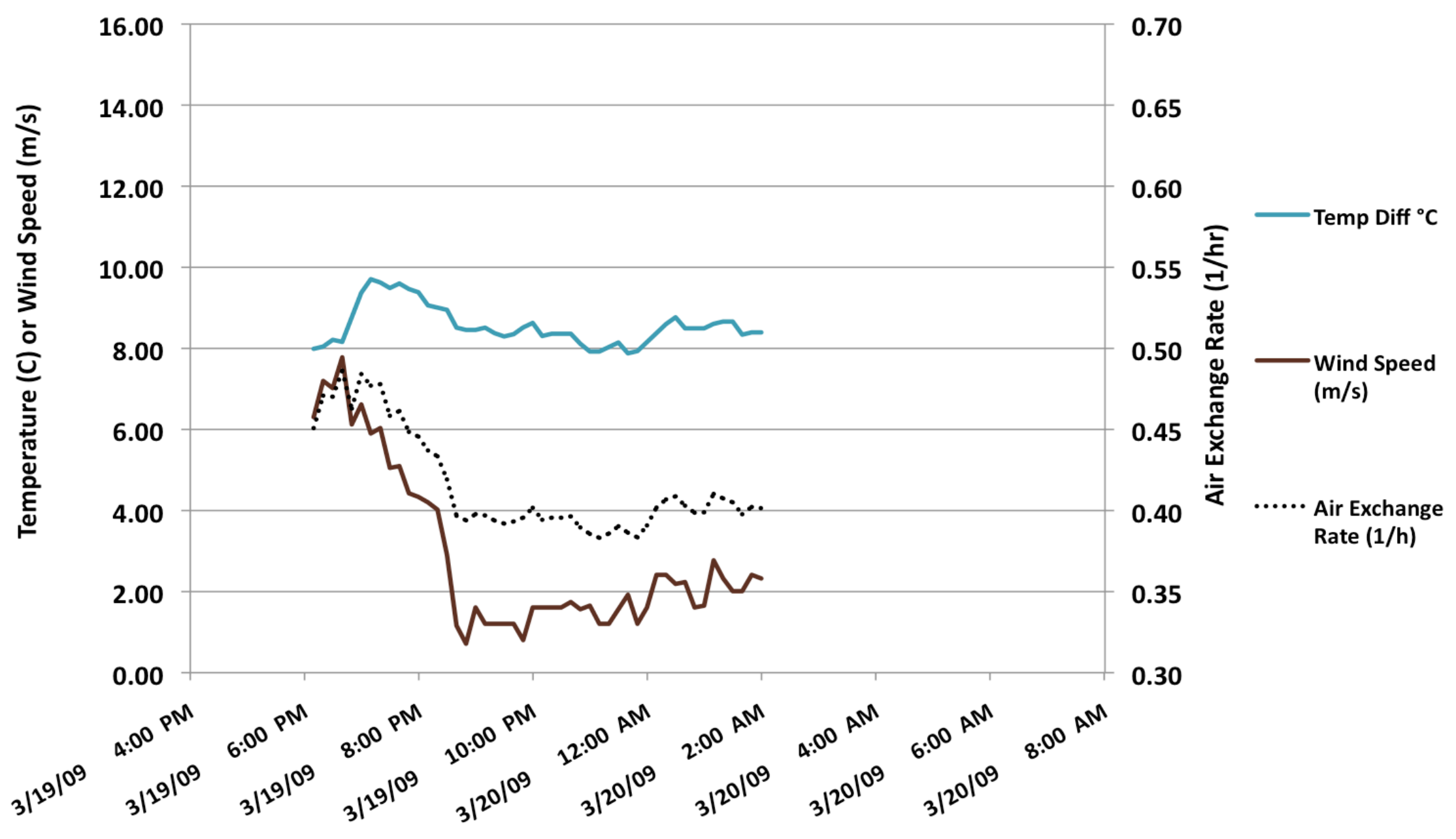

